\title{
El método y el rol de la Comparación Jurídica Observaciones en torno a su impacto en la mutación y en la adaptación jurídica
}

\begin{abstract}
Renzo E. Saavedra Velazco*
Abogado por la Pontificia Universidad Católica del Perú. Profesor de Derecho de las Personas en la Universidad Peruana de Ciencias Aplicadas.

Profesor de Derecho de las Obligaciones en la Universidad ESAN.

Estudios de maestría de Derecho de Empresa con mención en Derecho del Mercado en la Universidad Peruana de Ciencias Aplicadas.

Diploma de Especialización en el Programa Latinoamericano de Law and Economics por la Universidad George Mason y por la Asociación Latinoamericana y del Caribe de Derecho y Economía (ALACDE). Miembro de la Associazione Italiana di Diritto Comparato. Miembro de la Asociación Latinoamericana y del Caribe de Derecho y Economía (ALACDE).
\end{abstract}

SUMARIO:

I. Premisa.

II. Sobre la necesidad de una nueva taxonomía de los sistemas jurídicos y su vinculación con la mutación jurídica.

III. La circulación de los modelos jurídicos: La mutación por difusión.

IV. La competencia entre ordenamientos: Un mecanismo de difusión 0 una nueva manera de imperialismo.

V. Hacia una tipología de los trasplantes jurídicos:

1. Trasplante motivado por ahorro de costos;

2. Trasplante motivado por mandatos externos;

3. Trasplante motivado en razones empresariales;

4. Trasplante motivado en la creación de legitimidad.

VI. El rol de la "función" en la comparación jurídica: La metodología dominante.

VII. Cuestionando la hegemonía cultural en el Derecho: La aproximación postmoderna.

VIII. Contrapunto a la posición postmoderna: ¿Cuál es el futuro de la comparación jurídica?

IX. A manera de conclusión.

Asociado del Estudio Osterling. Árbitro del Centro de Análisis y Resolución de Conflictos de la PUCP. 


\section{PREMISA}

Permítanme iniciar el presente estudio haciéndolos partícipes de una experiencia personal. Sé muy bien que tal manera de proceder no es usual en una investigación jurídica, pero a pesar de ello no creo que resulte impertinente. El relato que quiero compartir con ustedes dio inicio hace poco más de un lustro y admito que no guarda, al menos no explícitamente, una relación clara con aquello que será expuesto en las siguientes páginas.

En el año 2007, luego de pasar alrededor de un año absorto entre la elaboración de mi tesis de licenciatura y la necesaria espera para la determinación de la fecha del examen de grado, tuve la grata oportunidad de iniciar labores docentes y de asumir el cargo de abogado asociado en una firma legal. Sin embargo, tal vez el evento más relevante fue el reencuentro -a través de la fría conexión electrónica- con alguien que ocupa un lugar preponderante en mi vida y que, de una u otra manera, siempre se encuentra presente en aquello que realicé de allí en adelante.

Tengo para mí que esa experiencia fue especialmente valiosa pues me permitió comprender el rol que desempeñan los detalles, nutriendo de esta manera mi curiosidad por reconstruir, en más de una oportunidad, el contexto en que se produjo tal o cual evento. Vale decir, gracias a esa experiencia procuré hacerme de un método que facilitara aquellos objetivos que, por una u otra razón, deseaba alcanzar. Desafortunadamente no siempre se logra aquello que se desea y se generan algunos ligeros impasses, quien no ha oído (o pronunciado) frases como: si ya se cumplió con el objetivo que se deseaba, aunque ello sucediera con una alternativa imprevista; o, en palabras más llanas, si hay dos maneras para cumplir un mismo objetivo y lo importante es el cumplimiento de la meta, entonces por qué com- plicarse discutiendo por cuál de las dos opciones debió elegirse.

Intuyo que esta historia comienza a aburrirlos y a suscitarles una serie de interrogantes, tales como: ¿cuándo se abordarán los temas jurídicos? o ¿cuál es la relación de este breve relato con el asunto que se ha elegido como tema del presente ensayo? Pues bien, iniciaré con la que fue la segunda pregunta. Como se ha visto, en la vida suelen acontecer eventos en los que se ven varias posibles soluciones a un mismo impasse, en ocasiones la diferencia entre uno y otro es inexistente (se logra el objetivo y no hay efectos paralelos, o de existir son marginales); en otros casos, sí se perciben con claridad las diferencias entre las alternativas, sea por los costos anexos a cada una de ellas o simplemente porque solamente una ofrece la solución integral al problema que se enfrenta. De esa misma manera, en el campo jurídico, y en particular en los debates en torno a la comparación jurídica, también existen alternativas que ofrecen solución a un particular problema, en ocasiones tales soluciones resultan casi intercambiables, mientras que en otros ello no será así

Teniendo presente esta última idea, quiero descender un poco más a la realidad. En un país en el que se percibe que las leyes no son buenas (o, más en general, los productos jurídicos), en la medida que no dan solución a los problemas que enfrente la sociedad, es de esperar que quien ostenta el poder normativo no goce de gran legitimidad'. Esto se ve exacerbado por la escasa (o nula) capacitación jurídica ${ }^{2}$, ya ni que decir sobre el potencial impacto económico que tendrían estas normas en caso fuesen promulgadas, por lo que el legislador nacional tenderá a buscar legitimidad en los productos jurídicos foráneos y su impacto será aún mayor cuando el país del que se tomará prestado goza de hegemonía ${ }^{3}$

1. MONATERI, Pier Giuseppe. The weak law: Contaminations and Legal Cultures. En: Transnational Law \& Contemporary Problems, vol. XIII, 2003, p. 575 y ss.

2. Hay quien hablaría aquí de escases de recursos humanos, me refiero al trabajo de SCHÄFER, Hans-Bernd, Rules versus standards in rich and poor dountries: Precise legal norms as substitutes for human capital in low-income dountries. En: Supreme Court Economic Review, vol. XIV, 2006, p. 113 y ss.

3. SCHLAG, Pierre. Normativity and the politics of form. En: University of Pennsylvania Law Review, vol. CXXXIX, núm. 4, 1991. p. 801 y ss., ivi. pp. 849-855. 
(pienso en los Estados Unidos) o de autoridad (en el Perú, dependiendo de la materia se prestará atención a países europeos y en mucha menor medida en países sudamericanos).

En concreto, tendremos "productos nacionales" con baja calidad (o poco "valorados" dentro del mercado) o "productos extranjeros" que se perciben como valiosos y de calidad (normas, figuras doctrinales o fórmulas jurisprudenciales). Aquí se suscitará la pregunta de si debemos importar estos productos o si basta la producción nacional. La historia reciente nos indica que se preferirá la importación jurídica (circulación de modelos), lo cual se realizará a través de los fenómenos que se denominan legal transplants. En ciertos casos observamos que entre los sistemas existe homogeneidad (convergencia jurídica) en las propuestas dirigidas a solucionar los inconvenientes que se perciben en la sociedad, pero hay construcciones que se muestran como económicamente deseables pues facilitan la interpretación y la aplicación por parte del operador jurídico a cargo de tales labores (creando así los incentivos necesarios en los distintos miembros de la sociedad). Por su parte, en otros casos, las propuestas serán heterogéneas y la elección de un producto importado se torna complicada, pues los costos económicos que se asumen son difícilmente cuantificables.

Lo que quiero dar a entender es simple. La creación normativa es costosa tanto ex ante como ex post. Los trasplantes jurídicos tienden a minimizar los costos ex ante, pero es sumamente complicado que se defina-sin contarse con estudios previos-si podrá minimizarlos ex post. La elección entre alternativas jurídicas no necesariamente importa que estas sean indistintas, es más es posible que los problemas que conlleva determina opción supere el estrecho margen de lo económico. Así, la labor del profesional del Derecho en un sistema como el nuestro será sumamente complicada, pues tendrá que estudiar sistemas foráneos para conocer cuáles son las alternativas a la mano y tratar de justificar la adopción de una u otra regla. El inconveniente no queda allí, pues tendrá que hacer frente a grupos de interés al interior de su sistema y de organismos fuera de sus fronteras estatales.

Oportunamente indiqué que la comparación jurídica tiene como propósito afrontar todas las temáticas aludidas. Creo que con esta constatación se percibirá la utilidad que tiene el estudio de este método para una sociedad como la nuestra. Es más puede decirse que, aún sin saberlo a nivel consciente, la mayoría de nuestros estudiantes han aprendido a lidiar con ciertas reglas de la comparación jurídica cuando se les enseña las "fuentes" del derecho nacional. En cambio, existen sistemas en que este método es casi desconocido para las masas de abogados ${ }^{4}$. Así, si observamos al interior de nuestras fronteras encontraremos a académicos nacionales que son especialistas en derechos extranjeros, mientras que resulta altamente probable que se sufrirá una gran decepción ${ }^{5}$ al constatar que no existen en otros sistemas un académico o profesional estudiando el Derecho peruano ${ }^{6}$.

Verificar esta afirmación no debiera ser de gran interés, salvo por una única razón: sería, para decirlo sin ambages, la confirmación de la debilidad y falta de legitimidad de nuestro sistema jurídico. Aspectos que, desafortunadamente, se encuentran fuera de cualquier duda. Empero, el punto a favor de la tendencia generalizada del

4. Incluso quienes lo conocen como CAPPALI, Richard B. At the point of decision: The Common Law's advantage over the Civil Law. En: Temple International and Comparative Law Journal, vol. XII, núm. 1, 1998, p. 87 y ss., tienen una vision desfavorable en los productos jurídicos creados en el Civil Law.

5. HYLAND, Richard. Shall we dance? En: Aa. Vv., Codici: Una riflessione di fine millenio, Atti dell'incontro di studio, al cuidado de Paolo Cappellini y Bernardo Sordi, Per la storia del pensiero giuridico moderno, vol. LXI, Giuffrè, Milán, 2002 , p. 377 y ss.

6. HYLAND, Richard. Shall we dance? En: Aa. Vv., Codici: Una riflessione di fine millenio, Atti dell'incontro di studio, al cuidado de Paolo Cappellini y Bernardo Sordi, Per la storia del pensiero giuridico moderno, vol. LXI, Giuffrè, Milán, núm. 4, 2002, p. 377 y ss. 
legislador peruano a la importación masiva de normas legales, figuras doctrinales y fórmulas jurisprudenciales; es que facilita la labor de quienes, como quien escribe estas líneas, promueve el desarrollo de la comparación jurídica. El sentido de tal ventaja se encuentra en que torna evidente la necesidad de prestar atención a la opinión de juristas extranjeros, pues son ellos quienes nos pueden explicar la función que tales productos jurídicos importados cumplían en sus sistemas de origen, así como brindarnos una guía sobre cómo su aplicación e interpretación.

Urge, finalmente, dar respuesta a la primera respuesta. En las próximas páginas espero brindar un cuadro global general sobre el método y el rol de la comparación jurídica, aspectos que en gran medida están dirigidos al público que se aproxima por primera vez a esta metodología.

\section{SOBRE LA NECESIDAD DE UNA NUEVA TAXONOMÍA DE LOS SISTEMAS JURÍDICOS Y SU VINCULACIÓN CON LA MUTACIÓN JURÍDICA}

No es desconocido que buena parte del desarroIlo que alcanzó el Derecho durante el siglo XIX estuvo estrechamente vinculado con la aplicación de algunas categorías y métodos propios de las ciencias naturales ${ }^{7}$. En ese contexto, se procuró estudiar las relaciones existentes entre los diversos componentes del engranaje jurídico de la misma manera en que un naturalista habría llevado adelante el análisis de un organismo vivo. La finalidad que los juristas perseguían con la aplicación de este procedimiento se centraba en comprender la manera en que operaban tales relaciones ${ }^{8}$ y las razones que explicaran por qué surgían estas relaciones, empero la curiosidad del profesional del Derecho no quedaba allí, pues se deseaba formular una serie de postulados de carácter descriptivo que permitieran luego proponer soluciones a casos concretos.

En no pocas oportunidades esta manera de proceder ocasionó que quien realizaba labores de investigación jurídica se comportase como un filósofo o un matemático ${ }^{9}$, toda vez que primero observaba el principio o el postulado formulado, para luego derivar -en vía de deducción- las consecuencias jurídicas que "necesariamente" tendrían que cumplirse y aplicarse en un caso u escenario concreto. Así, al aproximarse a cualquier tema con relevancia jurídica, el profesional del Derecho empleaba, prioritariamente, operaciones lógicas de deducción e inducción, por lo que su razonamiento era básicamente de carácter silogístico. Tal procedimiento no se limitó a los aspectos prácticos del Derecho, sino que se extendió a aquellas discusiones en las que se intentaba evaluar en abstracto las cualidades de cierto fenómeno, por lo que se podía aplicar a campos en los que el debate involucraba únicamente categorías jurídicas (incluyendo a ramas, sistemas o familias jurídicas).

Desafortunadamente, una práctica de este tipo genera uno de dos vicios que deben rechazarse de raíz. Por un lado, un excesivo interés teórico por parte del estudioso, sin prestarle atención a las consecuencias prácticas de sus posiciones ${ }^{10}$, por no hablar del trasfondo que cada una de las potenciales soluciones tiene (la preeminencia de un interés sobre otro); y, por otro lado, la respuesta exactamente contraria, la atención absoluta sobre el caso concreto, minusvalorando el rol de las

7. MENGONI, Luigi. Voz "Dogmatica giuridica". En: Enciclopedia giuridica Treccani, vol. XII, Istituto della Enciclopedia Italiana, Roma, 1989, pp. 2-3 (de la separata).

8. Este punto es ejemplarmente expuesto por KENNEDY, Duncan, Savigny's family/patrimony distinction and its Place in the global genealogy of classical legal thought. En: The American Journal of Comparative Law, vol. 58, núm. 4, 2010, p. 811 y ss.

9. HOEFLICH, M. H. Law \& geometry: Legal science from Leibniz to Langdell. En: The American Journal of Comparative Law, vol. 30, núm. 2, 1986, p. 96.

10. Idea que inspiro la aguda crítica de JHERING, Rudolph von. En el cielo de los conceptos jurídico: Una fantasia. En: Bromas y veras en la ciencia jurídica: Ridendo dicere verum, traducción de Tomás A. Banzhaf, Civitas, Madrid, p. 215 y ss. 
categorías y de las teorías, así como del impacto sistémico que podría ocasionarse ${ }^{11}$ con una praxis de este tipo. Naturalmente, el camino correcto es una combinación de ambas perspectivas, vale decir, se deberá incentivar la creación teórica siempre que se sustente en la realidad empírica y solucione aquellos problemas que motivaron su formulación ${ }^{12}$, todo lo cual permitirá evitar la abstracción de unos y la arbitrariedad de los otros.

La labor conjunta de los teóricos y pragmáticos, por si fuera necesario recordarlo, le ha legado al campo jurídico más de una figura que conjuga la utilidad en el tráfico comercial y la riqueza conceptual. Pienso, por ejemplo, en los contratos preparatorios $^{13}$ y en la culpa in contrahendo ${ }^{14}$. Tal vez la manera más sencilla de resaltar el inescindible ligamen entre ambas aproximaciones sea compartiendo la siguiente opinión: " $E I$ desdén hacia las teorías a la manera del 'tópico', cuando no la hostilidad antidogmática, malogra, por consiguiente, tanto la contribución de la teoría como las tareas de la práctica. Se comprende que al entendimiento común pueda la teoría parecer incomprensible, esotérica, y hasta jocosa. Platón ha hecho inmortal, en el 'Teeteto', la risa de la criada tracia burlándose de Tales, que (según cuentan) contemplando las estrellas se cayó a un pozo, y Hans Blumenberg ha elegido esta risa como título y leitmotiv de una 'prehistoria de la teoría.' No obstante, según una anécdota relatada por Aristóteles, Tales supo aprovechar muy bien en la práctica sus capacidades teóricas, pues, fundándose en sus conocimientos astronómicos, previó una favorable cosecha de olivas, alquiló a tiempo todas las prensas de aceite y obtuvo una elevada ganancia. La especial gracia de esto estriba en que, en realidad, Tales no se había caído al pozo, sino que había descendido voluntariamente al mismo, al objeto de utilizar la superficie del agua para observaciones astronómicas. Este es el signo del auténtico teórico o, como nosotros los juristas acostumbramos decir, del dogmático: él está por buenas razones dentro de su pozo y no se deja confundir por la incomprensión y la burla de vulgares criadas." 15

No obstante lo antes expuesto, en los últimos años la aplicación de categorías y métodos que caracterizan a las ciencias naturales para el análisis de fenómenos jurídicos ha recibido grandes críticas. Algunas de ellas son, en esencia, oportunas (la idea de prestar atención al contexto, en especial el aspecto cultural, sin olvidar el político-económico); otras resultan prejuicios que ya han obtenido carta de ciudadanía en casi todos los sistemas jurídicos. Empero, considero que las importantes y útiles lecciones que brindan las ciencias naturales no pueden (ni deben) ser soslayadas, toda vez que no es necesario que los investigadores se empeñen continuamente a (re)descubrir la rueda.

Así, entre las categorías que la ciencia jurídica recogió de las ciencias naturales se encuen-

11. Al respecto es sugerente el enfoque propuesto por CANARIS, Claus-Wilhem. Función, estructura y falsación de las teorías jurídicas, traducción de Daniela Brückner y José Luis de Castro, Civitas, Madrid, 1995, pp. 35-36.

12. Así se lograría evitar los absurdos de las posiciones antagónicas referidas, las cuales son graficadas con total claridad en un conocido sintágma latino: "theoria sine praxis sicut currus sine axis, praxis sine theoria sicut caecus in via". Idea que ha sido también resaltada por los profesores MATTEI, Ugo y REIMANN, Mathias. New directions in comparative law: Introduction. En: The American Journal of Comparative Law, vol. XLVI, núm. 4, 1998, pp. 597-598.

13. Cuestión que ha sido doctamente evidenciada en nuestro medio por el profesor LEÓN, Leysser L. La buena fe en la negociación de los contratos: Apuntes comparatísticos sobre el artículo 1362 del Código Civil peruano y su presunto papel como fundamento de la responsabilidad precontractual. En: Themis-Revista de derecho, núm. 49, 2005, p. 127 y ss.; asimismo es de interés la consulta de MUSTARI, Manuela, La fuga dal consensualismo - Genesi e caratteri del «contratto preliminare» nell'Italia otto-novecentesca. En: Revista internacional de direito da Unicap, http://www. unicap.br/rid/artigos2004/lafuga.doc, Universidad Católica de Pernambuco, 2004.

14. Sobre el punto me permito remitir a SAAVEDRA VELAZCO, Renzo E. Análisis Crítico de la Teoría de Gabriele Faggela sobre la Responsabilidad Precontractual: Revisitando (o reconociendo) a un clásico. En: Revista peruana de derecho privado, año I, núm. 1, 2011, pp. 47 y ss., ahora también disponible, con ciertos cambios puntuales, en http:// works.bepress.com/renzo saavedra/.

15. CANARIS, Claus-Wilhem. op. cit., pp. 122-123. 
tra la taxonomía ${ }^{16}$. Cabe precisar que el afán de clasificación propio de la taxonomía no se verifica en exclusiva en el Civil Law, sino que también se presenta en el Common Law. Además, habría que destacar que el interés (si es que no la necesidad) que se percibe en los diversos sistemas para la correcta clasificación de los fenómenos jurídicamente relevantes, objetivo que se alcanzará a través de un enfoque taxonómico, sólo se reforzará con el trascurso de los años ${ }^{17}$.

En este orden de ideas, el papel que desempeña la taxonomía no se percibe únicamente en el campo jurídico o en las ciencias naturales, casi podría asegurar que la propia centralidad de su rol es inherente al conocimiento humano, en la media que facilita el acopio de la información, su procesamiento y, en última instancia, su trasmisión. Por tal motivo, difícilmente nos debería causar sorpresa constatar que en el sistema estadounidense, a pesar de los fuertes rezagos del realismo jurídico ${ }^{18}$, existe más de un esfuerzo dirigido a lograr la unificación ${ }^{19}$ de algunas de las teorías del derecho privado ${ }^{20}$.

En la comparación jurídica estos esfuerzos no son desconocidos. La taxonomía básicamente permite que los abogados se comuniquen entre sí, sin que las nacionalidades o peculiaridades de sus sistemas jurídicos se conviertan en un escollo insalvable, a fin de discutir los problemas que comparten sus diversas sociedades. Así, podría afirmarse que esta mecánica facilitará que se formulen o se propongan soluciones derivadas de "principios" análogos. Si ustedes creen, en opinión que comparto, que esto resulta viable (o cuanto menos deseable) entonces habría que admitir que: "la taxonomía es la gramática del discurso jurídico"21.

16. El impacto de esta categoría, su relación con las ciencias naturales y la utilidad de la relación son discutidas por SAMUEL, Geoffrey. Can Gaius really be compared to Darwin? En: The International and Comparative Law Quarterly, vol. 49, núm. 2, 2000, p. 297 y ss.; y, GREY, Thomas C., Holmes and legal pragmatism. En: Stanford Law Review, vol. 41, núm. 4, 1989, p. 787 y ss.

17. Cuestión que es abordada por SHERWIN, Emily. Legal taxonomy. En: Legal Theory, vol. 15, núm. 1, 2009 , p. 25 y ss.

18. De esta corriente se derivaron escuelas tan influyentes como los Critical legal studies o el análisis económico del Derecho. Sin embargo, tal como puede rastrearse, el realismo jurídico norteamericano hunde sus raíces en el denominado "movimiento del Derecho Libre" (o Freirechtsbewegung).

El realismo jurídico norteamericano abanderaba la idea de que el Derecho podía ser definido al margen de cuestiones morales, además de ofrecer una crítica frontal a las aproximaciones formales o conceptuales, por lo que tenía que ser aprehendido desde la realidad y no desde las cuatro paredes de la biblioteca en la que se movía el académico clásico (para una ilustrada aproximación a esta corriente consúltese el texto de RODOTÀ, Stefano. II realismo giuridico americano: A propósito di un libro recenté. En: Rivista del Diritto Commerciale e del Diritto generale delle obbligazioni, Año LXVI, primera parte, 1963, p. 45 y ss.). Por este motivo, en los Estados Unidos se creó un sentimiento natural de aversión a aproximaciones conceptuales, sentimiento que sólo se consolidó en las últimas décadas.

Sobre la influencia germana en el realismo jurídico norteamericano: HERGET, James y WALLACE, Stephen. The German free law movement as the source of American legal realism. En: Virginia Law Review, vol. 73, núm. 2, 1987, p. 399 y ss.

19. En otros campos del conocimiento se observa un fenómeno análogo, por ejemplo, en la física se pretende alcanzar la Grand Unified Theory (GUT) que permita unir los postulados de la mecánica cuántica con los de la teoría de la relatividad; en la psicología se busca la Grand Theory of Human; entre otras. Aspecto que es subrayado por SCALISE Jr., Ronald J. Why no "efficient breach" in the Civil Law?: A comparative assessment of the doctrine of efficient breach of contract, En: The American Journal of Comparative Law, vol. LV, núm. 4, 2007. p. 721 y ss.

20. Cabría mencionar aquí los trabajos de ilustres autores como CALABRESI, Guido. Toward a unified theory of torts en Journal of Tort Law, vol. 3, núm. 1, artículo 1, 2006, disponible a través del portal web eScholarship: http://escholarship.org/uc/item/9tc933wq; GORDLEY, James, Contract and delict: Toward a unified theory of obligations. En: Edinburg Law Review, vol. 1, núm. 3, 1997, pp. 345 y ss.; y, COOTER, Robert, Unity in tort, contract and property: The model of precaution, en California Law Review, vol. 73, núm. 1, 1985, p. 1 y ss.

21. Cfr. MATTEI, Ugo. Three patterns of law: Taxonomy and change in the world's legal systems. En: The American Journal of Comparative Law, vol. XLV, núm. 1, 1997, p. 5. 
Empero, la gramática es meramente el conjunto de reglas que disciplina el uso de determinado lenguaje. Una gramática sin palabras con las que se puedan transmitir ideas o mensajes es tan poco útil que difícilmente pueda empleársela como mecanismo de comunicación y, peor aún, designarla como "lenguaje". Lamentablemente, en cuanto a la materia que nos convoca, se ha criticado que la comparación jurídica no tiene un lenguaje propio ${ }^{22}$ y, a renglón seguido, que prácticamente cada investigador sigue un propio método.

En un escenario como el descrito, sería razonable esperar que las discusiones taxonómicas no hayan ocupado un lugar preponderante, ya que primero debería haberse emprendido la tarea de alcanzar un número suficiente de interlocutores que empleen esta lengua para luego pasar a afrontar la complicada labor de regulación de su uso. Ciertamente, cualquiera podría oponer, creo que con razón, que el uso diario de una lengua, y no las reglas que puedan emitirse para disciplinarla, será lo que -en última instanciafije la manera en que los interlocutores (esto es, los hablantes) se comunican.

Curiosamente, en la comparación jurídica se dio precisamente lo contrario. Los comparatistas se centraron en las labores de clasificación más que en la creación y desarrollo del lenguaje en el que se comunican. Esta última tarea, que aún hoy se encuentra pendiente (e incluso-como se verá más adelante- puede afirmarse que el cabal cumplimiento de esta tarea se encuentra atado al éxito o al fin de la comparación jurídica), es precisamente la que permite la difusión y la consolidación de un lenguaje, amén de la utilidad que debieran percibir los hablantes (tanto para su aprendizaje, como para su comunicación con los demás).

Desafortunadamente, la comparación jurídica no ha calado en todos los sistemas. Este defecto se explica en una diversidad de motivos que abordaré más adelante. Lo que sí puedo adelantar es que la ausencia de un lenguaje propio sumado a la multiplicidad de perspectivas empleadas por quienes hacen comparación jurídica (sea como método de análisis jurídico, sea como rama del Derecho), ha significado un gran escollo para quien tenga interés en impulsar su difusión ${ }^{23}$.

La comparación jurídica tiene gran utilidad para la comprensión y la mejora del derecho patrio, en especial cuando el sistema (o cultura jurídica) involucrado resulta débil o, en otras palabras, si se muestra particularmente receptivo a fenómenos de importación jurídica ${ }^{24}$. El Perú, qué duda cabe, calza perfectamente en esta descripción de cultura jurídica débil ${ }^{25}$. La aplicación de la comparación jurídica, sin embargo, requiere sumo cuidado $y$, tal vez, un esfuerzo superior al de otras aproximaciones al Derecho. Ese esfuerzo se manifiesta en la atención que el estudioso deberá dispensar a la diversas de metodologías que se reconducen a la comparación jurídica, las cuales no siempre son diferenciadas, y ni que decir acerca de la diligencia con la que tendrá que evaluar los sistemas jurídicos bajo análisis.

22. En el trabajo de GERBER, David J. System dynamics: Toward a language of comparative law?, en The American Journal of Comparative Law, vol. XLVI, núm. 4, 1998, pp. 719 y ss., ivi p. 719, se afirma, con total claridad, que: «ila comparación jurídica no tiene un lenguaje! No tiene sentido que se tenga un conjunto pequeño de sustantivos especializados propios, los sustantivos no forman un lenguaje.»

Una evidencia del léxico breve de la comparación jurídica se observa en Merryman, John Henry, Comparative law scholarship, en Hastings International and Comparative Law Review, vol. XXI, núm. 4, 1998, pp. 771 y ss., ivi pp. 776777, si bien no tiene una finalidad exhaustiva sirve como índice de lo denunciado por David Gerber.

23. Comparten tal opinión: VALCKE, Catherine. Comparative law as comparative jurisprudence: The comparability of legal systems. En: The American Journal of Comparative Law, vol. LII, núm. 3, 2004, pp. 713 y ss., ivi pp. 713-720; y, REITZ, John C. How to do comparative law. En: The American Journal of Comparative Law, vol. XLVI, núm. 4, 1998, pp. 617 y ss., ivi pp. 617-618.

24. Debate que, en nuestro medio, fue abierto por LEÓN, Leysser L. Weak legal cultures \& legal transplants: Unificación de la responsabilidad civil y otras importaciones de los años noventa, en Cardozo Electronic Law Bulletin, vol. 12, 2006, p. 1 y ss. (de la versión pdf), disponible en http://www.jus.unitn.it/cardozo/Review/.

25. MONATERI, Pier Giuseppe. op. cit., passim. 
Los problemas anotados se incrementan exponencialmente cuando en las clases universitarias, el profesor enfrenta la durísima tarea de explicar las ventajas para el cabal estudio del derecho nacional que ofrece un método como la comparación jurídica, en especial cuando se cae en la cuenta que el legislador es desde hace décadas un prolífico -más no exitoso- importador. Aun cuando se supere dicho escollo el profesor tendrá frente a sí otro inconveniente: a la fecha no hay en nuestro país (ni en nuestro idioma) demasiados estudios que informen sobre el método ha emplearse para acometer una empresa de la magnitud anunciada (la mejora del derecho nacional).

En los siguientes acápites intentaré ofrecer al lector una visión panorámica a las perspectivas más usuales en la comparación jurídica moderna. Empero, procuraré abordar al propio tiempo diversos asuntos vinculados a la comparación jurídica que nos brinden, al menos parcialmente, las reglas morfológicas y de sintaxis necesarias para el empleo de este lenguaje. Naturalmente, la tarea de contribuir en su desarrollo y expansión solamente se logrará con el decisivo aporte de quienes, seguramente de modo casual, leerán el presente ensayo y/u ostenten un legítimo interés en esta materia; quién sabe si de este modo se logra crear un diálogo fluido en el Perú sobre esta aproximación jurídica.

De acuerdo con tal pretensión, creo necesario abordar lo que suele ser el primer tema de las clases de comparación jurídica: encuadrar en algunas pocas categorías la gran multiplicidad de sistemas jurídicos. El sentido de esta clasi- ficación, ya se ha visto en las páginas precedentes, es ordenar la información, procesarla y luego trasmitirla de manera coherente; todo ello nos da la posibilidad de focalizar la atención sólo en los elementos que se presentan como definitorios de un sistema jurídico dado. Asimismo, la taxonomía que se proponga podrá ayudar a predecir cómo y por qué se producen los cambios o mutaciones jurídicas en determinado sistema, sea producto de su interrelación con sistemas semejantes, sea con sistemas del todo distintos.

Acaso la clasificación más conocida, si es que no la más importante, fue la propuesta por René David. Al punto que aún hoy en ciertas Facultades de Derecho de la capital, como por ejemplo en la Pontificia Universidad Católica del Perú, las clases reflejan fielmente tal clasificación. Así, se propuso dividir los sistemas jurídicos en cuatro (4) grandes familias ${ }^{26}$ : (i) el Common Law, (ii) el Civil Law; (iii) el derecho imperante en los países socialistas; $y$, como categoría residual, (iv) otras concepciones del derecho.

Como toda clasificación, la propuesta del ilustre comparatista francés no se encuentra exenta de críticas. En efecto, más de un autor la ha considerado fuertemente euro-céntrica, objeción con la que difícilmente podría estarse en desacuerdo, en la medida que tiende a marginalizar a los sistemas que no se han acoplado a una de las grandes familias del mundo occidental ${ }^{27}$. Por otro lado, habría que destacar que el mundo ha sufrido cambios de gran trascendencia desde el tiempo en que se formuló tal clasificación ${ }^{28}$.

26. Cfr. DAVID, René y SPINOSI, Camille Jaufrett. I grandi sistemi giuridici contemporanei, Quinta edición italiana al cuidado de Rodolfo Sacco, Cedam, Padua, 2004, passim.

27. Cfr. MATTEl, Ugo. op. cit., pp. 7-12.

28. Pienso, por ejemplo, en la transición a la democracia y/o al capitalismo de los países socialistas una vez que se produjo tanto la desaparición de la Unión de Repúblicas Socialistas Soviéticas, como la caída del muro de Berlín. Este itinerario ha sido expuesto por AJANI, Gianmaria. By chance and prestige: Legal transplants in Russia and eastern Europe. En: The American Journal of Comparative Law, vol. XLIII, núm. 1, 1995, pp. 93 y ss., ivi pp. 95-98.

El razonamiento apenas expuesto, sobre todo en cuanto al progresivo -y decisivo- avance del capitalismo, se reproduce en el Derecho chino. Así, para un análisis de esta experiencia se aconseja la lectura de LUBMAN, Stanley B. Studying contemporary Chinese law: Limits, possibilities and strategies. En: The American Journal of Comparative Law, vol. XXXIX, núm. 2, 1991, p. 293 y ss. 
Por este motivo, si la clasificación sugerida por David no reproduce fielmente la realidad debe procurarse su adaptación o su abandono ${ }^{29}$, este es el destino de cualquier categoría doctrinal $u$ enfoque que pierda de vista el sentido esencialmente pragmático que inspiró su creación. Tal circunstancia ratifica la necesidad de volver a prestar atención a las labores taxonómicas.

A fin de cumplir dicho objetivo, me inclino por una clasificación flexible como la propuesta por Ugo Mattei $^{30}$. Con esta fórmula se lograría incluir a todos los sistemas jurídicos (un requisito de toda taxonomía en la comparación jurídica) y tendría el mérito de favorecer el abandono -por lo menos parcial- de una visión eurocéntrica. El Derecho sería, en esencia, una herramienta de organización social y no una construcción formal necesariamente que tiene que cumplir con el conjunto de postulados que se han erigido $a$ priori $^{31}$, la mayoría de veces característicos de los modelos occidentales; así, los sistemas jurídicos hoy condenados a la periferia por el esquema de David perderían tal calidad y también se lograría explicar cómo se producen ciertos cambios al interior de cada sistema jurídico.

Me explico. Las normas, cuyo propósito son la regulación de las relaciones sociales o -en otras palabras- la creación de incentivos para ciertas conductas, emanan básicamente de: (i) fuentes políticas, (ii) fuentes jurídicas y (iii) fuentes filosóficas o religiosas. En cambio, la clasificación de David giraba, como se ha dicho, en torno a la concepción occidental del Derecho, en la que se niega -con mayor o menor intensidad y alcance- la trascendencia de la política o el papel de las perspectivas filosófico-religiosas ${ }^{32}$.

Como es fácil de constatar en la realidad profesional y académica, los operadores jurídicos de occidente no prestan demasiada atención, al menos a nivel de retórica expresa, a aspectos de carácter político y/o filosófico/religioso. Esto no debería causar perplejidad, se nos entrena a percibir y comprender el Derecho como un sistema que es dado por una entidad distinto a los ciudadanos (sea el legislador, sea el juez), quien deberá resolver -en términos expresos y de manera general- las materias de su competencia. A su vez, también se nos educa a ignorar las fuentes tácitas o mudas (esto es, aquellas fuentes que no requieren de un organismo externo a los ciudadanos) del Derecho, sentando las bases de un sentimiento de rechazo o menosprecio hacia tales fuentes. Tal sentimiento se explica en el hecho de que la sociedad (o su sistema de creencias) participará en la creación de las normas jurídicas ${ }^{33}$, afectando con ello la percepción -casi consustancial a la visión europea u occidental- del carácter técnico del Derecho.

Por su parte, al observar cómo los operadores jurídicos interactúan con las fuentes enunciadas podremos concluir que existen algunos patrones. Así, gracias a la dilucidación de los patrones, se podrá agrupar a los sistemas jurídicos en atención a la fuente normativa que

29. CANARIS, Claus-Wilhem. op. cit., pp. 122-123.

30 MATTEl, Ugo. op. cit., p. 12.

31. Para una visión amplia de este fenómeno y de el impacto de la visión política en las distintas etapas que se han observado en el desarrollo de la comparación jurídica, se recomienda el ensayo de KENNEDY, David- The methods and the politics, en Aa. Vv., Comparative legal studies: Traditions and transitions editado por Pierre Legrand y Roderick Munday, Cambridge University Press, 2004, p. 345 y ss.

32. Esta negación se deriva, fundamentalmente, de la consolidación de perspectivas positivistas. Con sujeción a este paradigma, se tenía que extraer del Derecho todo elemento que fuese externo a la norma jurídica, así se promovió la desvinculación de lo jurídico de cuestiones como la moral, la política y la sociedad. Sobre el impacto de esta aproximación, aunque con mayor énfasis a los aspectos económicos, puede consultarse los trabajos de MATTEI, Ugo. The rise and fall of law and economics: An essay for judge Guido Calabresi. En: Maryland Law Review, vol. 64, núm. 1-2, 2005, p. 220 y ss.; y KATZ, Avery Wiener. Positivism and the separation of Law and Economics. En: Michigan Law Review, vol. 94, núm. 7, 1996, p. 2229 y ss.

33. SACCO, Rodolfo. Mute law. En: The American Journal of Comparative Law, vol. XLIII, núm. 3, 1995, p. 455 y ss. Ivi, pp. 456 y $465-467$. 
ostenta un rol preponderante, al operador que cobra protagonismo y cómo se construyen las normas. Con un trabajo de esta naturaleza se identificará que los patrones ${ }^{34}$ en cuestión permiten resumir toda la complejidad en aquellos sistemas jurídicos ${ }^{35}$ en básicamente tres categorías. Los sistemas se reconducirán a un sistema en el que impere: (i) el Derecho generado por los profesionales, (ii) el Derecho estimulado por la intervención política o (iii) el Derecho basado en la tradición.

Naturalmente, es posible $-y$, en realidad, es lo usual- que identifiquemos que en los sistemas jurídicos bajo estudio alguna de las fuentes aludidas desplegará un rol hegemónico, pero no se deberá concluir de esta constatación la ausencia de interacción entre ellas, ni mucho menos su falta de vigencia. Incluso, debe reconocerse que es posible que en ciertas áreas del Derecho la fuente que tenga preeminencia resulte distinta a la que es distintiva para ese sistema jurídico en particular, estas circunstancias acreditan la flexibilidad de la taxonomía sugerida y la propia complejidad de la realidad que se quiere aprehender. A manera ilustrativa se puede recordar la historia reciente del Perú, el cual se encuentra enmarcado dentro de los sistemas en los que impera el Derecho generado por los profesionales, empero existen casos en los que luego de haberse tomado determinada decisión -sea a nivel judicial o legislativoel Gobierno intervino políticamente para enmendarla o alterarla. Tales intervenciones se produjeron, sea expresa o tácitamente, en virtud a factores de conveniencia política (recobrar "estabilidad" es la excusa preferida) o para recoger un pedido concreto de la sociedad $^{36}$.

Ahora bien, es momento de dar un poco más de contenido a la clasificación sugerida. A efectos del presente ensayo, considero oportuno resaltar las siguientes características de los patrones aludidos ${ }^{37}$ :

(i) Cuando en un sistema existe hegemonía profesional (o, en otras palabras, cuando impera el Derecho generado por los profesionales) se diferencia con total claridad el campo jurídico del campo político; $y$, a su vez, el proceso de creación normativo se encuentra profundamente secularizado. La diferenciación entre ambos campos tiene como propósito hallar legitimidad en el tecnicismo (aspiración racionalista) y no en justificaciones externas al Derecho (manifestación individualista ${ }^{38}$, si es que no positivistas). Así las cosas, es fácil explicar por qué, en términos generales, estos sistemas guardan una estrecha relación con la democracia (al menos a nivel de retórica expresa) y con el rule of law.

34. MATTEI, Ugo. Three patterns of law: Taxonomy and change in the world's legal systems, cit., p. 19.

35. Si bien la propia noción de sistema ha sido objeto de cuestionamiento, al respecto NELKEN, David. Towards a sociology of legal adaptation, en Aa. Vv., Adapting legal cultures edición a cargo de David Nelken y Johannes de Feest, Hart Publishing, Oxford, 2001, pp. 7 y ss., ivi p. 24 y ss.

36. No sugiero un caso específico pues lo interesante de dejarlo en estos términos es que deja a la memoria individual el recordar algunos de estos recientes hechos (que no son tan esporádicos o eventuales como se pudiera pensar inicialmente).

Al no brindar un ejemplo apelo al denominado sesgo de disponibilidad (availability bias), sin mencionar a la propia escala de valores del lector, quien elegirá tal recuerdo en función a su propia percepción de aspectos que le generaron un impacto particular. Acerca de los efectos (así como los defectos) que la percepción y el procesamiento de información producen sobre los individuos me permito sugerir la consulta de un ensayo que publiqué tiempo atrás, me refiero a SAAVEDRA VELAZCO, Renzo E. Deconstruyendo al homo economicus: Una revisión conductual a un paradigma del Law and Economics. En: lus et veritas, año XXI, núm. 42, 2011, p. 54 y ss., ahora también disponible en http://works.bepress.com/renzo saavedra/49/.

37. MATTEl, Ugo. op. cit., pp. 23-40.

38. VAN HOECKE, Mark y WARRINGTON, Mark. Legal cultures, legal paradigms and legal doctrine: Towards a new model for comparative law. En: International and Comparative Law Quarterly, vol. XLVII, núm. 3, pp. 503-505. 
Aquí cabría una sub-clasificación ulterior, la cual serviría para echar por tierra una discusión institucional en la comparación jurídica occidental ${ }^{39}$. En efecto, al interior del presente patrón existirían tres familias jurídicas, las cuales son muy conocidas para la mayoría. Me refiero al Common Law (Inglaterra, Estados Unidos, Australia, etc.), al Civil Law (Alemania, Francia, Italia, Portugal, Perú, etc.) y a los Mixed Legal Systems (Israel, Escocia, Sudáfrica, etc.).

(ii) Cuando en un sistema existe hegemonía política (o, si se quiere, cuando impera el Derecho estimulado por la intervención política) no se produce per se la diferencia entre el campo jurídico y el campo político. Por este motivo, a menudo el proceso de creación normativo (o, más en concreto, la toma de decisiones jurídicas) se ve influido por las relaciones políticas. Tales intrusiones no son eventuales, ni mucho menos esporádicas (participación que, a nivel de discurso, resulta patológico en los términos del patrón precedente), sino que resultan normales u ordinarias (sobre todo en las relaciones entre el Estado y los particulares).

En concreto, puede decirse que el concepto poder gubernamental ${ }^{40}$ limitado no se encuentra claramente incorporado en tales sistemas jurídicos. Así, la actuación de los operadores jurídicos se regirá por factores exógenos al Derecho (entendido en térmi- nos meramente técnicos). Como corolario lógico de lo anterior, la legitimidad de los sistemas jurídicos que siguen este patrón se sustenta de modo ad hoc, vale decir, en atención a las necesidades del momento en el que se toma la decisión y a las ventajas anexas a dicha decisión (valoración que se replicará e impactará en la legitimidad del gobierno y en la propia legitimidad de las conductas realizadas).

Aquí también cabría una sub-clasificación ulterior. En este patrón se encontrarían otras dos familias jurídicas, las cuales se diferenciarían en atención al momento en que políticamente se encuentran; vale decir, existirían: a) sistemas en transición (piénsese en las ex repúblicas socialistas soviéticas); y, b) sistemas en desarrollo.

(iii) Cuando en un sistema existe hegemonía filosófico-religiosa (o, en otras palabras, cuando impera la tradición) no se produce una diferencia entre el campo jurídico y el filosófico-religioso ${ }^{41}$, por lo que la dimensión individual y la social se encuentran vinculadas entre sí. No obstante ello, hay figuras o instituciones jurídicas al interior de los sistemas que siguen este patrón. Tal vez la única verdadera diferencia entre esta patrón respecto de los demás se centra en que su legitimidad no se construye a través de una retórica técnica o si se quiere de la satisfacción de las necesidades de un momento específico, sino por la existencia

39. La referencia es a los debates sobre la convergencia entre el Civil Law y el Common Law. Si ambas familias forman parte del mismo patrón no tendría mayor sentido discutir este aspecto. Empero, de ello no se debe concluir de que no existen fenómenos de trasplantes entre los sistemas pertenecientes a cada una de estas familias. Ello será materia de análisis más adelante.

La negación sobre la convergencia entre ambas familias (en el plano europeo) ha sido duramente criticada, si bien por otras razones, por LEGRAND, Pierre. European legal systems are not converging, En: International and Comparative Law Quarterly. vol. XLV, núm. 1, 1996, p. 52 y ss.

40. Aspectos que se pueden observar en el desarrollo efectuado por FOSTER, Frances H. Information and the problem of democracy: The Russian experience. En: The American Journal of Comparative Law. vol. XLIV, núm. 2, 1996, p. 243 y ss.

41. En palabras de ABEL, Richard. Comparative law and social theory. En: The American Journal of Comparative Law, vol. XXVI, núm.2, 1978, p. 219 y ss., ivi p. 220, "la dificultad es incluso más aguda cuando el sistema jurídico se encuentra íntimamente vinculado a una de las grandes religiones y también expresa los sentimientos nacionales y supranacionales". 
de un orden sobrenatural, el cual debe ser seguido y respetado.

Aquí la sub-clasificación ulterior se limitaría a dos familias. En síntesis, existirían: a) sistemas orientales ${ }^{42} \mathrm{y}$ b) sistemas islámicos ${ }^{43}$.

Cabe destacar, como en toda aproximación taxonómica, que puede continuarse con la labor de clasificación. La razón es sencilla, siempre pueden identificarse elementos diferenciales en los sistemas jurídicos que siguen cierto patrón, así como sucede en el caso de cualquier organismo vivo que es estudiado por la taxonomía biológica. Por ejemplo, si se piensa en el ser humano se puede decir, siguiendo aquí al siempre crítico Marco Aurelio Denegri, que: "El hombre es un miembro del reino animal, del filum de los cordados del subfilum de los vertebrados, de la clase de los mamíferos, de la subclase de los euterios, del grupo de los placentarios, del orden de los primates, del suborden de los pitecoides, del infraorden de los catarrinos, de la familia de los hominoides, de la subfamilia de los homínidos, del género homo y de la especie stupidus."; con este ejemplo se ilustra el nivel de precisión que se puede alcanzar en una labor de clasificación como la iniciada.
De esta misma manera, uno podría proseguir en la clasificación de los sistemas jurídicos. Así, se podría sugerir que en el Civil Law existen los sistemas en los que se manifiesta la influencia germana y sistemas en los que se percibe la influencia francesa ${ }^{44}$. Por su parte, en el Common Law existirían el sistema norteamericano y aquellos que tienen influencia inglesa. Finalmente, en los mixed legal systems se tendría, por un lado, a los sistemas escandinavos $y$, por otro lado, a los sistemas mixtos tradicionales (tales como Escocia, Sudáfrica y Lousiana). Sin embargo, en tanto que proseguir con esta labor no nos brindaría mayores luces sobre lo que es el objeto del presente ensayo, prefiero dejar en este punto el desarrollo de esta materia.

Teniendo en cuenta lo apenas expuesto resultará más sencillo comprender como los sistemas jurídicos mutan o, si se quiere, se adaptan. Nuevamente, y como sucede sistemáticamente en los últimos años, los hallazgos de algunas de las ciencias sociales ${ }^{45}$ nos ayudarán a comprender los mecanismos que se despliegan en cada uno de los sistemas para facilitarles la adaptación a las exigencias del mundo actual (como las nuevas realidades a regular $\left.{ }^{46}\right)$. Aquí la antropología ${ }^{47}$ y la sociología ${ }^{48}$

42. Cuyas características serían una aproximación colectivista y una percepción sobre el orden natural de las cosas. Sobre el punto consúltese VAN HOECKE, Mark y WARRINGTON, Mark. Legal cultures, legal paradigms and legal doctrine: Towards a new model for comparative law, cit., pp. 505-507.

43. En este extremo podría ser de utilidad, de manera general, la consulta de VAN HOECKE, Mark y WARRINGTON, Mark. Legal cultures, legal paradigms and legal doctrine: Towards a new model for comparative law, cit., pp. 507-508.

44. MATTEI, Ugo. Why the wind changed: Intellectual Leadership in western law. En: The American Journal of Comparative Law. vol. LXII, núm. 1, 1994, p. 200. En donde se diferencia entre las formas en las que ambos sistemas obtuvieron, en su momento, el liderazgo intelectual de occidente. En efecto, el derecho francés lo hizo a través de la importancia del Code Napoléon, mientras que en el caso de Alemania la influencia se obtuvo a través de la influencia de los trabajos de sus académicos.

45. SOMMA, Alessandro. Tanto per cambiare... mutazione del diritto e mondializzazione nella riflessione comparatistica. En: Boletín Mexicano de Derecho Comparado. nueva serie, año XXXIX, núm. 116, 2006, p. 535 y ss., ivi p. 537.

46. Es cierto que también puede ser fruto de lo que ha sido denominado como Imperial Law, pero creo que el lugar que le corresponde a esta discusión es el acápite 5 . Al respecto es de interés el estudio de MATTEl, Ugo. A theory of Imperial Law: A study on U.S. hegemony and the Latin resistance. En: Indiana Journal of Global Legal Studies. vol. 10, núm. 1, 2003, p. 383 y ss.

47. Resulta sugerente la consulta del libro de SACCO, Rodolfo. Antropologia giuridica: Contributo ad una macrostoria del diritto, Mulino, Bolonia, 2007, pp. 41-58.

48. Para una manifestación acerca de cómo la sociología puede provocar sugerentes nuevas maneras de observar el Derecho (o bien alterar la percepción del mismo) me remito a GAGO PRIALÉ, Horacio. Sociedad espontánea y Derecho: Cómo la teoría jurídica de Joaquín Costa puede explicar la nueva sociedad urbana y mestiza de Lima, Civitas, Madrid, 2000, pp. 187-213. 
son de suma utilidad para la comprensión de estos fenómenos.

En términos sencillos, el enfoque antropológico permite que identifiquemos y comprendamos las causas de la mutación, merced a las reflexiones que tales ciencias realizaron por el influjo de las corrientes evolucionistas y difusionistas. Por su parte, la perspectiva sociológica brindará los esquemas que se observan en los cambios de discurso y en los cambios sociales, así como los nexos entre ambas modificaciones ${ }^{49}$.

Se sostiene que las corrientes evolucionistas inspiran -muchas veces de manera equívoca- una visión de desarrollo de carácter unilateral que se sintetiza en la consecución de un objetivo ${ }^{50}$. A pesar de la autoridad de quienes efectúan tales críticas puede oponerse que, como puede ser constatado en más de un caso, existe una multiplicidad de mecanismos o vías por las cuales los sistemas jurídicos (o, en general, las culturas) se desarrollan ${ }^{51}$. En efecto, no podemos perder de vista que las culturas, a pesar de lo diversas que resultan, sí se comunican y se enriquecen recíprocamente en más de un aspecto. Me explico. Los hablantes toman prestados de otros idiomas ciertas palabras que por diversas razones no son transferibles de manera directa (en la medida que no existe un término equivalente) a su propia lengua o, en la mayoría de casos, los adaptan a sus propios estándares (no por nada el castellano está plagado de galicismos y más recientemente de anglicismos). En la gastronomía moderna se producen fenómenos de fusión, cuyos sorprendentes resultados son por lo general aplaudidos (y no únicamente por sibaritas). Celebraciones de culturas ajenos, con componentes religiosos, históricos, etc., se trasplantan por influjo de la moda o del consumismo (con mayor énfasis en nuestro tiempo), o por el grado de participación en las sociedades importadoras de miembros de las culturas de origen. Como es claro, los ejemplos y campos a los que se puede aludir son interminables (en la genética tal asunto no es siquiera debatible).

Lógicamente tales cambios pueden alcanzarse sin que exista creación (o una constante labor de "redescubrir la rueda"), sino meramente imitación ${ }^{52}$. En efecto, y en última instancia, las mutaciones pueden producirse por influencia de aspectos o elementos endógenos, por lo que dichos elementos se comportarán como condiciones que estimulan o inhiben el cambio; o, en otro escenario, se erigirán como su causa u origen ${ }^{53}$.

Por su parte, las corrientes difusionistas -a diferencia de lo que es predicado por las teorías evolucionistas- parten de la premisa de que los cambios o mutaciones se producen a causa de la interrelación entre culturas en la medida que la creatividad o la innovación se presentaría de manera eventual (sería, por lo tanto, contingente y excepcional) $)^{54}$. Con ello se aceptaría que existe un área (no necesariamente geográfica) en la que se manifestaría una influencia cultural

49. SOMMA, Alessandro. Op. cit. p. 537.

50. MERRYMAN, John Henry. Comparative law and social change: On the origins, style, decline \& revival of Law and Development movement. En: The American Journal of Comparative Law. vol. XXV, núm. 3, 1977, p. 457 y ss., ivi pp. 461-473.

51. SACCO, Rodolfo. Diversity and uniformity in the law. En: The American Journal of Comparative Law. vol. XLIX, núm. 2, 2001, p. 171 y ss. Ivi. pp. 179-189.

52. WATSON, Alan. Aspects of reception of law. En:The American Journal of Comparative Law. vol. XLIV, núm. 2, 1996, p. 335 y ss.; Id., From legal transplants to legal formants. En: The American Journal of Comparative Law. Vol. XLIII, núm. 3,1995, p. 469 y ss.

53. Cfr. HOROWITZ, Donald L. The Qur'an and the common law: Islamic law reform and the theory of legal change. En: The American Journal of Comparative Law. Vol. XLII, núm. 2, 1994, pp. 233 y ss., ivi p. 246.

54. SACCO, Rodolfo. Legal formants: A dynamic approach to comparative law. En: The American Journal of Comparative Law (Installment II). Vol. XXXIX, núm. 2, 1991, p. 343 y ss., ivi p. 398. 
(o, si se quiere, un área de influencia jurídica $)^{55}$, que explicaría diversos fenómenos.

Como es fácil concluir, las familias jurídicas que presentan un patrón similar se encontrarán en mejores condiciones de influenciarse recíprocamente, toda vez que la labor del operador se encuentra allanada debido precisamente a las similitudes. Puede predecirse entonces que la influencia entre tales sistemas se presentará de manera sencilla y consistente; mientras que en el caso de sistemas que forman parte de patrones distintos, el margen de influencia se reduce ostensiblemente.

Empero, si bien somos de la opinión que la influencia entre sistemas jurídicos es -desde un punto vista empírico- un dato fáctico innegable, también habría que aceptar que -desde un punto de vista teórico-se pueden elevar críticas a esta manera de analizar la mutación jurídica y la interrelación entre los sistemas. En efecto, para calificar, de la manera en que lo hacen las corrientes difusionistas, la interrelación e influencia entre varios sistemas se tiene que partir por aclarar donde se encuentran los límites entre estos sistemas ${ }^{56}$, lo cual no siempre es una tarea sencilla de realizar.

Atendiendo precisamente a la dificultad existente para diferenciar entre sistemas jurídicos es que opté por sugerir la clasificación propuesta por Mattei. Asimismo, es por tal dificultad que la exposición de la clasificación en cuestión se ha efectuado antes de exponer las perspectivas que emplean las diversas corrientes dentro de la comparación jurídica. Con este esquema en mente -cuya simplicidad y detalles son de destacar-se tendrá una guía sobre los límites entre los sistemas jurídicos y también una teoría que permita explicar los mecanismos por los que se interrelacionan. A tal efecto se atenderá a las fuentes que generan las normas, entendidas éstas como medio de control social o de creación de incentivos y no en su sentido formal. A lo antes expresado se añadirá la gran flexibilidad de la clasificación propuesta, en la medida que permite que las fuentes se relacionen entre sí, a pesar de la hegemonía de alguna de ellas ${ }^{57}$.

\section{LA CIRCULACIÓN DE LOS MODELOS JURÍDICOS: LA MUTACIÓN POR DIFUSIÓN}

En la comparación jurídica, entendida como metodología, se observan múltiples enfoques que van desde aproximaciones de corte estructuralista ${ }^{58}$, transitando por las perspectivas de tinte funcionalista ${ }^{59}$, luego por lecturas de cariz culturalista ${ }^{60}$, para culminar -si cabe el términoen propuestas post-modernas ${ }^{61}$.

55. Idea que ya se encontraría presente en la afirmación de Tullio Ascarelli quien creía que en América Latina se daría la síntesis entre el Civil Law y el Common Law dada su posición geográfica y por su no afiliación total a una u otra perspectiva. Esta afirmación es doctamente recordada por LEÓN HILARIO, Leysser L., Common Law vs. Civil Law: La competencia entre ordenamientos jurídicos, en Foro Jurídico, año IV, núm. 7, 2007, p. 266.

56. MONATERI, Pier Giuseppe. Op. cit., § 1.

57. Aspecto que también es recogido, de modo parcial y un tanto diverso, en los aportes de René David. Sobre el particular puede ser de interés el texto de ESQUIROL, Jorge L. René David: At the head of the legal family, en Aa. Vv., Rethinking the masters of comparative law edición a cargo de Annelise Riles, Hart Publishing, Oxford, 2001, p. 212 y ss.

58. Cfr. SACCO, Rodolfo. Introduzione al diritto comparato, en Tratatto di diritto comparato dirigido por Rodolfo Sacco, 5ta. edición, Utet, Turín, 1992, passim. Asimismo, el egregio autor resalta lo diversos que pueden ser los métodos empleados para hacer comparación jurídica (p. 11).

59. MICHAELS, Ralf. The functional method of comparative law, en Aa. Vv., Oxford Handbook of Comparative Law edición a cargo de Mathias Reimann y Reinhard Zimmermann, Oxford University Press, Nueva York, 2006, p. 339 y ss., ivi pp. 340-343.

60. LEGRAND, Pierre. Comparative legal studies and commitment to theory. En: Modern Law Review. Vol. LVIII, núm. 2, 1995, p. 262 y ss., ivi p. 263; Id., On the singularity of law. En: Harvard International Law Journal. vol. XLVII, núm. 2, 2006, pp. 517 y ss.; Id., European legal systems are not converging, cit., pp. 56-64.

61. AINSWORTH, Janet E. Categories and culture: On the 'rectification of names' in comparative law. En: Cornell Law Review. Vol. LXXXII, núm. 1, 1996, p. 19 y ss., ivi pp. 24-25. 
En el presente acápite deseo detenerme brevemente en el análisis de la difusión o circulación de los modelos jurídicos. La razón de tal interés no se centra únicamente en que se trataría de una de las maneras usuales en las que-como se constata en la realidad empírica- se producen las mutaciones jurídicas (y por ende se erigiría en uno de los asuntos que con mayor frecuencia abordan los comparatistas), sino por tratarse del enfoque predilecto de las corrientes que han sido denominadas "estructuralistas" 62 .

Antes que nada habría que dedicar algunas líneas al esclarecimiento de lo que se entiende por una aproximación estructuralista. En síntesis, serían aquellas posturas que pretenden explicar y comprender los sistemas (jurídicos) en función al análisis de las posibles relaciones entre sus componentes ${ }^{63}$. Dicha aproximación se generó, fundamentalmente, en las ciencias sociales y las ciencias cognitivas ${ }^{64}$, pero ha logrado extenderse a nuevos campos, como las matemáticas y hace algunas décadas al Derecho.

La investigación jurídica comparada de corte estructuralista posee, por lo menos, las siguientes características: (i) no persigue ningún objetivo o finalidad ${ }^{65}$ más que el propio conocimiento ${ }^{66}$; (ii) el desarrollo del Derecho patrio se produce, básicamente, a través de trasplantes jurídicos o préstamos jurídicos, los cuales se revelan en la realidad como fenómenos de imitación (si bien es posible la innovación, hay que aceptar que ésta se presenta eventualmente) y de imposición (en un primer momento estuvo asociado a algún tipo de dominación militar, lo cual explicaba el reflejo in toto de aspectos del sistema dominador en el país dominado, pero en la actualidad se manifiesta, por lo general, a causa de la influencia económica y/o política); y, (iii) se efectúa una descripción científica - sin cargas valorativas- de la manera en que se interrelacionan los elementos al interior de un mismo sistema jurídico o con elementos de otro sistema ${ }^{67}$.

Ahora bien, puede afirmarse que los líderes intelectuales dentro de esta perspectiva de análisis son, fuera de cualquier discusión ${ }^{68}$, Rodolfo Sacco y Alan Watson.

62. Sobre el punto consúltese: DERRIDA, Jacques. Structure, sign, and play in the discourse of the human sciences. En: Writing and difference. Traducción de Alan Bass, Routledge, Londres, 1981, pp. 278-284, ahora también disponible a través de http://hydra.humanities.uci.edu/derrida/sign-play.html.

63. MATTEI, Ugo y DI ROBILANT, Anna. The art and science of critical scholarship: Postmodernism and international style in the legal architecture of Europe. En: Tulane Law Review. Vol. LXXV, núm. 4, 2001, p. 1053 y ss., ivi p. 1078, quienes señalan que el «[e]structuralismo apunta a comprender un sistema observando la relación entre sus elementos ("formantes" en la terminología de Sacco) que erigen la estructura del sistema. El estructuralismo se inicia en la lingüística (Ferdinand de Saussure, Noam Chomsky, Roman Jacobson, Emile Beneviste) y encontró su camino hacia la antropología (Claude Levi Strauss), el psicoanálisis (Jacques Lacan), psicología (Jean Piaget), filosofía (Louis Althusser, Michel Foucault), semiótica (Umberto Eco), y, finalmente, en el Derecho. El estructuralismo intenta desarrollar un método científico describiendo el derecho que gobierna la relación entre los elementos de una estructura y entre la estructura y el sistema en su totalidad.»

64. Sobre el particular sería aconsejable la consulta del artículo de KENNEDY, David, Critical theory, structuralism, and contemporary legal scholarship. En: New England Law Review. Vol. 21, núm. 2, 1985, pp. 248-271.

65. SACCO, Rodolfo. Legal formants: A dynamic approach to comparative law. En: The American Journal of Comparative Law (Installment I). Vol. XXXIX, núm. 1, 1991, p. 1 y ss., ivi pp. 4-6.

66. Cfr. LEGRAND, Pierre. Per l'analisi giuridica comparatistica: A proposito di un libro di Rodolfo Sacco. En: Rivista di Diritto Civile. Año XL, núm. 6, segunda parte, 1994, p. 597 y ss.,

67. SOMMA, Alessandro. At the patient's bedside? Considerations on the methods of comparative law. En: The Cardozo Electronic Law Bulletin. Vol. 13, 2007, pp. 7-12 (de la version pdf), consultado el 20 de enero de 2012, www.jus. unitn.it/cardozo/Review/2007/somma2.pdf; Id., Tanto per cambiare... mutazione del diritto e mondializzazione nella riflessione comparatistica, cit. p. 541.

68. Para una presentación más completa, pero aun así breve, sobre las posiciones aquí expuestas consúltese el trabajo de Marella, Maria Rosaria, Critical family law, en Journal of Gender, Social Policy \& the Law, vol. XIX, núm. 2, 2011, p. 721 y ss. 
La construcción de Sacco nos parece particularmente interesante debido a que toma prestados de los estudios lingüísticos y fonéticos una diversidad de conceptos para luego reformularlos ${ }^{69}$ con la finalidad de emplearlos en las investigaciones jurídicas. A través de dicha tarea se acuñó el término formante $e^{70}$ jurídico, posiblemente la voz que mayor éxito y difusión ha tenido en el campo de la comparación jurídica, a fin de resumir -en términos muy sencillos- la manera en que se descomponen las fuentes ( $y$ el contenido) de las diversas reglas existentes al interior de cierto sistema jurídico. Con el empleo de este concepto se demostraba el equívoco de aquella posición que pregonaba la unidad del sistema jurídico (tan propia del positivismo jurídico).

En este orden de ideas, existirían tres formantes, a saber: (i) el formante legal, (ii) el formante doctrinal y (iii) el formante jurisprudencial ${ }^{71}$.

De acuerdo a esta propuesta, los diversos formantes pueden coincidir entre sí en la manera en que enfrentan determinado aspecto de relevancia jurídica o bien pueden arribar a soluciones diversas. Un ejemplo puede aclarar el panorama, pensemos en el interesante debate sobre la naturaleza de la culpa in contrahendo, ahora preguntémonos ¿cuál es la solución al interior del sistema italiano ${ }^{72}$ ? Por un lado, en el formante legal se dicta, en el artículo 1337 del Codice Civile, que en los tratos preliminares las partes deben comportarse de acuerdo a la buena fe y por ende la responsabilidad por su violación sería de naturaleza contractual; por otro lado, en el formante jurisprudencial ${ }^{73}$ se sostiene que la verdadera naturaleza de esta responsabilidad es extracontractual, a pesar que el hecho generador de responsabilidad importa la violación de la norma antes aludida (contenida en el libro de contratos); $y$, por último, el sector mayoritario del formante doctrinal italiano sostiene que la responsabilidad precontractual es de naturaleza contractual por la existencia de una relación jurídica obligatoria que carece de deber primario de prestación $\mathrm{n}^{74} \mathrm{o}$, si se quiere, una obligación de fuente legal cuyo contenido son sólo deberes de protección ${ }^{75}$.

Como se observa la lógica de los formantes no sólo permite explicar con un lenguaje muy llano y sistemático las diferencias (o asonancias) que se presentan al interior de un sistema jurídico, sino que además contribuye a identificar cómo los diversos criterios involucrados en el caso se encuentran en la aptitud de alterar «la regla operativa». La trascendencia de este último factor resulta patente, en especial al momento en que se estudia «el» Derecho. Asimismo, no puede

69. SACCO, Rodolfo, Op. cit., p. 22.

70. En la fonética se entiende por formante al pico de intensidad en el espectro de un sonido, lo cual nos permite diferenciar el habla. Por su parte, en el campo jurídico el término acuñado tiene como propósito llamar la atención del operador acerca de cómo la regla promulgada puede no ser en los hechos la regla que es aplicada o incluso la regla puede encontrarse deformada o complementada por las interpretaciones doctrinales.

71. SACCO, Rodolfo. Introduzione al diritto comparato, cit., p. 43 y ss.

72. Elegí tal sistema jurídico dado que en nuestro país aún no existe una posición consolidada en ninguno de los formantes sobre tan compleja materia.

73. Me remito a la sentencia 9645 , de fecha 16 de junio de 2001, emitida por las Salas Reunidas de la Corte de Casación italiana. En tal resolución, se llego a una decisión del todo conforme a la sentencia 749, de fecha 6 de marzo de 1976, y a la sentencia 93, de fecha 11 de enero de 1977.

Todas estas sentencias las he citado en un trabajo anterior: SAAVEDRA VELAZCO, Renzo E. La responsabilidad precontractual en debate. En: Responsabilidad Civil Contemporánea, Ara Editores, Lima, 2009, nota al pie (46), texto y nota.

74 MENGONI, Luigi. Sulla natura della responsabilità precontrattuale. En: Rivista del diritto commerciale e del diritto general delle obbligazioni, II, 1956, p. 360 y ss.

75. Al respecto v. SAAVEDRA VELAZCO, Renzo E. Una obligación sin prestación o sólo una hipótesis de cumplimiento defectuoso: La responsabilidad del médico dependiente. En: Enfoque Derecho, 17 de julio de 2010, http://www.enfoquederecho.com/?q=node/405, disponible también, con las necesarias referencias bibliográficas, en http://works. bepress.com/renzo saavedra/27/. 
obviarse que con una propuesta de este cariz se torna más sencilla la labor de seguimiento de los fenómenos de circulación de modelos jurídicos, un tópico al que Sacco le ha dispensado un vivo interés.

En efecto, la circulación de los modelos jurídicos es claramente el mecanismo en el cual opera la difusión de fórmulas jurisprudenciales, reglas legales o construcciones teóricas. No obstante ello, aún no se ha dicho nada sobre las razones que justifican tal fenómeno. Históricamente las principales razones que explican el por qué se efectúa un trasplante jurídico son la imposición y/o el prestigio ${ }^{76}$ (sin embargo, en el acápite siguiente procuraré ser un tanto más preciso en lo que sucede hoy en el mundo).

Si bien admito sin mayores reparos que existe más de una crítica a esta manera de observar los fenómenos de cambio o mutación jurídica, creo que resulta incuestionable que los trasplantes ocurren, negarlo sería tan provechoso como arar en el mar. En ocasiones, un legal borrowing (o préstamo jurídico) se produce a través de la imposición o por la admiración que un sistema foráneo genera (tal vez, en ánimo de ser más preciso, debiera aclarar que es la simpatía por las soluciones de su judicatura, sus construcciones teóricas o sus reglas legales); lo curioso es que la bondad (o el éxito) del préstamo no siempre guarda una relación directa con la razón que lo motivó. En efecto, la aplicación del Code Napoléon en territorio belga es un conocido ejemplo de imposición normativa, ¿alguien pondría acaso en duda el aplastante éxito del Code en dicho territorio o incluso las bondades del préstamo? Por el contrario, si bien también existen casos en los que el trasplante se sustentó en la admiración o el prestigio, resulta lógico predecir que tal justificación no basta para garantizar el éxito de la operación (y en el Perú tenemos más de un ejemplo de este tipo de trasplantes).
Las razones que podrían explicar este particular fenómeno son múltiples, pero podría cuanto menos esbozarse las siguientes respuestas:

(i) El desconocimiento del importador sobre cómo se interpretaba o aplicaba la regla, fórmula o teoría trasplantada ${ }^{77}$ en su país de origen;

(ii) La ausencia de un proceso de preparación del sistema que recibirá el trasplante, un proceso que estaría dirigido a lograr que la regla, fórmula o teoría trasplantada no sea percibida como un ente extraño (por lo que, como se verá, se generaría la denominada reacción de "irritación"); o

(iii) El contexto social, económico, político o cultural del país de origen es totalmente distinto al del país receptor; condiciones que fueron las que tornaron exitosa a la solución pero que no pueden replicarse en el sistema del país importador, por lo que el préstamo resultará en sí mismo inaplicable o generará perturbaciones de carácter sistémico ${ }^{78}$.

Por su parte, como se percibe de lo antes expuesto, la manera en que se ejecuta el préstamo es muy importante para su éxito. Por lo general en la mayoría de sistemas jurídicos el proceso de importación normativo es defectuoso y a lo sumo resulta parcial (¿les suena conocido?). En nuestro medio, por ejemplo, se toman discursos foráneos sin que previamente se procese de manera adecuada todas sus virtudes y defectos, sin que se repare en el recorrido que tuvieron que cumplirse para la adaptación a las legislaciones nacionales y al law in action (otra prueba del interés que debe darse al mute law y al discurso sobre los legal formants). Entonces, como ha sido analizado por un sector importante de nuestra doctrina, si existen problemas al realizar

76. SACCO, Rodolfo. Legal Formants: A Dynamic Approach to Comparative Law (Installment II), cit., p. 398.

77. SACCO, Rodolfo. Legal Formants: A Dynamic Approach to Comparative Law (Installment I), cit., p. 3.

78. Aspecto que será luego analizado cuando se observe las opiniones de TEUBNER, Gunther. Legal irritants: Good faith in british law or how unifying law ends up in new divergences. En: Modern Law Review, vol. LXI, núm. 1, 1998, p. 11 y ss. 
importaciones en los formantes doctrinales de dos sistemas jurídicos, ¿qué puede esperarse (o imaginarse) cuando se procede a un préstamo en el formante jurisprudencial? o, peor aún, en el legal (el cual, contradictoriamente, ha sido el más prolífico pues los legisladores, no siempre tienen -ni tendrían por qué tenerlo- conocimiento jurídico, más si les cabe responsabilidad por la escasa o nula asesoría de calidad).

Las nociones de imposición y prestigio son, por tanto, medulares para asimilar los fenómenos de circulación. Me explico. Cuando se produce un préstamo o una importación, el operador no se limita exclusivamente a aprehender el discurso, norma o precedente; sino que -en mayor o menor medida- lo adapta, transforma o modifica. Evidentemente, y en virtud a la justificación de la importación, el proceso antes mencionado se presentará con mayor frecuencia y alcance. Si la importación se produce por admiración (o prestigio) el operador podrá intervenir con un mayor grado de libertad, a diferencia de si la razón de la importación es la imposición. Empero, en este último caso existe un margen de adaptación producto de los formantes jurisprudencial y doctrinal.

En este contexto, considero aconsejable detenerme un momento en las nociones involucradas.

Bajo la denominación imposición se incluyen fenómenos tales como la conquista, la invasión o la intervención de un país sobre otro (jno necesariamente en términos militares!); mientras que la denominación prestigio resulta un tanto más ambigua. Al respecto, son de suma utilidad las ideas expresadas hace unos años por Mattei ${ }^{79}$, quien al referirse al liderazgo intelectual en la tradición jurídica occidental afirma que «[e]l desplazamiento del liderazgo intelectual del que estamos discutiendo aquí parece confirmar la regla de que el liderazgo intelectual no tiene mucho que ver con el aspecto práctico del Derecho. No tiene mucho que ver con las reglas del derecho positivo que realmente produce un país o que copia de otro. En lugar de ello tiene que ver con las formas en las que se piensa el Derecho. De los cambios de liderazgo que hemos discutido puede observarse que cuando una cultura jurídica asume una estrecha aproximación positivista, que se centra en sus particulares textos o asuntos locales, es menos probable que alcance el liderazgo dentro de la informada academia mundial». Si se cambia la referencia al liderazgo a fin de reemplazarla por prestigio ${ }^{80}$-si es que acaso fuese necesario ya que ambas ideas se encuentran en estrecha relación-, entonces se tiene un índice para comprender esta imagen tan imprecisa.

Asimismo, vinculado a la idea de prestigio ${ }^{81}$, tiene que recordarse que las reglas se encuentran muchas veces imbuidas explícitamente de elementos políticos. En estos casos la posibilidad de circulación de dichas reglas estará ligada directamente al éxito que alcance la idea a la cual se emparenta. En otras palabras ${ }^{82}$, las reglas que se presentan políticamente neutrales tenderán a circular con mayor facilidad que aquellas que posean una impronta política expresa, sea en un

79. MATTEI, Ugo. Why the wind changed: Intellectual Leadership in western law, cit., p. 195 y ss., ivi pp. 213-217.

80. La idea del prestigio o, en términos más precisos, a su ausencia (y la consecuente reducción en la trascendencia de la ciencia jurídica) se observa ya en JHERING, Rudolph von. Geist des römischen Rechts, vol. l, 2ª edición, 1866, p. 14 y ss. [citado por Zweigert, Konrad y Siehr, Kurt, Jhering's influence on the development of comparative legal method. En: The American Journal of Comparative Law, vol. XIX, núm. 2, 1971, p. 215 y ss., ivi p. 218], quien afirmaba que la «[c]iencia jurídica ha sido degradada a una jurisprudencia provincial, y los límites de la ciencia jurídica coincide con las fronteras políticas. iQué humillante y poco valiosa forma de ciencia! Sin embargo, es por la ciencia que se trasciende tales fronteras y se preserva el futuro su antiguo carácter de transnacionalidad, en la nueva forma de jurisprudencia comparada.

81. MATTEI, Ugo. Why the wind changed: Intellectual Leadership in western law, cit., p. 201, quien nos sugiere efectuar un sencillo test, se sostiene que: «un test de liderazgo es la capacidad de los sistemas jurídicos o de algunos de sus producto (códigos, piezas de legislación, instituciones jurídicas, escritos académicos) de ejercer influencia no sólo dentro de sistemas jurídicos con los que guarda una estrecha vinculación, sino también fuera de ellos».

82. SACCO, Rodolfo. Introduzione al diritto comparato, cit., p. 151. 
sentido u otro. Esto se justifica en la aspiración al tecnicismo (si es que no a la neutralidad) que tienen los sistemas en los que impera el Derecho generado por los profesionales; cuanto sobre todo por la idea de la separación entre el campo jurídico y el político. Como consecuencia, la regla desprovista de elementos políticos luce como más imparcial, técnica y por ende puede circular en función a su propio prestigio; vale decir, de esta manera la regla no asumirá la carga que significa muchas veces una opción política que la sustenta o propugna.

Por su parte, Watson construye una teoría de la difusión jurídica que considera a la imitación $\mathrm{o}$, si se quiere, al trasplante jurídico ${ }^{83}$ como el mecanismo por el que se genera la mutación. Sin embargo, la propuesta tiene varios extremos que resultan del todo sugerentes en tanto que el autor se cuida de ofrecer una multiplicidad de ejemplos en los que se evidencia los específicos fenómenos de imitación. Con dicho material Watson desea mostrar que los sistemas incurren en imitación o efectúan trasplantes casi por una impronta natural de su desarrollo. Si bien tal fenómeno se manifiesta como una consecuencia natural de la atracción que ciertas estructuras jurídicas tienen sobre los operadores ${ }^{84}$ (o, si se quiere, en una elite), también se reconoce el papel que la suerte o el azar despliega en dichos eventos ${ }^{85}$.
La descripción de los fenómenos antes aludidos nos lleva a concluir, sin mayores esfuerzos, la existencia de determinada "path dependency» en los sistemas jurídicos. Vale decir, el camino (o itinerario) que ha recorrido en el pasado determinado sistema afecta las decisiones o, si se quiere, las opciones que se tendrán en el futuro; por lo que las decisiones que se tomaron en el pasado son tomadas en cuenta en el futuro. Desde luego, es más sencillo que se mantenga el rumbo definido o que se ha venido siguiendo, que esforzarse por alterarla. La idea tiene un fuerte componente de inercia o, si se quiere, de comodidad por parte de los operadores.

En efecto, el alto grado de accesibilidad y el ahorro de energías que significa para el sistema jurídico (o sus operadores) seguir la corriente de los últimos años (o incluso más) favorece que el camino trazado -consciente o inconscientemente- no sea siquiera cuestionado. Esto, como es de esperar, nos llevará a una forma de conservadurismo, que buscará proteger el status quo del poder de los profesionales del Derecho ${ }^{86}$.

Si el mecanismo por el que se produce la mutación, de acuerdo al pensamiento de Watson ${ }^{87}$, es el trasplante, entonces se tendrá que prestar atención luego a aquel fenómeno por el cual la regla importada se incorporará al sistema jurídico nacional. A este fenómeno se le denomina

83. WATSON, Alan. Legal change: Sources of law and legal culture. En: University of Pennsylvania Law Review, vol. CXXXI, núm. 5, 1983, p. 1121 y ss.; Id., Aspects of reception of law, cit., p. 335 y ss.; Id., From legal transplants to legal formants, cit., p. 469 y ss.

84. WIEGAND, Wolfgang. Americanization of Law: Reception or convergence?, en Aa. Vv., Legal culture and the legal profession edición a cargo de Lawrence M. Friedmann y Harry N. Scheiber, Westview Press, Colorado, 1996, p. 137 y ss., ivi p. 147; Id., The reception of American law in Europe. En: The American Journal of Comparative Law, vol. XXXIX, núm. 2, 1991, p. 229 y ss.

85. WATSON, Alan. Aspects of reception of law, cit., pp. 339-340.

86. Entre otros muchos aspectos que son subrayados por LEVINE, Samuel. Professionalism without parochialism: Julius Henry Cohen, Rabbi Nachman of Breslov, and the stories of two sons. En: Fordham Law Review, vol. LXXI, núm. 4, 2003, p. 1339 y ss.\}

87. Si bien la terminología ha sido acuñada en su versión definitiva, y difundida internacionalmente, por Watson se pueden encontrar autores que, con anterioridad, emplearon esta misma metáfora. Cabe recordar aquí a FRANK, Jerome. Civil law influences on the common law - Some reflections on 'comparative' and 'contrastive' law. En: University of Pennsylvania Law Review, vol. CIV, núm. 7, 1956, p. 887 y ss., ivi pp. 915-916; por su parte, y en el mismo año de la publicación del trabajo fundamental del autor escocés sobre los trasplantes jurídicos, KAHN-FREUND, Otto, On uses and misuses of comparative law. En: Modern Law Review, vol. XXXVII, núm. 1, 1974, p. 1 y ss., ivi pp. 5-6. 
recepción y tiene dos posibles interpretaciones. Por un lado, en un sentido amplio se entiende por recepción a aquel proceso que se genera al incorporar o adoptar una regla foránea (legal, doctrinal o jurisprudencial) en un nuevo sistema jurídico; en cambio, en un sentido un tanto más restringido, también se entiende por recepción a la incorporación in toto de determinado cuerpo legislativo de un sistema jurídico foráneo ${ }^{88}$. Como es natural, la recepción strictu sensu se presenta, cuando se hace manera consciente, en la realidad de manera más frecuente, toda vez que implica una importación total de instituciones foráneas; mientras que la recepción latu sensu es sólo una importación parcial (la cual, como somos testigos, es altamente probable que traiga aparejada una multiplicidad de inconvenientes) ${ }^{89}$.

Asimismo, la teoría de los legal transplants tiene una arista adicional que genera un encendido debate (y varias agudas críticas) de parte de un sector de la comparación jurídica. Este aspecto es el referido a la desvinculación entre los cambios jurídicos y las necesidades sociales que se perciben en un sistema dado. Me explico. Si, como sostiene Watson, el motor de la mutación jurídica es el trasplante, entonces (prioritariamente) las reglas legales (y las figuras doctrinales, mientras que en menor medida las fórmulas jurisprudenciales) no se instaurarían en virtud de las exigencias que se perciben en determinada sociedad, sino que las mismas se incorporarían a un sistema debido princi- palmente a que la élite que detenta el poder normativo conoció la regla importada.

Frente a tamaña afirmación se concluiría que la realidad (en sus diversos componentes, sean sociales, económicos y/o políticos) no se manifestan en las normas de manera directa (esto es, el operador jurídico no procederá a recoger las necesidades y a manifestarlas en las reglas -en sentido amplio- a ser creadas), sino que se materializará a través de la impronta particular del sujeto encargado de realizar dicha tarea ${ }^{90}$.

No obstante lo antes expresado, sí existen una serie de factores que controlan la relación entre las reglas y la sociedad, por lo que solamente a través de una comprensión de tales factores y la manera en que interaccionan entre sí se aprehenderá integralmente la mutación jurídica ${ }^{91}$. Como es natural existirán algunos factores que estimularán la mutación, mientras que otros la inhibirán. En los diversos estudios de Watson se pueden identificar los siguientes factores:

(i) La importancia de las fuentes jurídicas. Como es conocido, existen fuentes que formulan normas retrospectivamente (la jurisprudencia y la costumbre), mientras que otras lo harán prospectivamente (la legislación y la doctrina). Las primeras no ofrecen la posibilidad de efectuar grandes cambios de manera célere, aunque si permiten pequeñas mutaciones o adaptaciones en un breve período de tiempo. El perfil que muestran las fuentes

88. HOEFLICH, M. H. Law, society and reception: The vision of Alan Watson. En: Michigan Law Review, vol. LXXXV, núm. 5/6, 1987, pp. 1083 y ss., ivi p. 1083.

89. Recientemente, se ha invocado con plena autoridad la labor de recepción crítica que los académicos de esta parte de América debe desempeñar para hacer frente tanto a la globalización (que no es otra cosa que se ha venido a denominar como Americanization), como a la importación irreflexiva de los esfuerzos codificadores europeos. Los invocaciones pueden ser leídas en LEÓN, Leysser L. De la admiración a la recepción crítica: El apagado eco de la codificación del derecho privado europeo en América Latina. En: Revista de Derecho privado. Universidad de Los Andes, núm. 45, 2011, p. 1 y ss.

90. MOUSOURAKIS, George. Towards a comparative theory of legal change. En: Kansai University Review of Law and Politics, vol. XXVII, núm. 3, 2006, p. 53 y ss., ivi p.60.

Por su parte, WATSON, Alan. Aspects of reception of law, cit., p. 335 y ss., sostiene que su teoría se explica por el carácter practico del trasplante (y que elimina el esfuerzo del legislador); por el azar; la necesidad de autoridad y la dificultad de una visión clara.

91. WATSON, Alan. Comparative law and legal change. En: Cambridge Law Journal, vol. XXXVII, núm. 2, 1978, p. 313 y ss. 
retrospectivas se explica en la necesidad de contar con algún tipo de precedente o antecedente en el cual fundar la solución ${ }^{92}$. Por su parte, las fuentes de carácter prospectivo permiten efectuar grandes cambios de manera acelerada, pero su velocidad de respuesta a las pequeñas alteraciones del día a día es sustancialmente menor.

(ii) La presión que generan los grupos de interés que consideran que determinado cambio jurídico resultará beneficioso ${ }^{93}$. Como es previsible, el nivel de presión que podrá generar un grupo de interés se encuentra estrechamente vinculado a varios factores relevantes como la ubicación socio-económica de sus miembros y el nivel de influencia que pueden ejercer sobre quienes detentan el poder normativo ${ }^{94}$.

(iii) La oposición de los grupos de interés que consideran que efectuar determinado cambio importará un perjuicio (sea para ellos o para la sociedad), aquí se repite lo expuesto precedentemente para el caso de la presión a favor de cierta mutación.

(iv) La constatación de una tendencia a efectuar trasplantes jurídicos importa que en los sistemas existe un grado de receptividad hacia la admisión de estructuras o de figuras foráneas. Esta tendencia se observa desde antiguo, en una etapa inicial se trasplantaba o se adoptaba in toto ciertos sectores del Derecho Romano, luego se manifestó en la rápida difusión del Code Napoléon, pasando por la influencia de la dogmática alemana del siglo XIX y, en la actualidad, en la Americanization ${ }^{95}$.

(v) La existencia de una élite ${ }^{96}$ de operadores jurídicos que tenga el conocimiento, la imaginación y la experiencia que conduzca a la creación de reglas y que decida, en última instancia, el trasplante jurídico.

(vi) El rol que desempeñará la discrecionalidad de quienes tengan que ejecutar en la realidad las reglas emitidas, sea a través de una decisión judicial que torne inocua aquello que fue reconocido legislativamente (sea una titularidad o una tutela), o que se genere un reconocimiento contrario a lo que determinada fuente ya había admitido ${ }^{97}$.

(vii) La generalidad que caracterice a la regla emitida, situación que prescribirá que un grupo de personas sea tutelado o reciba cierto beneficio. Empero, esta situación ostenta un inconveniente: mientras más general sea la enunciación de una regla jurídica, mayor será la dificultad para subsumir en ella la particular situación de hecho que afecta a un grupo ${ }^{98}$.

(viii) La inercia o desinterés de un determinado grupo social, o incluso de la élite, para luchar o incorporar aquella regla que resulta más satisfactoria para los conflictos o para el objetivo que esta llamado a cumplir ${ }^{99}$ alguna institución o figura jurídica.

92. WATSON, Alan. Comparative law and legal change, cit., p. 323.

93. Cuestión que ha sido el centro de atención del Public Choice. Para una primera aproximación a esta materia se recomienda a BUCHANAN, James M., Public Choice: The origins and development of a research program En: Center for Study of Public Choice. George Mason University, Fairfax, 2003, pp. 1-13, artículo que se puede descargar en http://www.gmu.edu/centers/publicchoice/pdf\%20links/Booklet.pdf.

94. HOEFLICH, M. H. Law, society and reception: The vision of Alan Watson, cit., p. 1085.

95. WATSON, Alan. Legal change: Sources of law and legal culture, cit., p. 1125.

96. WATSON, Alan. From legal transplants to legal formants, cit., p. 469.

97. WATSON, Alan. Comparative law and legal change, cit., p. 330.

98. WATSON, Alan. Two-tier law: A new approach to law-making. En: International and Comparative Law Quarterly, vol. XXVII, núm. 3, 1978, p. 552 y ss., ivi p. 554.

99. WATSON, Alan. Legal change: Sources of law and legal culture, cit., p. 1135. 
(ix) La percepción (o la sensación) extendida de necesidad que debe generar el grupo de oposición (o el grupo de presión) en aquellos individuos que toman la decisión de crear o trasplantar cierta regla ${ }^{100}$.

En función a estos factores se ha concluido que: "[e]xiste un equilibrio entre los factores que sustentan el cambio y los factores que se oponen a él. De acuerdo a Watson, la relación entre la sociedad y las reglas jurídicas puede ser expresada de manera gruesa como una ecuación matemática: una regla jurídica será estable cuando el sentimiento de necesidad, debilitado por el factor discrecional que hubiese activado una fuerza de presión por la afectación del factor de generalidad, y que trabaja con la fuente jurídica relevante, resulte menos potente que la inercia y la fuerza de oposición combinadas; por otro lado, ocurrirá un cambio jurídico cuando la fuerza del sentimiento de necesidad debilitado por el factor discrecional que hubiere activado una fuerza de presión por la afectación al factor de generalidad, trabaje sobre la fuente jurídica, todo lo cual se verá modificado por la tendencia al trasplante y por los abogados que dan forma a las leyes, siempre que ella sea más grande que la fuerza de inercia más la fuerza de oposición. En otras palabras, la relación precisa entre reglas jurídicas y la sociedad en la que opera puede ser expresada como el equilibrio entre dos conjuntos de factores opuestos, el primero inhibidor del cambio y el segundo alentador del cambio» ${ }^{101}$.
Con una visión panorámica de la propuesta del ilustre comparatista escocés nos quedaría sólo restaría presentar una re-lectura a ella. Acometeré esta tarea no sólo porque la juzgo acorde a los fines del presente acápite (completar la imagen de la teoría de los legal transplants), sino a causa de la autoridad de quien sugiere tal re-lectura. Me refiero al profesor Pier Giuseppe Monateri, quien en nuestro medio es conocido por sus valiosas contribuciones en el campo de la responsabilidad extracontractual y por su visión crítica al análisis económico del Derecho ${ }^{102}$.

Ahora bien, un aspecto a resaltar es que el autor aludido pertenece a la escuela de Sacco, por lo que logra incorporar ciertos extremos de la teoría de los formantes jurídicos a la teoría de Watson. El resultado es una teoría ecléctica pero con perfiles innovadores ${ }^{103}$.

La construcción de Monateri recoge varios de los elementos de la propuesta de Watson, tales como: (i) la existencia de una élite que crea o trasplanta el Derecho; (ii) que los trasplantes son el principal motor de la mutación jurídica; $y_{\text {, (iii) }}$ que las reglas que se crean o trasplantan bajo este esquema pueden no guardar vinculación alguna con las características de la sociedad que las importa. Sin embargo, emplea los elementos característicos de la teoría de los trasplantes jurídicos como una powerful tool for a critical theory of comparative law ${ }^{104}$ [herramienta poderosa para una teoría crítica ${ }^{105}$ de la comparación

100. WATSON, Alan. Legal change: Sources of law and legal culture, cit., p. 1124.

101. MOUSOURAKIS, George. op. cit., p. 66.

102. MONATERI, Pier Giuseppe. Resultados y reglas (Un análisis jurídico del análisis económico del derecho), traducción de Leysser L. León. En: Revista jurídica del Perú, año LI, núm. 26, 2001, pp. 187 y ss.

103. MONATERI, Pier Giuseppe. "Everybody's talking: The future of comparative law. En: Hastings International and Comparative Law Review, vol. XXI, 1998, p. 825 y ss., ivi pp. 841-843.

104. MONATERI, Pier Giuseppe. The "weak" law: Contaminations and legal cultures. En: Global jurist advances, vol. I, issue 3, art. 5, 2001, p. 8 (de la versión pdf), consultado el 19 de mayo de 2010, www.bepress.com/gj/advances/vol1/ iss3/art5.

105. Dada la complejidad de la teoría crítica no pretendo agotar en el presente artículo, ni mucho menos en una referencia al pie de página, el alcance, fundamentos y aspectos problemáticos de esta Escuela. No obstante, considero cuanto menos necesario precisar que la teoría crítica nace como una relectura del pensamiento marxista y que abandera la idea que todo discurso, incluido el jurídico, tiene detrás una agenda política o un compromiso con ciertos objetivos a alcanzar (sea la prolongación del status quo, sea la obtención de poder); por ello se sostiene que tales discursos deben ser deconstruidos a fin de identificar tales agendas y revelar el real objetivo de sus pro- 
jurídica], permitiendo deslegitimar así el proceder de los operadores jurídicos que detentan el poder normativo ${ }^{106}$.

En efecto, los operadores actúan muchas veces movidos por su personal percepción sobre los debates jurídicos, si es que no en aras de su propio beneficio, por lo que tienen una inclinación a los trasplantes (en especial por aquellos que les permiten legitimar su posición de poder). Las características enunciadas evidencian la existencia de una weak legal culture [o cultura jurídica débil]. Sin embargo, habría que reconocer que la existencia de un fenómeno de importación no significa que el sentido original de la figura logre superar siquiera el proceso de trasplante. Esta afirmación se comprende en atención a que si el operador jurídico pretende que el trasplante legitime su posición, entonces es posible que el sentido de la regla se vea alterado. Esto sucede incluso sin que entre a tallar la interrelación -conflictiva o no- de los formantes jurídicos ${ }^{107}$.

El riesgo de alteración de la regla foránea se presenta, como se ha visto, por una alteración (más o menos consciente) de parte del operador jurídico, en aras de un interés personal o de grupo. Es a este último punto (vale decir, a la manipulación consciente de los discursos) al que le presta un vivo interés la visión postmoderna de la comparación jurídica y que será objeto de análisis más adelante (si bien esta perspectiva no niega que los operadores no se encuentren conscientes de los esquemas mentales impuestos para su dominación, pero aun en este caso la modificación de la figura importada se haría conscientemente a fin de enmarcarla a aquel esquema mental).

En cambio, la modificación inconsciente de lo que es el objeto (o contenido) del trasplante se explicaría por la ausencia de preparación, por un defecto en el conocimiento del operador o por una reacción del sistema en contra de la labor efectuada (lo cual es el meollo de la teoría de los irritantes jurídicos). Los dos primeros inconvenientes se superan con un correcto empleo del método comparado y por ello son de escaso interés en el presente estudio, pero son los que han generado una fuerte corriente crítica a la corriente estructuralista. Debido a la razón apenas esgrimida acometeré en los acápites 6 y 7 el estudio de las construcciones teóricas que se oponen al estructuralismo por la hegemonía en la comparación jurídica. Por su parte, en el siguiente acápite analizaré un fenómeno que recientemente ha focalizado la atención de un sector de académicos, me refiero a la competencia entre ordenamientos jurídicos.

\section{LA COMPETENCIA ENTRE ORDENAMIENTOS: UN MECANISMO DE DIFUSIÓN O UNA NUEVA MANERA DE IMPERIALISMO}

En los últimos años se discute, en más de un foro, acerca de la vinculación que tendría para el "desarrollo económico" la mayor adaptabilidad exhibida por los derechos nacionales hacia los modelos foráneos ${ }^{108}$. A efectos de desplegar ta-

motores. La cientificidad es una mera apariencia, mientras que la objetividad y la neutralidad un imposible. Para una aproximación más detallada me permito recomendar la lectura de ANTONIO, Robert J., Immanent critique as the core of critical theory: It's origins and developments in Hegel, Marx and contemporary thought. En: The British Journal of Sociology, vol. XXII, núm. 3, 1981, p. 330 y ss.; WHITE, Stephen K., Foucault's challenge to critical theory. En:The American Political Science Review, vol. LXXX, núm. 2, 1986, p. 419 y ss.; VAN DEN BERG, Axel, Critical Theory: Is there still hope? En: The American Journal of Sociology, vol. LXXXVI, núm. 3, 1980, p. 449 y ss.; y, FRASER, Nancy, What's critical about critical theory? The case of Habermas and gender. En: New German Critique, vol. XXXV, 1985, p. 97 y ss.

106. MONATERI, Pier Giuseppe. Black Gaius: A quest for the multicultural origins of the "Western legal tradition". En: Hastings Law Journal, vol. LI, 2000, pp. 479 y ss., ivi p. 511.

107. MONATERI, Pier Giuseppe. The "weak" law: Contaminations and legal cultures, cit., p. 21.

108. BERKOWITZ, Daniel; PISTOR, Katharina y RICHARD, Jean-Francois. The transplant effect. En: The American Journal of Comparative Law, vol. LI, núm. 1, 2003, p. 164 y ss. 
maño esfuerzo de comparación, se ha intentado recoger ciertos datos económicos relevantes, aunque no necesariamente se subrayan aquellos aspectos que definen a los sistemas jurídicos ${ }^{109}$.

Esta cuestión ha sido presentada a (y por) los comparatistas en términos que nos resultan más conocidos: los fenómenos de convergencia o armonización jurídica.

Cabe recordar que la convergencia jurídica se presenta de manera imprevista e involuntaria en los sistemas jurídicos ${ }^{110}$, como viene sucediendo -por ejemplo- en el campo de los cánones interpretativos de los testamentos ${ }^{111}$. En dicho campo los sistemas del Civil Law y del Common Law tienden naturalmente hacia criterios subjetivos. Por su parte, y a diferencia de lo anterior, la labor de armonización o uniformización jurídica requiere de un esfuerzo consciente de los profesionales del Derecho (e incluso un compromiso político de los gobernantes de turno $)^{112}$, quienes deberán elegir qué regla producirá -en sus términos- los resultados deseados. Tal cuestión será, de ordinario, evaluada en relación a criterios económicos o numéricos, como la posibilidad de atraer inversión extranjera ${ }^{113}$.
En un contexto como el descrito cobra particular preponderancia, y sobre el que se discutirá a lo largo de las páginas siguientes, la competencia que se generará entre los sistemas jurídicos a fin de erigirse en proveedores o exportadores de normas jurídicas. Las razones por las que un sistema jurídico desea convertirse en un proveedor de normas se reconducirían a la búsqueda de prestigio, a un esfuerzo por facilitar las relaciones internacionales o sencillamente como un mecanismo para consolidar su influencia ${ }^{114}$.

En este orden de ideas, habría que identificar ${ }^{115}$ aquellas situaciones en que las reglas podrían ser consideradas como un producto homogéneo, por lo que la convergencia ocurrirá de modo espontáneo; a fin de distinguirlas de aquellas situaciones en que las reglas jurídicas posean una o más características particulares, por lo que la convergencia jurídica difícilmente se producirá de manera natural. Como se intuirá, en el segundo escenario descrito se requerirá de la labor coordinada entre los profesionales del Derecho para lograr la armonización (y aún en este caso no se ha determinado con total certeza si esto es un fin deseable) ${ }^{116}$.

109. Estas es la crítica más extendida, y con justicia, a trabajos como los efectuados por LA PORTA, Rafael; LÓPEZ-DESILANES, Florencio; SHLEIFER, Andrei y VISHNY, Robert W., Legal determinants of external finance. En: The Journal of Finance, vol. LII, núm. 3, 1997, p. 1131 y ss.

110. MERRYMAN, John Henry. On the convergence (and divergence) of the Civil Law and the Common Law. En: Stanford Journal of International Law, vol. XVII, 1987, pp. 357 y ss.

111. SAAVEDRA VELAZCO, Renzo E. ¿Interpretamos la voluntad del testador o sólo lo literalmente expresado en el testamento? Consideraciones desde la óptica de la comparación jurídica. En: Revista del Foro, núm. 96, 2010, p. 11 y ss.

112. HARLOW, Carol. Voices of difference in a plural community. En: The American Journal of Comparative Law, vol. L, núm. 2, 2002, p. 339 y ss.

113. En los últimos meses el Perú ha sido testigo del afán, por decir lo menos, estatal por mejorar en el ranking del Doeing Business. Tal interés ha justificado algunas modificaciones normativas muy poco consistentes con el interés de los inversionistas, con la teoría jurídica y que con el propio sentido común. Pienso, por ejemplo, en la Ley 29720 que fijaría una responsabilidad objetiva de los Directores por actos que puedan ocasionar un daño a los accionistas.

114. No debiera sorprender por ello que en otras experiencias jurídicas se hable de sus creaciones como de libros casi sagrados. Al respecto, resulta ilustrativo el ensayo de FLETCHER, George P. Three nearly sacred books in Western Law. En: Arkansas Law Review, vol. LIV, 2001, p. 1 y ss.

115. En este punto sigo la propuesta del profesor OGUS, Anthony. Competition between national legal systems: A contribution of economic analysis to comparative law. En: The International and Comparative Law Quarterly, vol. XLVIII, núm. 2, 1999, p. 405 y ss.

116. Una exposición persuasiva sobre las desventajas de la uniformización se encuentra en el ensayo de SACCO, Rodolfo. Diversity and uniformity in the law, cit., pp. 177-179. 
La teoría de la competencia entre ordenamientos jurídicos es un intento de traspasar a la labor de creación normativa algunos de los principios que rigen la competencia en los mercados. Las enseñanzas que se extraen de la microeconomía nos dictan que a mayor número de oferentes, los demandantes tendrán mejores posibilidades de elegir por precio y por calidad los bienes y servicios que requieren. En contrapartida, en un mercado monopólico el oferente tendrá un menor incentivo a lograr la mejor combinación calidad/precio, lo cual no significa que no haga un esfuerzo por dar buenos productos a un precio atractivo (sobre todo si en el mercado no se observan altas barreras de acceso), por lo que el consumidor recibirá un bien o servicio que no tendrá la calidad de un mercado competitivo y a un precio más alto.

De la misma manera, en un sistema jurídico se suele tener en cierta medida un monopolio en la creación normativa ${ }^{117}$ a favor del legislador, los cuales se encuentran morigerados por más de un componente que favorece la competencia (piénsese en las elecciones y en la gradación de normas jurídicas que dispone la constitución) al interior del propio sistema. Empero, acaso lo que más nos interese sea la posibilidad de competencia que se genera en el sistema jurídico a consecuencia de la labor desplegada por otros legisladores en el resto de jurisdicciones. En la definición de las jurisdicciones resultan competitivas para el sistema nacional se puede tomar prestada la taxonomía ofrecida precedentemente (la pertenencia a un mismo patrón facilitará la influencia) y la lógica inherente a los trasplantes jurídicos (se prestará mayor atención a los sistemas con mayor "prestigio").

En el contexto mundial se percibe con claridad la presión que pueden llegar a ejercer ciertos actores económicos en la producción normativa. Me refiero no sólo a las transnacionales, sino a los propios países que intentan (vía tratados de libre comercio) influir en sus friendly markets para facilitar el comercio internacional. Paralelamente, se vive en Europa un fenómeno que es de vivo interés teórico, el fenómeno de uniformización y armonización normativo, puesto que la coordinación entre los profesionales del Derecho proviene de órganos supranacionales y por ello contaría con aval político. Esta realidad no hace más que incentivar la influencia existente entre los sistemas jurídicos, colocando como objetivo la incorporación de derecho acorde a las exigencias de tales actores económicos ${ }^{118}$.

Tal constatación genera un beneficio económico importante para la labor de las legislaturas: la reducción de los costos de transacción involucrados a la identificación de las necesidades que experimentan dichos actores, así como la solución normativa para tales necesidades. Empero, esta constatación puede generar más de un inconveniente, sobre todo una óptica de derecho comparado como la que se acoge en el presente ensayo, los actores económicos tienen escaso o nulo interés en reconocer las diferencias conceptuales entre los principios que reinan en uno u otro sistema, lo importante para ellos es el resultado último ${ }^{119}$. Este problema, sumamente conocido en otras latitudes, es constantemente olvidado en nuestro sistema jurídico e incluso se achaca a las instituciones nativas el ser ineficientes cuando el inconveniente suscitado debe asignarse al defecto en el trasplante.

Naturalmente, la inclusión de una nueva especie a un ambiente extraño puede devenir en una serie de costos que no pueden ser obviados. Aspecto que denota la enorme complejidad que subyace a la operación de importación jurídica. Además habría que recordar que no siempre los inversionistas o actores económicos lograrán impulsar determinada reforma, pues existen

117. Al menos para la de creación legislativa, aunque aquí cabrían reiterar las precisiones que se efectuaron cuando se estudio la teoría de los formantes jurídicos.

118. SMITS, Jan. A European private law as a mixed legal system: Toward a ius commune through the free movement of legal rules. En: Maastricht Journal of European and Comparative Law, vol. V, núm. 4, 1998, p. 328 y ss.

119. OGUS, Anthony. op. cit., p. 409. 
otros actores que se manifiesten en contra o dificulten tal modificación. Entre dichos actores tal vez los más importantes, cuanto menos en los sistemas que siguen nuestro patrón jurídico, sean los abogados, quienes podrían oponerse debido a su temor de perder preeminencia (sea como grupo o como individuos) ${ }^{120}$.

Volviendo a la diferenciación con la que inicié el presente acápite, resulta aconsejable dividir a las normas en dos. Por un lado, las normas que se presentan como un producto homogéneo $y$, por otro lado, aquellas normas que se presentan como un producto heterogéneo. En primer lugar, aclararé que se entiende por cada una de estas normas.

Los productos jurídicos homogéneos son aquellos que permanecen constantes en los diversos sistemas jurídicos. Esta situación se explica por las necesidades y preferencias exhibidas por los actores económicos, las cuales son consistentes y permanentes, sin que interese la jurisdicción en la que nos movamos. En términos sencillos, se tratan de normas que tienden a facilitar las conductas de los individuos, permitiéndoles alcanzar los objetivos que desean; ejemplos de tal categoría serían los contratos y las personas jurídicas. Por este motivo, las reformas legales que se sugieran tenderán a la reducción de los costos de transacción involucrados, aspecto que explica por qué la competencia sobre estos productos es tan alta (todos los sistemas quieren a la larga favorecer cierto tipo de intercambios e incentivar la creación de organizaciones para la consecución de fines considerados socialmente valiosos).

Nótese que no afirmo que las reglas o las instituciones que pertenecen a esta categoría sean iguales en todos los países, lo cual sería absolutamente falso ${ }^{121}$. Lo único que deseo resaltar es que los intereses y necesidades que buscan satisfacerse con tales figuras son exactamente las mismas, por lo que es natural esperar que las modificaciones que se introduzcan tiendan a la mejora de la función que desempeñan y reduzcan los costos involucrados a su empleo. En los mercados observamos que existen bienes y servicios que satisfacen ciertas necesidades que se repiten constantemente, las respuestas que se alcanzan tienden precisamente a satisfacer la necesidad identificada y de allí en adelante se produce un fenómeno de mejora en cuanto a los resultados alcanzados y a los costos involucrados, lo mismo sucederá en el campo jurídico.

Por su parte, los productos jurídicos heterogéneos serán aquellos que no permanecen iguales en todos los sistemas jurídicas. Esta situación se explica porque el objetivo de tales productos es la tutela de ciertos interés relevantes para el propio sistema jurídico (esto es, la sociedad), por lo que estas normas tienden a intervenir más en las conductas y acuerdos de los sujetos, llegando incluso a superponerse a ellos. Algunos ejemplos de estas normas se encuentran en el campo de la responsabilidad civil y el derecho administrativo, pero también alcanza a ciertas manifestaciones del derecho contractual en los que se desea proteger a un sector de sujetos, tal como sucede en la protección al consumidor y en el derecho laboral.

En estos campos, las reformas legales modificarán en mayor o menor medida el equilibrio de los costos y beneficios que asumen cada una de las partes involucradas, sea otorgando alguna tutela (o ampliándola), sea incrementando (o precisando) las conductas que son exigibles. Aquí los sectores que tienen intereses contrapuestos intentarán ejercer presión en el legislador a fin de obtener normas que les resulten más favorables, en desmedro de su contraparte. Siguiendo este razonamiento será complicado encontrar fenómenos de convergencia en estos campos, dado que cada sociedad tendrá un nivel de preferencia distinto sobre lo que resulta

120. Cfr. RUBIN, Paul H. y BAILEY, Martin J. The role of lawyers in changing the law En: Journal of Legal Studies, vol. XXIII, núm. 2, 1994, p. 807 y ss.

121. LEGRAND, Pierre. Per l'analisi giuridica comparatistica: A proposito di un libro di Rodolfo Sacco, cit., pp. 600-601, donde se explica con pulcritud la diferencia entre el contract inglés y el contrat francés. 
un riesgo o beneficio razonable, la influencia que pueda ejercerse en el legislador será distinta ya que tendrá que intentar equilibrar múltiples intereses en juego (entre ellos el suyo), entre otras diversas variables.

Teniendo en cuenta lo antes expuesto creo resulta válido preguntarse si todo el debate que se nos expone no resulta más que un mecanismo por el que se intenta justificar un fenómeno de imperialismo jurídico. En el pasado, ya se han experimentado situaciones de este tipo ${ }^{122}$, en las que un sistema hegemónico tiende a colonizar, pero ciertamente los mecanismos a través de los cuales se produce este fenómeno van cambiando con el transcurrir del tiempo. En un inicio resultaba sencillamente la extensión al campo jurídico del poder militar que se ejercía sobre un espacio geográfico, para luego pasar a una influencia más sutil de carácter político (pero no por ello menos directa) y, por último, arribar a un modelo como el actual que se sustenta en no escasa medida en los aspectos económicos del comercio internacional (que se ofrece como una salida al sub-desarrollo).

Creo que las respuestas que se ofrecer a tal interrogante están profundamente teñidas por los aspectos ideológicos en juego. Por un lado, tenemos al bloque europeo intentando responder a este fenómeno oponiendo la cultura jurídica civil (en particular la alemana), a fin de refrenar el decidido avance que tiene la Americanization en todos los sistemas jurídicos. Por otro lado, tenemos a los seguidores de esta tendencia que exponen, con claridad y éxito, el discurso del desarrollo económico. Las alternativas, divididas como están, no ofrecen una salida clara para los sistemas jurídicos que se encuentran en medio de esta lucha ${ }^{123}$; acaso la única respuesta que se pueda sugerir-aunque parcial y dubitativa por añadidura- es analizar la realidad en la que vivimos (en contraste de aquella que se nos dibuja) y los discursos recibidos, las decisiones que deberán tomarse en los próximos años en el campo jurídico (ni que decir en el económico y político) determinarán el devenir de nuestra cultura jurídica ${ }^{124}$.

\section{HACIA UNA TIPOLOGÍA DE LOS TRASPLANTES JURÍDICOS}

En atención a los puntos que se han desarrollado en las páginas precedentes, podría resultar de utilidad hacer mención a una tipología de los trasplantes jurídicos que nos permita explicar las justificaciones o razones por las cuales determinada figura puede circular de un sistema a otro. Como se explicó, siempre hay intereses en juego que explican por qué se toma cierta decisión para efectuar una reforma jurídica que importe la inclusión de algún modelo foráneo, esto es más evidente en la actualidad (incluso nacional) cuando se escucha las declaraciones de, por ejemplo, políticos que sostienen que tal o cual reforma resulta deseable en función a cierto objetivo que éstos consideran valioso.

Una propuesta que me parece digna de rescatar es la ofrecida por el profesor Jonathan Miller, quien sostiene que los trasplantes se producen ${ }^{125}$ por: (i) ahorro de costos, (ii) por mandatos externos, (iii) razones empresariales y (iv) creación de legitimidad.

Si bien con esta clasificación se puede condensar la totalidad de trasplantes jurídicos, hay que

122. MICHAELS, Ralf y JANSEN, Niels. Private Law Beyond the State? Europeanization, Globalization, Privatization. En: The American Journal of Comparative Law, vol. LIV, núm. 4, 2006, pp. 843 y ss., ivi pp. 867-868.

123. KENNEDY, Duncan. Three of law and legal thought: 1850-2000, en Aa. Vv., The New Law and Economic Development: A Critical Appraisal, edición a cargo de David Trubek and Alvaro Santos, Cambridge University Press, 2006, p. 19 y ss.

124. GAROUPA, Nuno y OGUS, Anthony. A strategic interpretation of legal transplants. En: Journal of Legal Studies, vol. XXXV, núm. 2, p. 339 y ss., donde se define a la cultura jurídica como el conjunto de fenómenos de carácter lingüístico, conceptual y procedimental que sirven para diferenciar una comunidad jurídica de otra.

125. MILLER, Jonathan M., A tipology of legal transplants: Using sociology, legal history and Argentine examples to explain the transplant process. En: The American Journal of Comparartive Law, vol. LI, núm. 4, p. 839 y ss. 
reconocer que enfrenta dos limitaciones intrínsecas. En la medida que se trata de una tipología erigida sobre la base de las motivaciones que puedan tener los sistemas importadores no se tendrá mucha información (o, si se quiere, indicios) que nos expliquen por qué el trasplante fue o no exitoso. Otro límite igual de importante es que la clasificación presta poca atención al rol desempeñado por el sistema exportador, esta situación fue la que motivo que desarrollará en el acápite precedente un aspecto como el de la competencia entre ordenamientos jurídicos a fin de dar un vistazo a las motivaciones del sistema exportador.

\section{Trasplante motivado por ahorro de costos}

Esta es la motivación más sencilla y previsible para efectuar un trasplante jurídico. La idea que se encuentra detrás es reducir el tiempo y los costos anexos a la formulación de una propuesta de solución a una determinada circunstancia con relevancia jurídica.

La labor del legislador es la de ofrecer productos jurídicos que satisfagan las necesidades que percibe la sociedad, algunas de ellas de larga data, otras que se gestan con el desarrollo de las economías o con los cambios de la vida moderna. Empero, como toda tarea, su cumplimiento importa la asunción de ciertos costos o inversiones, los cuales pueden ser reducidos si es que el legislador nacional presta atención a los esfuerzos desplegados por legisladores de sistemas vecinos. Así, puede aprovecharse del trabajo realizado por tales legisladores tomando -sea el resultado, sea la información recabadapartido por su solución ${ }^{126}$.

El problema, como puede predecirse sin dificultad, radica en que el legislador nacional tiene la tendencia a realizar un trabajo de bricolage jurídico, sumando varias propuestas, apartándose las más de las veces tanto de las reales intenciones que incorporaba la figura exportada, como de las peculiaridades de nuestro propio sistema ${ }^{127}$.

Puede aceptarse que existe un ahorro de costos vinculado al trasplante, sobre todo en el plano de las inversiones efectuadas por el legislador, pero no estoy seguro a si en conjunto se da el mismo efecto. Me explico. En tanto que el legislador tenderá a efectuar una labor en la que se conjugan propuestas de diversos sistemas (más las ideas del propio legislador), generándose el Frankenstein jurídico del que tantas veces se ha oído hablar; por ello a ciencia cierta no sé si el ahorro de costos involucrados en la etapa formativa de las leyes compensará los costos que en la fase de aplicación tendrán que asumir el aparato judicial y los particulares (sea para aclarar el contenido de la norma, sus objetivos y determinar cómo se aplicará en adelante). Incluso, a fin que el cuadro sea completo, estos resultados debieran contrastarse con el coste económico que significaría la producción de normas sin que se admitan interferencias externas y que, por ende, tengan que ser formuladas a la luz de las peculiaridades de nuestra sociedad.

Como se ve, en este trasplante tiene un valor claramente instrumental, por lo que en exclusiva se justifica en razones de eficiencia. Aquí, con seguridad, cobrarán realce aquellos productos jurídicos que resulten homogéneos. Por lo que, en caso el trasplante se muestre como poco eficiente, debiera ser relativamente sencillo derogar la norma o modificarla.

\section{Trasplante motivado por mandatos externos}

Esta motivación se encuentra fuertemente vinculada a lo que se expuso en el acápite anterior. La idea es que un organismo, entidad o gobierno internacional solicita que se adopten

126. WATSON, Alan. Aspects of reception of law, cit., pp. 336-341.

127. Aspecto que ha sido denunciado en nuestro medio por LEÓN, Leysser L. Spamming y responsabilidad civil: Compensación pecuniaria y protección resarcitoria ordinaria en el régimen jurídico del correo electrónico comercial no solicitado. En:Themis-Revista de Derecho, núm. 50, 2005, p. 295 y ss. 
ciertas estructuras legales como una condición indispensable para efectuar negocios o para permitir un mayor grado de autonomía o para recibir algún tipo de beneficio ${ }^{128}$.

Recientemente se observa un incremento de este tipo de trasplantes jurídicos, muchas veces motivado de manera solapada (como en los ranking Doing Business) o de manera expresa (en los TLC se pide ciertas adaptaciones mínimas del país más débil a fin de recibir las ventajas de ser considerado un friendly market). Esto sería un índice a favor de aquella percepción que se mencionó acerca del fortalecimiento de un imperialismo jurídico que se legitima a sí mismo a través de una retórica de desarrollo.

Este último punto se vería ratificado por la presión ejercida por la Organización Mundial de Comercio y las amenazas de sanción que efectúan los Estados Unidos de América. En el caso de los países que salieron del bloque socialista tales presiones se centraron en la adopción de los diversos documentos internacionales sobre protección a los derechos humanos, mientras que la amenaza ${ }^{129}$ eran sanciones que iban desde bloqueos comerciales o la imposición de condiciones más onerosas.

Desde la perspectiva de la eficiencia, este tipo de trasplante sufre de un grave problema: no es que se juzgue la eficiencia sistémica del trasplante, meramente se produce por la presión que recibe el legislador, por lo que es probable que la solución sea -a largo plazocontraria a los intereses nacionales. Empero, también habría que reconocer que algunas de las estructuras o figuras trasplantadas pueden ser condenadas al desuetudo si los organismos internacionales se limitan sólo a exigir la incorporación a los sistemas nacionales, más no se ocupan de efectuar un seguimiento a su aplicación (salvo, que la figura sea en sí misma eficiente o hubiere logrado calar en la mentalidad de los ciudadanos del país importador).

\section{Trasplante motivado en razones empresariales}

En mi opinión este es el caso de trasplante más interesante y el que, con mayor frecuencia, ha permanecido en las sombras. En estos casos existen individuos o grupos que han invertido en tomar contacto con ciertas estructuras legales, por lo que luego se ocupan de alentar que tal figura sea acogida en sus respectivos sistemas jurídicos.

Si es que logran motivar la adopción de la estructura jurídica foránea, los actores económicos a los que se ha aludido recibirán beneficios de diverso cariz. Por un lado, obtendrán beneficios políticos al encontrarse vinculados a la incorporación de una estructura jurídicoeconómica en la que se percibe valor (no por nada se logró convencer al legislador a su adopción); $y$, por otro lado, se verán beneficiados económicamente dado que automáticamente el conocimiento que habían adquirido se tornará altamente valioso y su calidad de expertos se verá reforzada.

Naturalmente, creo que no debiéramos tener reparos en juzgar favorablemente a este tipo de trasplante e incluso al esfuerzo desplegado por el sector de profesionales que se ocupan de lograr su aprobación. En no pocas ocasiones tales esfuerzos se realizan por un compromiso de parte de estos actores con las ideologías y figuras a exportar. Pienso, por dar un ejemplo, en la labor desplegada por los profesionales del Derecho a inicios de la década de los años noventa por incorporar políticas de libre competencia, las cuales devinieron en la creación del Instituto Nacional de Defensa de la Competencia y de Protección de la Propiedad Intelectual-INDECOPI.

128. No necesariamente se produce en países en desarrollo, pues también se presenta en países desarrollados, como fue el caso de Suiza, quien recibió presión de la Comunidad Europea (pese a que no forma parte de ella). Sobre el punto consúltese el ensayo de BAUDENBACHER, Carl. Judicial globalization: New Development or old wine in new bottles? En: Texas International Law Journal, vol. XXXVIII, núm. 3, 2003, p. 505 y ss.

129. MILLER, Jonathan M. op. cit., pp. 847-848. 
Si bien tengo algunos cuestionamientos a las facultades otorgadas al INDECOPI, así como a las asonancias generadas por la inclusión de una agencia de competencia, sobre todo en materias que requieren (e incluso presuponen) el ejercicio de jurisdicción, hay que aceptar que el papel desempeñado por esta entidad ha sido muy superior al Poder Judicial. Además, cumple con el objetivo de fortalecer el mercado, aunque ciertamente con las limitaciones inherentes a su estructura y financiamiento.

Ahora, desde un punto de vista económico, el inconveniente de este tipo de trasplante es que resultará muy complicada la modificación de la estructura importada, sobre todo si el sector de profesionales que motivó su adopción ha obtenido gran poder político. Si permitiesen el cambio, previsiblemente, perderían la preeminencia que habían alcanzado (salvo que, como se sugirió, tengan un compromiso real o si han invertido para incrementar su conocimiento sobre las estructuras foráneas más novedosas).

\section{Trasplante motivado en la creación de legitimidad}

Esta motivación es una de las más conocidas y de las que con mayor frecuencia se aceptan de modo expreso al efectuar un trasplante. Hay, qué duda cabe, sistemas jurídicos que gozan de legitimidad y prestigio o, de manera más reducida, ciertas instituciones o figuras a su interior tienen tales juicios favorables tanto de sus ciudadanos, como de los profesionales del Derecho (incluso de otras latitudes). Tal prestigio podría encontrarse anexa al valor de la tradición o de la eficiencia de la regla ${ }^{130}$.
En mi opinión, el éxito de un trasplante jurídico o su eficiencia no dependerá en exclusiva de las características de la figura que desea importarse, más bien puede afirmarse que los aspectos que influyen más en este resultado son los que se presentan en el país importador. Si este se encuentra preparado para recibir un figura del sistema exportador o si, por el contrario, la idiosincrasia de la cultura jurídica del sistema importador condenará al fracaso tal trasplante.

Desafortunadamente, por las razones que justifican el trasplante es poco probable que se den muchas discusiones antes de la incorporación de la figura foránea, sobre todo en sistemas que se encuentran caracterizados por su debilidad (que guarda una correlación con la ausencia de legitimidad del propio sistema jurídico-político). Es por esto que los profesionales buscan que el propio sistema se fortalezca a través de la importación, obteniendo un poco de la autoridad y legitimidad emanadas del sistema extranjero ${ }^{131}$.

Un aspecto adicional que cabría recordar es que como el trasplante se sostiene por el poder que significa la legitimidad del sistema exportador, muchas veces la pérdida de ella (sea por desaciertos del propio sistema, sea por el advenimiento de un nuevo modelo) ocasionará que los legisladores sugieran el cambio de la estructura importada ${ }^{132}$.

\section{EL ROL DE LA “FUNCIÓN" EN LA COMPARACIÓN JURÍDICA: LA METODOLOGÍA DOMINANTE}

Las teorías funcionales analizan al Derecho, entendido como sistema social, en atención a la función

130. MATTEI, Ugo. Efficiency in legal transplants: An essay in comparative law and economics. En: International Review of Law and Economics, vol. XIV, 1994, p. 3 y ss., ivi p. 8.

131. FLETCHER, George P. Three nearly sacred books in Western Law, cit., p. 18.

132. En este punto resulta ilustrativo el trabajo de LEÓN, Leysser. Universidad y cultura de la codificación civil. En: Global Jurist, vol. VII, núm. 1, 2007, p. 2, quien recuerda el caso de Gustave Émile Boissonade de Fonterabie, el encargado de efectuar un Código Civil para el Imperio de Japón bajo la influencia del Código francés. El encargo no se convirtió en ley debido a que en el interregno se promulgó el BGB, por lo que la autoridad se desplazó de Francia a Alemania. 
que cada uno de sus componentes desempeña. En tal sentido, evalúan el equilibrio que el sistema alcanza a través de la contribución específica de cada uno de sus elementos (centrando su interés en las consecuencias ${ }^{133}$ y no en las motivaciones). En virtud a tal premisa es sencillo comprender porque esta perspectiva ve al Derecho como un sistema cerrado e incluso autorreferencial ${ }^{134}$.

En muchos sentidos podemos decir que esta perspectiva resulta la mayoritaria o cuanto menos la que mayor influencia tiene en las investigaciones que emplean la comparación jurídica como método. Por ello no causará sorpresa conocer que un sector de sus principales propulsores la consideren como la perspectiva de análisis, si es que no la única, para efectuar estudios en los que se aplique la comparación jurídica ${ }^{135}$. Empero, esta posición resulta un tanto curiosa si es que se recuerda que el principal exponente ideológico de esta perspectiva es el profesor Hein Kötz, un académico que ha expresado, en la propia obra que se erige como guía para esta corriente de opinión ${ }^{136}$, cierto desprecio por los debates metodológicos. Al ilustre profesor alemán le ha atraído siempre la idea de la inspiración (lo cual no significará jamás ausencia de investigación) ${ }^{137}$ en el estudioso. Es ante esta percepción particular de Kötz, por la que afirma, sin reparos, que las "ciencias que se ocupan de su propia metodología son ciencias enfermas».

Otra característica interesante de esta perspectiva se centra en que acepta que la Sociedad y el Derecho pueden ser conceptualmente escindidos. Empero, sus seguidores de inmediato se cuidan de destacar la fuerte vinculación entre ambos componentes. Con premisas de tal cariz, es comprensible que estos autores puedan afirmar que la función ${ }^{138}$ desplegada por una regla legal, por una figura doctrinal o por un precedente jurisprudencial se erige como el criterio en base al cual se efectuará la comparación (o, si se quiere, la "función" resulta el denominado tertium comparationis). Por su parte, también habría que destacar que la vinculación entre la Sociedad y el Derecho se manifiesta en el marcado interés que la perspectiva funcionalista le dispensa al case-method ${ }^{139}$.

En el contexto apenas descrito, y en virtud a que las instituciones jurídicas tienen una función que cumplir, es natural que siempre se encuentre algún punto de referencia que nos brinde la posibilidad de comparar dos sistemas jurídicos distintos. Esto será posible inclusive cuando las instituciones específicas posean una configuración o bien una explicación teórica de naturaleza diversa. En términos más sencillos: siempre que

133. MATTEI, Ugo y DI ROBILANT, Anna. The art and science of critical scholarship: Postmodernism and international style in the legal architecture of Europe, cit., p. 1078.

134. SOMMA, Alessandro. Tanto per cambiare... mutazione del diritto e mondializzazione nella riflessione comparatistica, cit., p. 559.

135. MICHAELS, Ralf. op. cit., p. 339.

136. ZWEIGERT, Konrad y KÖTZ, Hein. Introduction to comparative law, tercera edición, traducción de Tony Weir, Clarendon Press, Oxford, 1998, p. 33.

137. GORDLEY, James. Comparative legal research: Its function in the development of harmonized law. En: The American Journal of Comparative Law, vol. XLIII, núm. 4, 1995, p. 566, quien comenta que al compartir su propuesta de un estudio transtemporal y transnacional del Derecho con un colega recibió como respuesta que esa era una labor que sólo Hein Kötz estaría en capacidad de cumplir, lo cual evidencia a las claras el respeto que dicho autor genera en el ambiente académico. Por otro lado, también es interesante conocer los datos que son comentados por MICHAELS, Ralf. The second wave of comparative law and economics? En: University of Toronto Law Journal, vol. LIX, núm. 2, 2009, p. 197 y ss.

138. Cfr. GERBER, David J. Sculpting the agenda of comparative law: Ernst Rabel and the facade of language, en Aa. Vv. Rethinking the masters of comparative law edición a cargo de Annelise Riles, Hart Publishing, Oxford, 2001, p. 200.

139 MARKESINIS, Basil. Comparative law - A subject in search of an audience. En: Modern Law Review, vol. LIII, 1990, p. 1 y ss. 
las instituciones jurídicas afronten el mismo problema resultarán funcionalmente equivalentes.

Al respecto, resulta ilustrativo que Kötz considere que el principio metodológico fundamental de la comparación jurídica se centra en el estudio de la funcionalidad de las instituciones ${ }^{140}$. De esta afirmación algunos autores extraen la idea de un monopolio metodológico, por lo que -en opinión de este sector de los comparatistas- se estaría menospreciando el potencial aplicativo y crítico de la comparación jurídica o, por otro lado, el método aludido resultaría tan gaseoso (debido precisamente a su intención de cubrir la mayor cantidad de aspectos posibles) que tornaría a la categoría como inútil ${ }^{141}$. Si bien tengo reservas a aceptar tamaña conclusión de las ideas de Kötz, creo necesario aclarar que la perspectiva funcionalista maneja una diversidad de nociones respecto de lo que se comprende por funcionalismo ${ }^{142}$. Este último aspecto resulta casi tan interesante como problemático para quien se aproxime al estudio de la comparación jurídica.

Tal afirmación se sustenta en el hecho que la comparación jurídica (como método) se inspira, en casi igual, en discursos propios de las ciencias sociales y de la teoría general del Derecho.

A efectos del presente trabajo expondré brevemente cinco nociones sobre tal tópico, a saber:

\section{Funcionalismo neo-aristotélico.- Cuando la}

idea de telos (o causa finalis) sugerida por Aristóteles es aplicada al campo jurídico se llega a la conclusión de que el Derecho desempeña una función (o rol) en la sociedad que se centra, básicamente, en extraer un orden inherente que era definido como la naturaleza de las cosas. Tal conclusión llevó, en su momento, a que el Derecho intentará incorporar este orden inmanente, lo cual fue posteriormente dejado de lado con el advenimiento del racionalismo y, en especial, del positivismo ${ }^{143}$. Sin embargo, producido el ocaso del positivismo fue casi automático volver a los postulados aristotélicos bajo cuyos esquemas tanto los problemas, como las soluciones, que se gestaban en los diversos sistemas jurídicos resultan similares, en atención a que derivan de una base común: la naturaleza de las cosas.

Dentro de esta corriente de opinión se encuentran autores como el profesor alemán Josef Esser ${ }^{144}$ y el estadounidense James Gordley ${ }^{145}$. Por un lado, Esser entiende que las instituciones jurídicas son contingentes a diferencia de los problemas que están llamados a resolver, vale decir, los problemas son universales; por lo que Esser eleva la función que éstos despliegan a la categoría de tertium comparationis, así podrían identificarse principios jurídicos de carácter universal (replicando el papel que, en su momento, desempeñó el ius gentium). Por su parte, Gordley concibe

140. KÖTZ, Hein. Comparative law in Germany today, en Revue Internationale de droit comparé, 4, 1999, p. 753 y ss., ivi p. 755; y, ZWEIGERT, Konrad y KÖTZ, Hein. op. cit., p. 34.

141. MICHAELS, Ralf. op. cit., pp. 343-344.

142. Este punto ha sido resaltado con mayor autoridad, mucho tiempo atrás, con respecto a las aproximaciones funcionales en general. Al respecto cabía la lectura de COHEN, Felix S. Transcendental nonsense and the functional approach. En: Columbia Law Review, vol. XXXV, núm. 6, 1935, p. 909 y ss., ivi pp. 821-822.

143. Cuya característica más saltante, en lo que a la materia que nos convoca se refiere, en opinión de VALCKE, Catherine. Comparative law as comparative jurisprudence: The comparability of legal systems, cit., pp. 724-731, sería la percepción de que el sistema jurídico es plural pero no unificado.

144. Sobre la opinión del autor alemán nos remitimos a la consulta de la reseña bibliográfica de su obra más influyente en el tema de marras, nos referimos a Grundsatz und Norm in der richterlichen Rechtsfortbildung des Privatrechts: Rechtsvergleichende Beitraege zur Rechsquellen und Interpretationslehre, efectuada por RHEINSTEIN, Max. En: University of Chicago Law Review, vol. LIV, núm. 3, 1957, p. 597 y ss.

145. GORDLEY, James. Is comparative law a distinct discipline? En: The American Journal of Comparative Law, vol. XLVI, 1998, p. 607 y ss.; Id., Comparative legal research: Its function in the development of harmonized law, cit., p. 555 y ss. 
que la solución o la respuesta que ofrece un sistema jurídico a un problema universal resulta solo una propuestas de las tantas que pueden ofrecerse, no existen principios jurídicos de carácter universal, lo que existe es una homogeneidad en el intento de resolver el problema de carácter universal, elevándose este intento o esfuerzo al rol de tertium comparationis (replicando aquel rol que desempeñaba el ius commune).

2. Funcionalismo evolutivo.- El darwinismo también tuvo un impacto en el Derecho. Así, se teorizó una noción de sociedad en que ella, entendida como organismo complejo, evolucionaba como un todo a través de la cooperación brindada por cada uno de sus elementos, quienes al cumplir la función específica que les correspondía contribuían al desarrollo y crecimiento de la sociedad

Esta influencia se percibe -con claridad-en las ideas de un autor que ha contribuido a cimentar los estudios jurídicos en el Civil Lawy en el Common Law, si es que acaso no en todo el mundo. Me refiero a Rudolf von Jhering ${ }^{146}$. El ilustre autor alemán era de la opinión de que la ciencia jurídica (como cualquier otra ciencia) no podía (ni debía) encontrarse confinada por las fronteras nacionales.

Este aspecto era el que justificaba que la comparación jurídica estudiase directamente las formas específicas en que las sociedades afrontaban los problemas en su camino al progreso.
La aplicación de esta particular perspectiva del Derecho, combinada con los aportes de la propia comparación jurídica, generó aquella corriente de opinión denominada Law and Development ${ }^{147}$.

3. Funcionalismo estructuralista.- El desarrollo alcanzado por la sociología brindó más de un impulso a la comparación jurídica. Tal vez el mayor impacto se produjo cuando Émile Durkheim propuso una serie de pautas para lograr una investigación con mayor objetividad y tecnicismo. Así, se decía que la sociedad era más que la suma de sus partes, por lo que la interrelación entre sus elementos era lo que permitía sustentar dicha trascendencia. Por tanto, al estudiar tales interrelaciones se podía comprender por qué la sociedad tenía necesidades.

En virtud a este desarrollo, se consideró que el Derecho no solamente se encontraba en capacidad de comprender tales necesidades, sino que también podía satisfacerlas si es que se concentra en datos objetivos y en los hallazgos que se efectúan en otras sociedades. Entonces, la tarea del operador jurídico era desarrollar instituciones que resultasen aptas para satisfacer las necesidades sociales. En tal escenario, resulta por demás lógico que la comparación jurídica se eleve como una herramienta de enorme utilidad, toda vez que contribuirá en dicha tarea al analizar las diversas soluciones ${ }^{148}$ que se plantean en otras experiencias.

146. ZWEIGERT, Konrad y SIEHR, Kurt. op. cit., p. 218.

La influencia de Jhering en el pensamiento de Holmes resulta indudable, prueba de ellas son las referencias implícitas y explícitas en los trabajos del autor norteamericano, este aspecto ha sido puesto en evidencia por FRANK, Jerome. Civil law influences on the common law - Some reflections on 'comparative' and 'contrastive' law, cit., pp. 891893. Por su parte, la influencia de la doctrina germana no se limita a ello, como bien ha sido evidencia por muchas investigaciones, entre las que se encuentra HOEFLICH, M. H. Transatlantic friendship \& the german influence on American law in the first half of the nineteenth century. En: The American Journal of Comparative Law, vol. XXXV, núm. 3, 1987, p. 599 y ss.

147. MERRYMAN, John Henry. Comparative law and social change: On the origins, style, decline \& revival of Law and Development movement, cit., p. 457 y ss.

148. Cfr. LEPAULLE, Pierre. The function of comparative law with a critique of sociological jurisprudence. En: Harvard Law Review, vol. XXXV, num. 7, 1922, p. 838 y ss., ivi pp. 844-845, quien critica la idea de "balance de intereses" propuesta por Roscoe Pound. 
Si bien la tendencia anti-formalista se observa desde antiguo, con el funcionalismo estructuralista se inicia un proceso en el que se presta cada vez mayor atención a los aspectos subyacentes a las construcciones jurídicas, intentándose recoger material y datos empíricos que permitan una mejor comprensión de la realidad. Cabría aludir a Philipp Heck -el principal propulsor de la Interessenjurisprudenz-y a Roscoe Pound.

El trabajo de Pound se centró particularmente en el «derecho en acción y no en los libros» ${ }^{149}$ y en "como el mismo propósito frente a un problema puede ser cumplido por una institución, doctrina o precepto en un cuerpo de normas y por otra institución, doctrina o precepto del todo diferente en otra normativa» ${ }^{150}$. Con ambas formas de analizar el fenómeno jurídico se intentaba llamar la atención del operador hacia las funciones manifiestas (que son conocibles e intencionales) y a las funciones latentes que el Derecho ${ }^{151}$ cumple (las cuales muchas veces son desconocidas y no-intencionales).

En la comparación jurídica se cumple dicho objetivo cuando se presta atención a lo que los profesionales del Derecho hacen y no a aquello que dicen hacer ${ }^{152}$.

4. Funcionalismo neo-kantiano.- Merced al desarrollo alcanzado con el funcionalismo estructuralista, el funcionalismo perdió su fundamento filosófico, por lo que llegado el momento se recurrió al pensamiento kantiano. En efecto, al existir una diferencia entre el ser (el mundo del fenómeno) y el deber ser (el mundo del noúmeno) -esto es, la distinción clave para exponer las premisas del imperativo categórico y del imperativo hipotético- podía emplearse el pensamiento de Inmanuel Kant a fin de sustentar un Derecho construido sobre la base de la razón y que pudiera hace frente a la profunda critica de Kirchmann ${ }^{153}$.

La conclusión del esfuerzo emprendido fue el siguiente: aunque la ciencia jurídica se relaciona con universales, los cuales jamás eran las propias reglas jurídicas, tal lugar le correspondía a los problemas subyacentes que se intentaban afrontar; por lo que la comparación jurídica debía focalizarse en aquellas reglas que encontrándose en los diversos sistemas afrontaban el mismo problema.

5. Funcionalismo de equivalencia.- A causa del desarrollo de las distintas nociones de lo que es funcionalismo (o cómo debía ser enfocado) y fruto de la labor asumida por los comparatistas a lo largo de los años, se pasó a afirmar que instituciones similares en un momento y sociedad determinada podía desempañar funciones distintas; $y$, de manera correlativa, que necesidades funcionales similares podían ser satisfechas por instituciones del todo distintas.

En este orden de ideas, se concluyó que había una equivalencia funcional entre tales instituciones. Empero, no se ha aclarado todavía si ello se refiere a los valores que subyacen a las soluciones, más allá de la universalidad de aquellos problemas que las motivan.

149. POUND, Roscoe. Law in the books and law in action. En: The American Law Review, vol. XLIV, 1910, pp. 12-36.

150. POUND, Roscoe. What may we expect from comparative law. En: The American Bar Association Journal, vol. XXII, 1936, pp. 56 y ss., ivi p. 59

151. MERTON, Robert K. The unanticipated consequences of purposive action. En: The American Sociological Review, vol. I, núm. 36, 1936, p. 894 y ss.

152. Resulta interesante constatar la amplitud de la visión de Pound en este punto, lo cual es puesto en evidencia por VON MEHREN, Arthur Taylor. Roscoe Pound and comparative law. En: The American Law Review, vol. XIII, núm. 4, 1964, p. 507 y ss., ivi pp. 509 y 512.

153. Nos referimos a aquella lapidaria sentencia de "un plumazo del legislador y bibliotecas enteras se convierten en papel mojado". 
Si bien esto es un defecto metodológico de esta teoría, también le permite cierta flexibilidad. Además, tiene un mérito fundamental, al menos de acuerdo a mi manera de ver las cosas, al concluir que el desarrollo jurídico o el cambio que sufre el Derecho es meramente una de tantas posibilidades, $y$ no un hecho ineludible.

Así, el desarrollo y la mutación jurídica resulta del todo contingente, al no ser de tipo unidireccional (aspecto que le permite superar una de las críticas recurrentes de las posturas postmodernas acerca de la visión no-lineal del desarrollo y de la historia). A tal efecto se requerirá que el comparatista conozca la sociedad bajo análisis, aspecto que se añadirá a su conocimiento sobre los elementos que componen el Derecho de tal sociedad (ambos aspectos o conocimientos son estudiados - por lo general- de manera independiente) $)^{154}$.

Teniendo en consideración estas nociones, abordaré de manera más directa la opinión de Kötz sobre la perspectiva funcional en la comparación jurídica. Sin embargo, también deseo graficar que los comparatistas toman, por momentos indistintamente, una u otra noción de función. En línea a tal propósito, quisiera recordar que la propia idea de función conlleva, inherentemente, una visión teleológica del fenómeno jurídico y que ello se ve reforzado cuando se afirma que sólo resultan totalmente comparables los sistemas que han alcanzado un grado de desarrollo similar ${ }^{155}$ o cuando el devenir del Derecho se considera importante a efectos de establecer el rol que cumple ${ }^{156}$. Asimismo, las aspiraciones científicas del método comparatista pueden, en otros casos, verse frustradas del todo cuando se acepta que la función se determina, a veces, por intuición ${ }^{157}$.

El inconveniente metodológico apenas detectado se explica por algo que ha sido mencionado, Kötz, Rheinstein, Rabel ${ }^{158}$ y Pound tienen una visión pragmática ${ }^{159}$ de la comparación jurídica, lo cual los hace una presa fácil para quienes exijan sistematicidad. No obstante ello, o más bien precisamente por esta visión pragmática de la comparación, la perspectiva bajo análisis nos ha legado un sugerente análisis acerca de la utilidad que puede desempeñar la «función» de las instituciones o figuras jurídicas. Uno de los asuntos al que tanta atención se le dispensó desde la consolidación misma de esta aproximación metodológica.

Entre las funciones que se pueden identificar tenemos a:

(a) la función epistemológica ${ }^{160}$;

(b) la función de lograr comparabilidad ${ }^{161}$;

(c) la función de enfatizar las similitudes ${ }^{162}$;

154. VALCKE, Catherine. Comparative law as comparative jurisprudence: The comparability of legal systems, cit., p. 720 y ss.

155. Cfr. ZWEIGERT, Konrad y KÖTZ, Hein. op. cit., p. 3, quienes en este punto recuerdan al comparatista francés Lambert.

156. ZWEIGERT, Konrad y KÖTZ, Hein. op. cit., p. 8.

157. ZWEIGERT, Konrad y KÖTZ, Hein. op. cit., p. 33.

158. GERBER, David J. System dynamics: Toward a language of comparative law?, cit., p. 722, resalta que la metodología que enfatiza la función/contexto fue inicialmente desarrollada por Rabel, la cual fue planteada para contribuir en el proceso de unificación jurídica.

159. GERBER, David J. Sculpting the agenda of comparative law: Ernst Rabel and the facade of language, cit., p. 202, quien subraya, precisamente, que por estas razones Rabel logró convertirse en el intermediario entre el mundo académico y las necesidades del empresario y político alemán.

160. VAN HOECKE, Mark y WARRINGTON, Mark. Legal cultures, legal paradigms and legal doctrine: Towards a new model for comparative law, cit., p. 495 y ss.

161. GORDLEY, James. Is comparative law a distinct discipline?, cit., p. 611.

162. ZWEIGERT, Konrad y KÖTZ, Hein. op. cit., p. 40. Si bien ello ha generado tres tipos de crítica: 
(d) la función de construir un sistema jurídico ${ }^{163}$; (e) la función de determinar el mejor Derecho ${ }^{164}$; (f) la función de preparar la unificación ${ }^{165} ; y$, (g) la función de proveer herramientas para la crítica jurídica ${ }^{166}$.

La visión pragmática de los funcionalistas, sumado a las ventajas y desventajas anotadas, ha provocado que la mayoría de los estudios que siguen esta perspectiva se ocupen del análisis de una figura o situación específica. Así, se evita abordar discusiones de corte metodológico. Sin embargo, por lo sugerente de la construcción que se observa en uno de tales trabajos, el cual se ocupa del análisis de la buena fe dentro del sistema inglés, considero adecuado presentar algunos de sus perfiles más saltantes.

Como es conocido, en el Civil Law, particularmente en los sistemas de influencia germánica, el rol que despliega la buena fe es no sólo muy amplio, sino que incluso se puede afirmar que es distintivo y esencial para la configuración de una serie relevante de otras instituciones, así como definitorio de la manera en que se concibe el Derecho. Por su parte, en el Common Law, y sobre todo en los sistemas de influencia inglesa ${ }^{167}$, esta noción únicamente es conocida por los comparatistas (y ello no significa que sea vista de manera favorable) o por los profesionales que tienen vinculación con el comercio con países del Civil Law, salvo el espacio reconocido en determinados cuerpos legales en el sistema estadounidense. En un contexto como el descrito, el discutir cómo funcionaría la buena fe en un sistema como el inglés parecería ser el ejercicio intelectual de un académico universitario. Empero, ello no es así. La razón es sencilla, en la descripción efectuada no se tomó en cuenta el papel de la unificación europea.

En los últimos años, la Comunidad Europea ha ido promulgando una serie, más o menos amplia de

\footnotetext{
a) Por un lado, vulnera un principio medular del método científico: uno no debe probar sino poner a prueba la hipótesis de trabajo.

b) Por otro lado, viola uno de los principios de la comparación: el comparatista no debe favorecer lo similar sobre lo distinto; o, si se quiere, viola un principio metodológico autoproclamado: la neutralidad.

c) Finalmente, reduce el campo de aplicación de la comparación pues los elementos comunes no recaen en el todo y dependen de aspectos contingentes.
}

Al respecto V. CURRAN, Vivian Grosswald. Cultural immersion, difference and categories in U.S. comparative law. En: The American Journal of Comparative Law, vol. XLVI, num. 1, 1998, p. 43 y ss.

163. ZWEIGERT, Konrad y KÖTZ, Hein. op. cit., p. 38.

164. RHEINSTEIN, Max. Teaching comparative law. En: University of Chicago Law Review, vol. V, núm. 4, 1938, p. 615 y ss., ivi p. 617, quien sostiene que «[c]ada regla e institución tiene que justificar su existencia absolviendo dos interrogantes: Primero: ¿qué función cumple en la sociedad actual? Segundo: ¿cumple adecuadamente esta función o podría otra regla cumplirla de mejor manera? Es obvio que la segunda pregunta no puede ser respondida, salvo que se efectúe sobre la base de la comparación con otro sistema jurídico.»

165. Aspecto que se ha subrayado por la tendencia de la Comunidad Europea a promulgar normativa que pueda uniformizar ciertos aspectos jurídicos relevantes. Sobre el punto V. GERBER, David J. System dynamics: Toward a language of comparative law?, cit., p. 721.

166. VON MEHREN, Arthur T. An academic tradition for comparative law. En: The American Journal of Comparative Law, vol. XIX, núm. 4, 1971, p. 624 y ss.

167 El énfasis en los sistemas que tienen influencia inglesa y no estadounidense se explica, aunque no sea un dato extensamente conocido por la mayoría de operadores jurídicos nacionales, porque en este último si existen expresas referencias a la buena fe en ciertos cuerpos normativos tales como el Uniform Commercial Code y en el Restatement (Second) of Contracts. Si bien el alcance que se le otorga a la buena fe es más bien restrictivo, su reconocimiento tanto en el formante legal como en el jurisprudencial existe (recordemos que un Restatement es sencillamente una recopilación de sentencias que son condensadas y sistematizadas en ciertas reglas jurídicas). Para comprender las razones de ingreso de la buena fe en el sistema norteamericano es menester subrayar la enorme influencia que tuvo en la redacción del Uniform Commercial Code, un conocido y reconocido germanófilo como Karl Llewellyn (Why we need the Uniform Commercial Code. En: University of Florida Law Review, vol. X, núm. 4,1957, p. 367 y ss.). 
Resoluciones y/o Directivas, en las que se regula (o aconseja cierta regulación) respecto de algunos aspectos jurídicamente relevantes, todo ello con el fin de favorecer la consolidación del mercado común. Una de las Directivas, cuya enorme trascendencia en este punto resulta innegable, es la que se ocupa de la protección al consumidor. En tal Directiva se incorporó un artículo que califica como injusta (o, en un término más común en nuestro medio, abusiva) a aquella disposición contractual que al ser «contraria a las exigencias de la buena fe, cause un desbalance significativo entre los derechos y obligaciones de las partes derivados del contrato, en perjuicio del consumidor».

Atendiendo a esta circunstancia, el profesor Gunther Teubner recuerda, en primer lugar, un hecho relevante, el rechazo a nivel jurisprudencial de la buena fe, lo cual se sustentaría en la manera en que los ingleses sienten y piensan el Derecho ${ }^{168}$. Luego de ello, pasa a calificar a la buena fe como un virus que ha infectado al sistema jurídico inglés ${ }^{169}$; es por dicha razón que considera que el ataque de un ente externo a tal organismo generará, casi con seguridad, una respuesta inmunológica de rechazo o, al menos, de irritación ${ }^{170}$.

Para comprender la teoría de los irritantes jurídicos [o legal irritants] hay que aclarar que esta propuesta nace como una reacción crítica frente a la teoría de los trasplantes de Watson. Uno de los elementos que con mayor énfasis critica Teubner es la metáfora de los legal transplants, puesto que da la falsa impresión de que la "operación" realizada, aunque complicada, permite que el ente trasplantado se adecue al nuevo ambiente y manteniendo así la misma identidad que alcanzó en su contexto de origen, por lo que seguiría cumpliendo la misma función ${ }^{171}$. En línea con la propuesta de Teubner, también sería equivocada la idea de que sólo existen dos reacciones posibles: (a) el organismo receptor rechaza el trasplante jurídico efectuado; o, (b) el organismo receptor integra funcionalmente al ente trasplantado. En realidad, existirían más de una posibilidad intermedia y que resultan preocupantes debido a su carácter contingente e inesperado.

Las críticas de Teubner pueden, por razones de análisis, escindirse en dos. Por un lado, se tendrían las objeciones de naturaleza contextual; $y$, por otro lado, los efectos que el trasplante generará en el país importador. Con respecto al primer punto, se llama la atención sobre las particulares características de una cultura jurídica, ya que en última instancia -como se vio al analizar las tipologías de trasplantes- serán estos elementos los que permitan o imposibiliten determinada importación. Como sustento de su crítica emplea ciertos argumentos culturalistas expresados por Pierre Legrand, quien sostiene -como se verá más adelante-que los sistemas jurídicos (en particular, los europeos) no están convergiendo, pues el fenómeno que se viene produciendo sólo se limita al dato de la norma positiva y no alcanza a las estructuras jurídicas de base (y sus diversas manifestaciones); sencillamente porque ello no es posible. Así, todas las instituciones permanecen idénticas a sí mismas, sin incorporar las variables del resto de los sistemas jurídicos, alterar tal realidad importaría atender a las características que rodearon el surgimiento y desarrollo ${ }^{172}$ de cada una de estas instituciones.

168. TEUBNER, Gunther. Legal irritants: Good faith in british law or how unifying law ends up in new divergences, cit., p. 11. Para un interesante análisis sobre las características en que los juristas del common law razonan o perciben el Derecho V. LEGRAND, Pierre. European legal systems are not converging, cit., pp. 64-74.

169. GOODE, Roy. The concept of "good faith" in English law. En: Centro di Studio e ricerche di diritto comparato e straniero dirigido por M. J. Bonell, saggi, conferenze e seminari, núm. 2, Roma, 1992, disponible en http://servizi.iit.cnr. it/ crdcs/crdcs/frames2.htm.

170. TEUBNER, Gunther. op. cit., p. 12.

171. Para trasmitir esa idea recuerda la imagen que Otto Kahn-Freund (op. cit., pp. 5-6) sugiere sobre la diferencia entre un trasplante entendido en términos mecánicos de un trasplante entendido en el sentido orgánico.

172. Cfr. LEGRAND, Pierre. The impossibility of "legal transplants". En: Maastricht Journal of European and Comparative Law, vol. IV, 1997, pp. 111 y ss. [citado por Teubner, Gunther, op. cit., p. 14]. 
El empleo de tal perspectiva de análisis permite comprender mejor las objeciones de Teubner hacia la propuesta de trasplantes jurídicos, en la medida que uno de los autores más críticos a dicha teoría es precisamente el propio Legrand.

Sin perjuicio de lo anterior, Teubner emplea parcialmente la estructura criticada para construir su propia teoría. Tal construcción parte de reconocer que la teoría de los trasplantes jurídicos tiene el mérito de explicar, a través de sólidas evidencias empíricas, la existencia de una fuerte interrelación entre los sistemas jurídicos. Es esta interrelación la que facilita la importación o exportación de las reglas jurídicas de un sistema a otro, pese a las diversas estructuras socio-económicas que las sustentan, todo lo cual permite comprender:

(i) porque la comparación debe estudiar la interrelación entre los sistemas (y no las reglas foráneas),

(ii) que la principal fuente de la mutación sean los trasplantes jurídicos y que muchos de tales cambios se efectúan al margen de los cambios sociales $^{173}$.

Con estas afirmaciones, Teubner se estaría aproximando mucho a la posición de Watson, por lo que realiza luego algunas acotaciones dirigidas a precisar que el trasplante se produce no por la búsqueda de respaldo (o autoridad), sino por la propia lógica interna del discurso jurídico (aspecto que lo torna auto-referencial $y$, por ende, crea una preferencia para las transferencias entre los sistemas). Por su parte, con respecto el aislamiento de la mutación jurídica, si bien es correcto afirmar que -en vía de principio- las mutaciones ocurren al margen de los cambios sociales, no es menos cierto que existen muchos casos en los que estas se produjeron por una confluencia (o por influencia directa) de elementos políticos, culturales, económicos, entre otros ${ }^{174}$

Así, la idea de los irritantes jurídicos se colocaría en un punto intermedio entre la negación del trasplante planteada por Legrand y la posición de Watson que afirma la difusión generalizada de modelos jurídicos a través de trasplantes ${ }^{175}$. Con ello se describe que los trasplantes no se limitan a alterar -en todo o en parte- el sentido de la regla importada sino que producida su incorporación a un determinado sistema jurídico se presentan efectos del todo inesperados en el nuevo contexto en el que se desarrolla la figura importada (pues tendrá que adaptarse tanto a nivel discursivo, como a nivel de reconstrucción de su lógica interna).

Evidentemente, en el caso analizado por Teubner, la buena fe puede tener más de un efecto desestabilizador en un sistema jurídico como el inglés en el que ciertas expresiones de este concepto resultan del todo extrañas e incluso opuestas a los postulados sobre los que se erige, por citar la materia analizada por el autor, su derecho contractual.

\section{CUESTIONANDO LA HEGEMONÍA CULTURAL EN EL DERECHO: LA APROXIMACIÓN POSTMODERNA}

Como se observa la mayor parte de las críticas que se efectúa a la comparación jurídica (o a sus métodos) se centran en su tendencia a la neutralidad y en su búsqueda de objetividad en aras de lograr un conocimiento propiamente científico y técnico ${ }^{176}$. Frente a tales "defectos" surge una aproximación nihilista que cuestiona todas las na-

173. TEUBNER, Gunther. op. cit., pp. 15-16.

174. Cfr. EWALD, William, The American revolution and the evolution of law, en The American Journal of Comparative Law Supplement, vol. XLII, 1994, pp. 1 y ss.

175. SOMMA, Alessandro, Tanto per cambiare... mutazione del diritto e mondializzazione nella riflessione comparatistica, cit., p. 560

176. EBERLE, Edward J. The method and role of comparative law. En: Washington University: Global Studies Law Review. Vol. VIII, núm. 3, 2009, pp. 451 y ss. 
rraciones ya que ellas se constituyen en la manera en que se erigió el pasado ${ }^{177}$ y que aspira a preservar el status quo. Tal aproximación se funda en una visión postmoderna ${ }^{178}$ de la comparación jurídica que nos lleva a rechazar la dimensión histórica de los eventos que se analizan y se configura, en términos simples, como una reacción a aquellas tendencias - presentes por ejemplo en las corrientes funcionalistas y estructuralistas- que parten de tal dimensión para confirmar sus teorías ${ }^{179}$.

El sentido del rechazo de la dimensión histórica por parte de los comparatistas postmodernos tiene como propósito enfatizar las diferencias entre los sistemas ${ }^{180}$. No obstante ello, se presta especial atención a los eventos que rodean al fenómeno estudiado, y ello sólo es admisible en tanto se limite a períodos de tiempo reducidos, pues de ampliarlo surgirían las similitudes a las que tanta atención dispensan los funcionalistas; o, por otro lado, evidenciarían las influencias que tendencialmente podrían existir entre sistemas diversos (asunto al que le prestan mayor atención los estructuralistas). La comparación jurídica tradicional tendría, por lo tanto, que ser criticada por focalizar su análisis en aquellos elementos que evidencian que el razonamiento, el lenguaje y los juicios se encuentran influenciados por un marco epistemológico, lingüístico, cultural y moral de carácter ineludible e inconmensurable.

Con tales premisas, añadiendo el concepto de herméneutique amplifiante, puede explicarse en términos sencillos aquella percepción de que toda cultura jurídica debe ser decodificada con el fin de descifrar apropiadamente el significante y el significado de las instituciones que serán estudiadas ${ }^{181}$.
Ello, sin embargo, deberá conjugarse con otro dato que posee gran importancia: el conocimiento de las culturas jurídicas es el fruto de la interpretación personal del operador jurídico -asunto que permite identificar el origen nihilista de esta perspectiva-, por lo que el resultado de este proceso es una invención o probablemente sólo una narración. Vistas así las cosas, la tendencia de centrarnos en las diferencias se afianza. Sobre todo cuando se cae en la cuenta que la comparación jurídica (según este orden de ideas) efectúa un análisis diferencial que debe enfatizar las diferencias entre los eventos o nociones comparadas. Tan es cierto ello que, desde una perspectiva postmoderna, quienes propulsan teorías o practicas dirigidas a la unificación (o uniformización) jurídica no harían más que oponerse a la comparación jurídica.

Por esta razón el profesor Legrand sostiene que el Derecho no es más que una herramienta que es empleada por el sector dominante de la sociedad para establecer o mantener un orden social determinado. Así, la lucha por el poder se traslada a un campo de naturaleza distinta: el del discurso jurídico. Tal campo es en el que -con mayor éxito- se han movido los juristas y los comparatistas de la tradición occidental.

En este orden de ideas, la labor desempeñada por un comparatista debería, en primer lugar, abandonar esta manera de observar los fenómenos (que no es más que conservadurismo); $y$, en segundo lugar, procurar revelar aquellos intentos de atribuir poder (o mantenerlo) que se encuentran más o menos ocultos en los discursos técnico-jurídicos. Siempre las preferencias políticas, económicas o filosóficas del autor se

177. SOMMA, Alessandro. At the patient's bedside? Considerations on the methods of comparative law, cit., p. 30.

178. Cfr. ENGLE, Eric. Lex naturalis, ius naturalis: Law as positive reasoning \& natural rationality, Elias Clark Group, Melbourne, 2010, p. 336 y ss., quien precisa que: "[e]n cambio, post modernidad se define en atención a su escepticismo respecto de las ideas de progreso y las narrativas universales... Los postmodernistas arguyen que los valores son relativos y así que no existe moralidad objetiva y acaso tampoco conocimiento objetivo."

179. JAYME, Erik. Osservazioni per una teoria postmoderna della comparazione. En: Rivista di diritto civile. 1997, I, p. 814.

180. JAYME, Erik. Osservazioni per una teoria postmoderna della comparazione, cit., pp. 814-816.

181. SOMMA, Alessandro. At the patient's bedside? Considerations on the methods of comparative law, cit., p. 33. 
trasladarán a su posición jurídica, por lo que hay que estar advertidos de ello para deconstruir tal discurso y revelar los intereses subalternos, la neutralidad es negada de raíz.

La conclusión de la posición de Legrand es simple: los trasplantes jurídicos son un imposible, en la medida que en toda figura doctrinal, legal o jurisprudencial siempre existe un elemento o sustento cultural que como tal no es susceptible de importación. En este sentido, lo único que se respetaría en los fenómenos de trasplante o de préstamo jurídico sería la literalidad o el significante del discurso más no el contenido (o significado) de aquél. Si esto es cierto, tendría que rechazarse los planteamientos que consideran como el motor de la mutación jurídica a los trasplantes o préstamos jurídicos (la circulación de los modelos jurídicos); e incluso se daría un paso adicional -que es del todo consistente con las ideas expuestas hasta este momento- afirmar la inconmensurabilidad de los sistemas jurídicos ${ }^{182}$.

La noción de base de esta teoría es particularmente sencilla: el Derecho como fenómeno no resulta verdaderamente cognoscible si es que no se atiende al contexto en el que se gestó y desarrolló. Sin embargo, recordemos que esta atención sólo se dispensará al espacio-temporal limitado en el que se ha desarrollado la institución objeto de análisis y no se debe extender más allá de esos límites, so riesgo de caer en las perspectivas historicistas a las que se critica como correlato de las teorías difusionistas.

Por su parte, la posición de Somma toma como punto de partida la constatación de que incluso hoy un sector mayoritario de los académicos está afectado por los postulados del positivismo jurídico. Por esta razón, conciben al Derecho como un sistema completo y coherente, lo cual redundará en la percepción de que la regla ju- rídica es única y unívoca. Esta afirmación se ve retratada en las aproximaciones que pretenden otorgar un velo de objetividad y neutralidad a la comparación jurídica, en particular todo cuando se estudia los sistemas jurídicos y se da por sentado-siguiendo tales corrientes de opinión-que el conocimiento podrá ser alcanzado a través de un proceso empírico e inductivo.

En cambio, los comparatistas que asumen una perspectiva postmoderna enarbolarán aquellas críticas que, gracias al aporte de las ciencias sociales, se elevan contra el positivismo. Debido a estas circunstancias, los postmodernos conciben que el conocimiento jurídico se adquiere de manera deductiva y a menudo resulta sólo una probabilidad. Así, el conocimiento siempre será incompleto y, desde luego, se encontrará afectado por los sesgos particulares del observador, lo cual incluye sus apreciaciones culturales.

Luego de este razonamiento, Somma da el siguiente paso natural, concibe que no sólo debe ser estudiado el poder sino también los discursos (jurídicos) que son empleados para su creación o consolidación. Esta tarea debe ser efectuada por los comparatistas a fin de analizar las técnicas y los valores o, dicho en otros términos, el discurso jurídico y el orden social que promueve ${ }^{183}$. Con esa información a la mano, el comparatista podrá identificar cuál es el valor a promover y el sistema necesario para alcanzarlo.

En tal sentido las críticas postmodernas son cuanto menos las siguientes:

(i) La comparación jurídica clásica es sólo la proyección de la imaginación del académico ${ }^{184}$, en tanto que no existe un punto de vista externo que nos permita describir, comparar y evaluar cada específica solución jurídica.

182. GAMBARO, Antonio. The Trento theses. En: Global Jurist Frontiers. Vol. IV, núm. 1, art. 2, 2004, p. 7, disponible en http://www.bepress.com/gj/frontiers/vol4/iss1/art2.

183. SOMMA, Alessandro. At the patient's bedside? Considerations on the methods of comparative law, cit., p. 42.

184. Al respecto puede verse KENNEDY, David. New approaches to comparative law: Comparativism and international governance. En: Utah Law Review. Núm. 2, 1997, p. 554. 
Al no existir un punto de partida, el comparatista deberá aceptar que existen una serie de verdades distintas a la suya ${ }^{185}$, que no pueden ser descartadas ab initio. Asimismo, y ante la ausencia de un común denominador ${ }^{186}$ que garantice la posibilidad de encontrar significados neutrales y objetivos -un aspecto medular de la propuesta metodológica de las tesis difusionistas y funcionalistas ${ }^{187}$-, se evidencia que el Derecho en su conjunto se encuentra determinado por una serie de marcos epistemológicos, lingüísticos, culturales y morales que son del todo inevitables ${ }^{188}$. La conclusión de este razonamiento sería una sola: la imposibilidad de efectuar trasplantes jurídicos y, por lo tanto, la comparación no debería concebirse como una herramienta para la reforma (o para la armonización) del Derecho, sino más bien como un proyecto político de crítica ${ }^{189}$.

(ii) La investigación comparada se encuentra plagada de juicios ${ }^{190}$ valorativos, situación que se presentará al margen del intento que efectúe el comparatista por abstenerse de tal valoración. La razón es sencilla. Todas las personas nos encontramos irremediablemente sesgados por nuestro marco de referencia, así que todo intento por lograr neutralidad se encuentra condenado al fracaso o resulta meramente una ilusión. Estos intentos por alcanzar neutralidad no hacen más que ocultar las visiones euro-céntricas que subyacen a los intérpretes, vale decir, en los hechos los intérpretes ven y evalúan a los demás en función a sí mismos ${ }^{191}$.

Así las cosas, el comparatista no podrá superar aquellos límites impuestos por su propia percepción del Derecho. Tales límites influirán en la manera en que selecciona, depura y organiza la información ${ }^{192}$, afectando irremediablemente su investigación y sus propias conclusiones.

(iii) Si el conocimiento depende del marco de referencia de quien lo genera, si debemos centrar la atención en el análisis del poder (y en el Otro ${ }^{193}$ ) y si además la verdad como tal no existe (ni mucho menos la búsqueda de ella); habría que concluir que todo resulta una ideología. Vale decir, un constructo teorético cuyo propósito es ganar, cimentar y/o justificar el ejercicio del poder en desmedro, dominación y discriminación del Otro ${ }^{194}$.

Esta conclusión se confirmaría por la tenden$\mathrm{Cia}^{195}$ a incorporar al Otro a nuestro marco o sistema de referencia y con ello provocar su

185. CURRAN, Vivian Grosswald. Cultural immersion, difference and categories in U.S. comparative law, cit., p. 91.

186. En efecto, tal y como lo resalta VALCKE, Catherine. Comparative law as comparative jurisprudence: The comparability of legal systems, cit., pp. 720-721, para efectuar comparación se requiere tanto de unidad cuanto de pluralidad

187. PETERS, Anne y SCHWENKE, Heiner. Comparative law beyond post-modernism. En: International and Comparative Law Quarterly. Vol. XLIX, núm. 4, 2000, p. 811.

188. FRANKENBERG, Günter. Stranger than paradise: Identity \& politics in comparative law. En: Utah Law Review. Núm. 2 1997, p. 270; y, GERBER, David J. System dynamics: Toward a language of comparative law?, cit., p. 723.

189. Sobre este punto resulta ilustrativa la posición de KENNEDY, David. New approaches to comparative law: Comparativism and international governance, cit., p. 633.

190. CURRAN, Vivian Grosswald. Cultural immersion, difference and categories in U.S. comparative law, cit., p. 58.

191. FRANKENBERG, Günter. Critical comparisons: Re-thinking comparative law, en Harvard International Law Journal, vol. XXVI, 1985, p. 411 y ss., ivi p. 414.

192. SCHLAG, Pierre. Normativity and the politics of form, cit., pp. 808 y 812.

193. CURRAN, Vivian Grosswald. Comparative law's potential for broadening legal perspectives. En: The American Journal of Comparative Law. Vol. XLVI, núm. 4, 1998, p. 657.

194. SCHLAG, Pierre. Normativity and the politics of form, cit., pp. 803-804.

195. CURRAN, Vivian Grosswald. Cultural immersion, difference and categories in U.S. comparative law, cit., p. 49. 
desaparición como un punto de referencia distinto y externo. La comparación jurídica tradicional sería, por lo tanto, solamente un proyecto ideológico que obedece a una específica agenda política subalterna (o, en todo caso, es promovida de manera inconsciente), a saber: la hegemonía. Como se observa, la hegemonía se lograría a través de la asimilación o de la exclusión del Otro ${ }^{196}$, puesto que ambos medios permitirán que se perpetúe el esquema occidental y el poder que ostentan sus élites ${ }^{197}$.

En el contexto descrito es sencillo comprender porque se considera que el mainstream comparatista tiene una actitud acrítica sobre las necesidades sociales y económicas, por lo que (hipotéticamente) tenderían a una forma de conservadurismo ${ }^{198}$, aspecto que es ocultado bajo la faz de neutralidad y objetividad.

(iv) Atendiendo a los puntos precedentes, se observaría que toda construcción teórica que se funda en las premisas de (o que haya sido creada por) los comparatistas tradicionales, así como por cualquier otro operador jurídico, deberá ser re-examinada a fin de revelar los marcos específicos en los cuales se funda $y$, desde luego, la agenda política a la que sirve implícita u explícitamente ${ }^{199}$.
Esta situación se constata al prestar atención, por ejemplo, a las clasificaciones en las que se percibe una clara impronta occidental y reserva un puesto periférico (o categoría residual) al Otro (como sucedía con la clasificación de David). Esta situación es inclusive incuestionable en aquellas posturas que califican a un sector de culturas con términos como no-desarrolladas, primitivas, etc. En este orden de ideas, la labor del comparatista no debiera centrarse en calificar, sino en evidenciar los aspectos inarticulados (e incluso silenciosos) que se desarrollan en el Derecho.

(v) Por último, existe una crítica (puntual) que tiene como propósito arremeter contra las perspectivas funcionalistas. Como se ha visto en estos enfoques habría implícitamente la idea de que existe un tipo de universalismo en los fenómenos jurídicos ${ }^{200}$. Me refiero al reconocimiento de necesidades semejantes en los diversos sistemas jurídicos, aquello a lo que la corriente funcionalista ha denominado "equivalencia funcional" entre figuras o instituciones jurídicas.

La existencia de funciones sociales "universales" sería sólo una quimera ${ }^{201}$. Si bien habría que admitir que resulta comprensible

196. PETERS, Anne y SCHWENKE, Heiner. Op. cit., p. 823.

197. Cfr. OLSEN, Frances. The drama of comparative law. En: Utah Law Review. núm. 2, 1997, p. 278; KENNEDY, David. New approaches to comparative law: Comparativism and international governance, cit., p. 619; y, FRANKENBERG, Günter, Stranger than paradise: Identity \& politics in comparative law, cit., p. 261.

198. Ver retro texto y nota (82).

199. CURRAN, Vivian Grosswald. Cultural immersion, difference and categories in U.S. comparative law, cit., p. 48; y VALC$\mathrm{KE}$, Catherine. Comparative law as comparative jurisprudence: The comparability of legal systems, cit., p. 723.

200. Cfr. FLETCHER, George P. The universal and the particular in legal discourse. En: Brigham Young University Law Review. Núm. 2, 1987, pp. 335 y ss., ivi p. 350, quien luego de resaltar las diferencias básicas entre las nociones estadounidenses y germanas sobre la personalidad, afirma, con su acostumbrada lucidez, que «Estoy abogando por una aproximación a la comparación jurídica que tome en cuenta estas particularidades lingüísticas como el punto de partida para un análisis de nuestras divergentes culturas jurídicas. Existen diferencias entre el sistema jurídico del mundo industrializado que son mayores de lo que aparecen para una visión funcionalista. Hay muy poco que ganar si se ignora la riqueza de los lenguajes jurídicos», por ello concluye que "esta semejanza funcional, diría, sigue siendo superficial a menos que conozcamos los sustentos doctrinales de las que emanan estas manifestaciones de convergencia. La única manera para sondear tales profundidades es la de reconocer la divergencia lingüística como una pista de una serie de desacuerdos más sustanciales que el instinto y la inclinación particular al momento de razonar acerca de problemas jurídicos $»$.

201. KENNEDY, David. New approaches to comparative law: Comparativism and international governance, cit., p. 590. 
que una tendencia centrada en la búsqueda de semejanzas ${ }^{202}$ se perciba precisamente en la generación de académicos europeos que se trasladaron a diversos países (entre ellos Estados Unidos) para huir de la persecución nazi. Dichos académicos, coincidentemente, fueron quienes establecieron las bases de la comparación jurídica en el sistema estadounidense y en específico la corriente funcional de la comparación ${ }^{203}$.

Los postmodernos consideran que un análisis centrado en las posibles semejanzas entre los sistemas jurídicos incurre -sobre todo por influjo de la tendencia a la objetividad y neutralidad (que sería calificada por aquéllos únicamente como ilusión)- en un tipo de conservadurismo. Esta afirmación se sustentaría en que las aproximaciones funcionales de la comparación jurídica evitan abordar aquellos problemas o debates más relevantes (desde el punto de vista postmoderno), como la identificación y reconocimiento de los contextos en los que se gesta el Derecho, conformándose con resaltar únicamente los aspectos comunes entre los sistemas ${ }^{204}$.

Como se puede apreciar, la teoría de los trasplantes jurídicos y la circulación de modelos es un tópico sumamente controvertido en la comparación jurídico. La controversia al final del día se centraría en que al ignorar los marcos culturales en que se gestan las figuras jurídicas se olvida que estos elementos determinan la propia interpretación, aspectos que son medulares para la operatividad del Derecho. En igual medida, se discutirá si lo que subyace al trasplante jurídico no es más que un mecanismo por el cual se logra imponer una forma de pensamiento ajena a la cultura jurídica del país importador, para eliminarlo como tal y desde luego para cimentar el poder del sistema exportador.
Estos aspectos no pueden ser negados, la realidad nos fuerza a aceptarlos. Sin embargo, esto no imposibilite el trasplante, sólo torna cuestionable su motivación. En ocasiones las ventajas y la propia relectura nacional permiten que el trasplante no la figura doctrinal, norma legal o fórmula jurisprudencial importada se adapte al sistema importador. Acaso más importante a los efectos de la presente investigación sea que tal tendencia no se presentará siempre, sino solamente (al menos con claridad) en un número determinado de casos, tal como se observó al momento de analizar la tipología de trasplantes jurídicos

En el siguiente acápite efectuaré algunas críticas a la posición postmoderna y expondré una o más preocupaciones sobre el futuro de la comparación jurídica.

\section{VIII.CRÍTICA A LA POSICIÓN POSTMODERNA: ¿CUÁL ES EL FUTURO DE LA COMPARACIÓN JURÍDICA?}

A la posición postmoderna se le puede responder a todas las criticas expuestas de manera más o menos sencilla. A pesar que considero que muchas de las replicas dejan muy mal parada a la visión postmoderna, no puedo negar la necesidad de replantear el enfoque de la comparación jurídica.

Antes que nada no se puede olvidar que la comparación jurídica no es únicamente un área de las ciencias sociales (y que, por tanto, requiere de aportes culturalistas como los evidenciados por las posiciones nihilistas) sino que también lo es del Derecho (por lo que alguna utilidad de carácter práctica debe ser perseguida, además de ostentar un afán por la sistematización de los discursos y del propio conocimiento, todo ello

202. CURRAN, Vivian Grosswald. Comparative law's potential for broadening legal perspectives, cit., pp. 665-667.

203. CURRAN, Vivian Grosswald. Cultural immersion, difference and categories in U.S. comparative law, cit., pp. 66-78.

204. De las ideas expuestas por REITZ, John C. How to do comparative law, cit., pp. 620-623, se puede extraer que el autor considera factible una visión amplia de la comparación que partiendo de los elementos comunes en los sistemas jurídicos y observando la equivalencia funcional que ostenta, para luego, de ser el caso, resaltar sus diferencias. 
con el objeto de lograr su empleo por parte de los operadores jurídicos, so riesgo de que las discusiones comparatísticas se conviertan sólo en metafísica o peor aún generen, de una u otra manera, su extinción) ${ }^{205}$.

En tal sentido las respuestas a las críticas postmodernas serían las siguientes:

(i) Como se vio la primera crítica se centró en considerar inútil cualquier esfuerzo dirigido a comparar objetos que son incomparables per se. Ello, como es fácil percatarse, importa asumir una posición relativista fundada en los marcos de referencia que se despliegan al interior de cada sistema jurídico. Considero que, hasta allí, el asunto no presenta mayor complejidad, sin embargo, resulta curioso que la adhesión a una postura relativista ${ }^{206}$ no sea afirmada, expresamente, por los comparatistas postmodernos e incluso eviten usar la terminología vinculada a esta posición ${ }^{207}$.

El relativismo es una posición que niega la existencia de conocimiento universal (esto es, relativismo epistemológico) y de normas universalmente válidas (vale decir, relativismo moral). Así, el relativismo en el que se basa la lectura postmoderna de la comparación es una combinación de estas dos vertientes, con lo cual es susceptible de recibir las mismas críticas que se plantean en contra de ellas.

El discurso con realces culturalistas de autores como Legrand que afirman la influencia del marco de referencia incurre en una clara contradicción. En efecto, si, por un lado, se sostiene que personas de culturas distintas no pueden tener percepciones o teorías de carácter conmensurable entonces: ¿cómo podrían tales autores convencer a personas de culturas distintas a las suyas de que su postura culturalmente relativista es cierta si es que no existe, al menos, un punto de contacto que permita dicha comprensión? ${ }^{208}$ En tal sentido, cualquier esfuerzo que se realice en esta dirección resultaría manifiestamente inútil.

Por otro lado, una posición de este tipo estaría afirmando, implícitamente, la naturaleza impermeable, cerrada e inmutable de las culturas $^{209}$. Aspectos que no sólo me parecen difícilmente admisibles en el plano abstracto, sino que estudios como los de Watson, en los que existe una cantidad considerable de evidencia empírica de diversas experiencias culturales y momentos históricos, echan por tierra con facilidad. Incluso la forma de vida actual tiende, como es por demás claro, a hacer aún mas borrosa las fronteras (ya de por

205. VON MEHREN, Arthur T. An academic tradition for comparative law, cit., p. 629, quien plantea dos tipos de estudios, por un lado, aquellos que denomina estudios comparativos de sociedades, el cual se aprovecha de las herramientas brindadas por la sociología y antropología con la intención de aclarar la visión de algunos aspectos jurídicos para así lograr una mejor comprensión de las sociedades; y, por otro lado, un estudio más convencionalmente jurídico que intentará fortalecer la comprensión de las instituciones jurídicas.

206. ZECHENTER, Elizabeth. In the name of culture: Cultural relativism and the abuse of the individual. En: Journal of Anthropological Research. Vol. LIII, núm. 3, 1997, pp. 319 y ss, ivi p. 326, señala que «[e]l surgimiento del relativismo epistemológico coincide con la irrupción de muchas nuevas escuelas de pensamiento que alcanzaron reconocimiento en esa época, tales como el deconstruccionismo, postmodernismo y marxismo, todas las cuales atacaron la propia idea de razonamiento científico, racional o ético. El marxismo, por ejemplo, enfatiza la inevitabilidad de la consciencia de clase en la formación de los puntos de vista de los individuos (Kolakowski 1978). El deconstruccionismo y el postmodernismo profesan que no exista manera de conocer algo más allá de la experiencia directa y rechazan el concepto mismo de la realidad (Jameson 1991)».

207. Al respecto resultan ilustrativas el siguiente pasaje atribuible a LEGRAND, Pierre. European legal systems are not converging, cit., p. 56, en el que hablando de la cultura sostiene que «ocupa un lugar intermedio entre lo que es común a todos los seres humanos (si, en efecto, existe tal atributo en común) y lo que es único a cada individuo. La cultura se refiere a aspectos que no son universales pero que trascienden al individuo».

208. PETERS, Anne y SCHWENKE, Heiner. Op. cit., p. 814.

209. MONATERI, Pier Giuseppe. “Everybody's talking: The future of comparative law, cit., p. 839. 
sí gaseosas) entre las culturas. Piénsese en la influencia de la mass media, del comercio o sencillamente en las constantes migraciones (sean estas permanentes o no).

Un dato adicional que me parece ilustrativo de la imposibilidad de admitir una posición relativista extrema como la sugerida por la corriente postmoderna es que se permitiría sustentar tanto las violaciones de derechos fundamentales, como la existencia misma de un régimen dictatorial. En efecto, si los valores no son universalmente válidos, como se sostiene en la vertiente moral del relativismo, entonces podría afirmarse la naturaleza foránea de los valores que sirven de base a la construcción de tales derechos (pues, en sí mismos, no son más que una retórica occidental y euro-céntrica que busca consolidar el poder de las élites que la perpetúan; un argumento que creo no es del todo ajeno en nuestro medio, tal y como la historia política reciente nos lo demuestra).

(ii) La segunda crítica se centra en el sesgo creado por nuestros marcos de referencia y se alimenta de la premisa de que ellos son cerrados. Sobre tal equívoca percepción de los marcos de referencia me remito a lo expuesto en el punto precedente.

Sin embargo, algo más habría que decir sobre el sesgo o tendencia a emplear nuestros propios marcos de referencia al analizar u observar fenómenos foráneos, cuestión que es ásperamente criticada por los postmodernos. Al igual que en el caso anterior resulta por demás interesante constatar que la propia posición de los postmodernos es la que marca la pauta para criticar su construcción.
En efecto, para que los propios postmodernos puedan superar la critica que detectan en los comparatistas tradicionales deberían colocarse, al igual que su propia crítica, en una posición que se encuentre más allá de los marcos de referencia de los comparatistas tradicionales (porque de lo contrario no podrían darse cuenta del sesgo en el que estos incurrirían) y de sus propios marcos de referencia. El último punto resulta incluso más interesante de lo que parece pues si ellos mismos y sus discursos no pueden superar sus propios marcos de referencia, entonces quienes asumen esta posición deberán aceptar que: (i) su propio discurso no sería más que un constructo generado para obtener o bien mantener el poder, por lo que tiene una agenda no-expresa, vale decir, sería meramente un discurso sesgado y con una intención conservadora; y, (ii) para superar la peligrosa afirmación anterior (que minaría su legitimidad) tendría que aceptarse la posibilidad de hacer a un lado los marcos de referencia, lo cual de acuerdo a las bases de esta posición -que son las que le sirven de sustento para criticar tanto a las corrientes difusionistas, como funcionalistas-, resulta un imposible ${ }^{210}$.

El admitir que, de alguna manera, se puede superar el propio marco de referencia es un duro golpe para esta posición pues significaría que los comparatistas tradicionales a los que tan duramente se critican también se encuentran en posibilidad de hacer a un lado su marco de referencia al momento de efectuar un análisis o sugerir una propuesta, salvo que se considere que estos últimos carecen de alguna virtud personal o don que sí se encontraría presente en los postmodernos; o que tal posibilidad de superar el marco de referencia sólo se pre-

210. LEGRAND, Pierre. Comparative legal studies and commitment to theory, cit., p. 266, quien afirma con total claridad «la comparación objetiva es imposible, en tanto que el prejuicio no puede ser superado nunca. Siempre existirá una medida de sugestión de parte de la cultura en el acto de comparación: la empresa comparativa no puede hacerse en ausencia de valores. En primer lugar, uno no puede nunca ser observador de uno mismo como observado. En segundo lugar, la cultura juridica doméstica es necesariamente proyectada en el contexto jurídico ajeno»; y, PETERS, Anne y SCHWENKE, Heiner. Op. cit., p. 821. 
sentaría en la metodología postmoderna, lo cual tendría que ser demostrado ${ }^{211}$ y no únicamente afirmado.

(iii) La tercera crítica se circunscribe a afirmar que a los comparatistas tradicionales no les interesa la verdad sino, en realidad, el poder $^{212}$; quienes cumplirían con tal verdadero fin a través la promoción de una agenda política oculta. Es claro que esta crítica también se encuentra imbuida de varios elementos tomados del relativismo, y para ser un tanto más precisos, podría indicarse que la afirmación aludida se realiza teniendo como base elementos del relativismo epistemológico.

Los contra argumentos que hacen frente a este último aspecto ya han sido expuestos en el instante en que se refutó la primera crítica postmoderna. En términos sencillos, si es que no existen verdades -sino sólo los discursos que intentan ocultar las aspiraciones de poder de determinados gruposentonces tendríamos que admitir que la propia posición postmoderna no puede irrogarse el carácter de verdad (¡cómo podría hacerlo si es que la verdad no existe!) $)^{213}$, por lo que debería aceptar que ella misma no es más que un discurso que oculta una aspiración de poder, y a renglón seguido tendría que negar que pueda ser vista como una teoría (o un discurso científico) sino que en realidad se trata de una mera retórica.

Si bien no niego que existan trabajos o propuestas que tengan como fin último encubrir una intervención política o una aspiración de poder (negarlo sería pecar de inocentes), creo que no se puede atribuir tal carácter-de manera tan alegre- a todos los trabajos y creaciones teóricas. Si ello fuese así entonces se tendría que analizar cada trabajoy/o construcción jurídica para obtener una cabal comprensión del tema, así como cada uno de los posibles antecedentes vinculados a estas materias, todo lo cual redundaría en la imposibilidad de una discusión de fondo y en la ralentización de cualquier desarrollo o la solución de las necesidades que se experimenten en una sociedad dada.

(iv) La cuarta crítica gira, fundamentalmente, en torno a que las categorías y clasificaciones se encuentran influenciadas tanto por el marco de referencia del agente que las genera, como también por la específica agenda política que están llamadas a cumplir.

Empero, como se ha visto la crítica pierde fuerza por las razones expuestas: no siempre una construcción sigue agendas políticas subalternas (si bien no puede negarse que los autores tienen una posición determinada en el campo de la política, filosofía, economía, etc., creo que resulta exagerado sostener que toda la construcción se efectúa a fin de promover tal toma de posición inicial). En este orden de ideas, el proceso de clasificar se funda, por lo general, en la comparación de los diversos objetos de análisis para luego resaltar aquellos elementos comunes.

211. Así como la propia afirmación de que la comunidad científica se encuentra occidentalizada o tiene un sesgo occidental. La razón de ello es sencilla, si académicos de otras latitudes (vale decir, que no pertenezcan a occidente, o en términos más claros a Europa o los Estados Unidos) coinciden en las conclusiones y/o método, la pregunta que surge es: ¿de qué sesgo estamos hablando?, ¿no debiera encontrarse sólo presente en las categorías occidentales y sus profesionales, en lugar de también en los no-occidentales? Incluso si la respuesta fuese de que también puede presentarse en los no-occidentales, tendría que absolverse una interrogante: ¿por qué habría que considerar que esa concordancia de conclusiones y metodología es una imposición, en lugar de un desarrollo autónomo y auténtico, o al menos una adhesión consciente y libre?

212. Por lo que podría ser incluida dentro de las denominadas teorías del espejo [o mirror theory], esto es, una teoría que considera que el Derecho no es más que el reflejo de un conjunto de fuerzas (tal como la política, la economía, etc.), y por ello ser susceptible de las lapidarias criticas de EWALD, William. Comparative jurisprudence (II): The logic of legal transplants. En: The American Journal of Comparative Law. Vol. XLIII, núm. 4, 1995, p. 489 y ss.

213. AINSWORTH, Janet E. Categories and culture: On the 'rectification of names' in comparative law, cit., p. 25. 
Naturalmente el acto de selección desplegado no tiene porqué encontrarse totalmente imbuido de motivaciones exógenas, las tomas de posición impactarán finalmente en ciertas decisiones pero no importan, por definición, un intento dirigido a promover una agenda determinada. Este aspecto es particularmente importante en el campo que nos convoca pues el propósito de efectuar las clasificaciones tiene una marcada vocación de ordenar el conocimiento o, si se quiere, facilitar el análisis.

Sin perjuicio de lo anterior, y un tema que no es suficientemente resaltado, es que los esfuerzos de clasificación que se observan en el campo de la comparación jurídica no se realizan a priori, sino que se presentan luego de la investigación (y no únicamente de carácter intelectual pues también se sustenta en datos fácticos). Es por ello que no niego la posibilidad de crítica. Empero, una labor clasificatoria conlleva, de manera inherente, el riesgo de no recoger los elementos medulares que permitan construir una propuesta adecuada y, por ende, se deberá sencillamente re-examinar las taxonomías (como, inspirándonos en estas mismas ideas, se ha efectuado a lo largo del presente estudio). Tal labor reconoce uno de los extremos de la discusión que es ásperamente rechazada por la visión postmoderna en el campo de la comparación jurídica: que sujetos que no pertenecen a una determinada cultura jurídica pueden llegar a comprender sus estructuras de manera más o menos articulada y, como consecuencia, sugerir maneras en las que se estudien de manera comparada.

(v) La quinta crítica es, básicamente, una objeción contra el funcionalismo en el campo de la comparación jurídica, dirigida a subrayar que tal corriente no le dispensa la atención adecuada a elementos relevantes que diferencian a los sistemas jurídicos. Tal afirmación se encuentra influenciada por varios de los aspectos ya analizados: el sesgo de nuestros marcos de referencia, el carácter oculto de los discursos jurídicos como instrumentos para legitimar el poder y/o perpetuarlo, etc. En tal sentido, dar cuenta de ella no nos importará una labor excesivamente compleja, empero sí tiene extremos que brindarán enfoques alternativos de análisis.

En efecto, la idea de los comparatistas postmodernos es que al subrayar la función que cumple determinada figura doctrinal, regla jurídica o precedente jurisprudencial en aras de satisfacer necesidades sociales, se pasa por alto que estas instituciones en el plano de la realidad cumplen más de una función. Me explico. La critica en cuestión sería que se simplifica excesiva e injustificadamente los fenómenos jurídicos, y se sobrevalora el dato empírico, el cual en ocasiones contradice otros elemento relevantes que también deben ser sopesados.

Sin embargo, el razonamiento apenas expuesto no resulta del todo cierto. Las funciones que desempeñan las diversas instituciones jurídicas son analizadas en diversos niveles y variarán incluso de cultura a cultura, por lo que la aproximación funcional no resulta tan sencilla como se cree y puede producir resultados complejos ${ }^{214}$. Como prueba de ello se ofrece la elección de lo que resulta el tertium comparationis, decisión que se encuentra sometida al arbitrio de quien efectúa la observación, esto es, la función a valorar y la manera en que ésta se realiza la determina cada investigador. La consecuencia de ello es que -aún desde un punto de vista meramente técnico- es posible que se privilegian visiones economicistas (dentro de la corriente del comparative law and economics), jurídicas (en donde el interés se centra en la claridad de la enunciación de la institución, su coherencia con el resto del sistema, su eficacia, etc.), políticos (sea para proteger a la élite o

214. Cfr. WATSON, Allan. Legal transplants: An approach to comparative law, 2a. edición, University of Georgia Press, Atenas y Londres, 1993, p. 4 [citado por PETERS, Anne y SCHWENKE, Heiner, op. cit., p. 828]. 
a grupos que, por una u otra razón, se desea beneficiar), etc.

Tal vez el lector crea, llegado a este punto, que sostendré - dada la extensión del presente estudio- la plena y cabal vitalidad de la comparación jurídica ${ }^{215}$. Lamentablemente ello no será así216, si bien considero que es una de las aproximaciones que con mayor éxito (casi al mismo nivel que el análisis económico) puede ser empleada en el estudio de los fenómenos jurídicos; sin mencionar que es ampliamente utilizada por los académicos de diversas materias (sobre todo europeos). Las razones que me llevan a considerar que la comparación jurídica sufre -si se quiere- de una enfermedad se centran, en gran parte, en lo que ha sido abordado a lo largo del presente estudio: la discusión excesivamente teórica con respecto al método que la caracteriza.

En efecto, es conocido el poco interés que la comparación jurídica ha generado en el sistema estadounidense, tal apatía (o indiferencia) puede ser explicada por una multiplicidad de factores. Algunas de las explicaciones que se han ensayado son: (i) que al ser los Estados Unidos el país que ostenta tanto el liderazgo intelectual como jurídico (por el fenómeno de Americanization) no se presenta (o se siente) ninguna necesidad real de dispensar atención a lo que sucede fuera de sus fronteras ${ }^{217}$; (ii) que si se busca en el extranjero siempre se podrá encontrar una posición que sustente lo que se desea, por lo que no sería una auténtica forma de encontrar soporte para la formulación de una decisión jurídica ${ }^{218} ;$ y, (iii) que aún dentro de la propia comparación jurídica se tienen posiciones que complican, de modo incomprensible, el análisis de los fenómenos a estudiar y que incluso si se aplicasen directamente nos llevarían a negar utilidad al propio método ${ }^{219}$.

La complejidad que se detecta en la comparación jurídica, la cual no puede negarse (e incluso -dentro de ciertos límites- es uno de sus méritos), lleva a desincentivar las investigaciones que podrían asumir tal enfoque ${ }^{220}$. Como se ha visto, a grandes rasgos la comparación sigue dos vertientes: por un lado, una versión clásica o débil (en la que se insertan las corrientes difusionistas y funcionalistas); $y$, por otro lado, una versión postmoderna o fuerte, que es la que genera mayor rechazo.

215. Posición que es sustentada por SACCO, Rodolfo. One hundred years of comparative law. En: Tulane Law Review. vol LXXV, 2001, p. 1159 y ss., quien afirma «[I]uego de cien años, existen buenas noticias. Luego de un siglo desde su primer congreso, la comparación jurídica triunfa.» (p. 1159).

216 MATTEI, Ugo. An opportunity not to be missed: The future of comparative law in the United States. En: The American Journal of Comparative Law. vol XLVI, núm. 4, 1998, p. 637, quien sostiene que el destino de la comparación jurídica se encontrará determinado por su habilidad para enlazar los diversos campos del derecho y las ciencias sociales.

217 REIMANN, Mathias. Stepping out of the European shadow: Why comparative law in the United States must develop its own agenda. En:The American Journal of Comparative Law. vol XLVI, núm. 4, 1998, p. 637 y ss.; MATTEl, Ugo. An opportunity not to be missed: The future of comparative law in the United States, cit., p. 637 y ss.; Id., Some realism about comparativism: Comparative law teaching in the hegemonic jurisdiction. En: The American Journal of Comparative Law Supplement, vol. L, 2002, p. 87 y ss.

Por otro lado, el interés por un estudio más integral de los fenómenos jurídicos como parte de un compromiso del operador jurídico para con el estado actual del mundo ya se detecta en RABEL, Ernst. On institutes for comparative law. En: Columbia Law Review, vol. XLVII, núm. 2, 1947, p. 227 y ss.

218. Al respecto nos remitimos a la consulta de las sentencias que son citadas en el trabajo de SIEMS, Mathias. The end of comparative law. En: Centre for business research. University of Cambridge, Working paper No. 340, marzo de 2007, p. 1.

219. En un trabajo en el que se analiza las ventajas del case-method para la enseñanza y el estudio del derecho comparado el profesor MARKESINIS, Basil. Comparative law - A subject in search of an audience, cit., p. 1 y ss., evidencia la utilidad que debe desempeñar tal materia y que centrará el objeto de estudio.

220. PALMER, Vernon Valentin. From Lerotholi to Lando: Some examples of the comparative law methodology. En: The American Journal of Comparative Law. vol. LIII, núm. 1, 2005. p. 261 y ss. 
La lectura fuerte pone el énfasis en el estudio interdisciplinario, critico y profundo del contexto histórico, social, económico, político, cultural y religioso de las instituciones jurídicas; vale decir, es necesario conocer las estructuras cognitivas del sistema jurídico a estudiar, así como los fundamentos del conocimiento ${ }^{221}$. En términos sencillos, me estoy refiriendo a la visión postmoderna de la comparación, tesis que, como se ha visto, subraya las profundas diferencias entre los sistemas jurídicos.

Una visión de este tipo nos dice en términos sencillos: si pretendes efectuar el estudio de un sistema tienes que entenderlo totalmente, casi como si fueras un nativo de dicho sistema pues, de lo contrario, no estarás en condición de comprenderlo en su real complejidad; si, por el contrario, no realizas tal esfuerzo en tus investigaciones no harás más que ejercer un tipo de control sobre los lectores que manifiesta el intento de imponerles una agenda política ${ }^{222}$. Si se quiere, es una petición de todo o nada. Lo curioso es que luego de realizar la labor exigida se nos informará que la comparación jurídica resulta un imposible, en tanto que los sistemas son inconmensurables ${ }^{223}$.

A pesar de tal circunstancia, algunos autores no están tan preocupados pues podrían afirmar, como lo hace Legrand, que la tarea de la comparación debe ser la de revelar las diferencias críticas. Aun cuando considerase válido el enfoque de la posición postmoderna, en contra de las críticas antes expuestas, habría que admitir que el rol que se le otorgaría a la comparación jurídica sería bastante limitado pues revelar que los sistemas son diferentes no es complicado. Un mero análisis superficial lo demuestra, y si se parte de aquellas premisas asumidas por la visión postmoderna el hecho es evidente. Entonces, ¿para que profundizar en ello? O incluso un asunto adicional, si sólo habría que revelar diferencias entonces la comparación jurídica nos estaría diciendo -visto desde un punto de vista práctico- únicamente que cosas son las que no se pueden hacer, pero no nos estaría diciendo nada acerca de lo que se debe hacer. Sería una teoría o método que se limitaría a la destrucción o deconstrucción de argumentos más no nos aportaría en la creación de propuestas.

Con lo antes explicado no es que quiera desmerecer las funciones críticas y deconstructivas, creo firmemente que es un rol fundamental que diferencia a la comparación jurídica de otras aproximaciones. Sin embargo, no puedo compartir la idea de que esta rama de estudio (cuyas potencialidades son enormes) se conforme con indicarnos negativamente su contenido (qué es lo que no se debe hacer) y no enfrente positivamente su encargo (qué esfuerzos tendríamos que realizar para lograr la mejora del Derecho). Una ciencia que se limite a discutir su método es una ciencia enferma, pero una ciencia que no tiene conocimiento positivo o práctico que brindar, sencillamente no es ni siquiera un tópico de conversación de café.

Empero, como el sentido del presente artículo es brindar un vistazo panorámico a las teorías sobre el cambio jurídico y de la comparación jurídica considero que no se puede finalizarse con el encargo sin dar algunas luces de cómo debiera proseguirse en el estudio de la comparación. Las pautas o criterios que ofreceré tienen como propósito sugerir o, si se quiere, prever cómo se desarrollará la comparación en los próximos años. Labor que debiera trazarse como meta el lograr que la comparación sea teóricamente consistente pero que, a su vez, logre un grado de pragmatismo que la torne más útil para los distintos operadores jurídicos y, por qué no decirlo, también más atractiva.

221. LEGRAND, Pierre. European legal systems are not converging, cit., p. 60, para hacer referencia a estos elementos se acuña el término de mentalité jurídica.

222. PALMER, Vernon Valentin. op. cit., p. 266

223. LEGRAND, Pierre. Econocentrism. En: University of Toronto Law Journal, vol. LIX, núm. 2, 2009, p. 215 y ss., ivi p. 215 , y, SIEMS, Mathias. The end of comparative law, cit., p. 6 
En mi opinión la comparación jurídica debe asumir algunos de los esfuerzos de las posiciones postmodernas en aras de alcanzar mayor reflexión sobre los tópicos que aborda, atendiendo a la cultura jurídica del sistema estudiado o en el que se inserta la institución a la que prestamos atención. En ese mismo sentido, debe existir un intercambio fluido de opiniones entre los comparatistas ${ }^{224}$ pero no centrando la atención sólo en la crítica sobre el trabajo ajeno, sino que se debe trasladar los esfuerzos hacia un compromiso real de comprender las razones que explican la divergencia de pareceres.

Si bien el conocimiento total del sistema ajeno es imposible, se debe intentar tener un buen manejo de la lengua del sistema estudiado y contar con las capacidades ${ }^{225}$ necesarias para afrontar la tarea, así como también tener conocimiento sobre el contexto en el que la figura jurídica a estudiar se inserta ${ }^{226}$. La atención a las similitudes, no de discurso sino respecto de los problemas afrontados, es algo que debe ser incentivado pues nos ayudará a ver al Derecho extranjero como más cercano y además brindará las herramientas que favorezcan la mejora del Derecho nacional. Sin embargo, no por ello se debe abandonar el esfuerzo de identificar las diferencias ${ }^{227}$ existentes y deconstruirlas para comprender el sentido de la diferencia ${ }^{228}$, así como de si los trasplantes ofrecidos tienen -como abogan los comparatistas postmodernos- un fin subalterno.

Por su parte, las semejanzas -en algunas ocasiones- alcanzarán a los valores que sirven de sustento a las instituciones jurídicas, por lo que se podría incentivar un constante análisis de los fenómenos de trasplante ${ }^{229}$. Con una perspectiva de este tipo la comparación volvería a ser una herramienta puesta al servicio del operador jurídico que debe solucionar o hacer frente a conflictos de intereses ${ }^{230}$; y no por ello pierde su rol decididamente crítico o subversivo ${ }^{231}$ de la realidad jurídica y política.

\section{A MANERA DE CONCLUSIÓN}

La principal preocupación que me deja el presente ensayo, así como la percepción que

224. EBERLE, Edward J. op. cit., pp. 457-460.

225. SACCO, Rodolfo. One hundred years of comparative law, cit., p.1174.

226. Uno de los nuevos objetivos que debería cumplir la comparación jurídica en opinión de GERBER, David J. System dynamics: Toward a language of comparative law?, cit., pp. 724-726.

227. SCHLESINGER, Rudolf B. The past and future of comparative law. En: The American Journal of Comparative Law, vol. XLIII, núm. 3, 1995, p. 477 y ss.

El interés por el derecho extranjero, sobre todo cuando es diverso del nacional, es sustentado por GORDLEY, James, Comparative law and legal education. En: Tulane Law Review, vol. XLV, núm. 4, 2001, p. 1003 y ss., ivi p. 1008.

228. REITZ, John C. How to do comparative law, cit., pp. 626-627.

229. KAHN-FREUND, Otto. On uses and misuses of comparative law, cit., p. 27, quien nos alerta que «el uso de la comparación jurídica para propósitos prácticos se convierte en un abuso solo si es motivado por un espíritu legalista que ignora el contexto del Derecho. Apelo a que quienes enseñen derecho comparado tengan cuidado ante tal riesgo y que transmitan tal cautela a sus estudiantes entre los cuales pueden encontrarse los que sean llamados a promover el intercambio de ideas en los procesos legislativos».

230. RHEINSTEIN, Max. Teaching tools in comparative law, en The American Law Review, vol. I, núm. 1/2, 1952, pp. 95 y ss., ivi p. 104, quien afirma que el dictado de un curso que permita a un estudiante tomar contacto con el derecho extranjero sería valioso si es que enseña que las instituciones, leyes y métodos nacionales no son más que una posibilidad en el mundo; estudiar las instituciones o métodos de un sistema altamente sofisticado puede ayudar a profundizar el conocimiento de sus pares en el sistema nacional; aprender a que, cuando se tenga contacto con operadores jurídicos de otro sistema, no necesariamente piensan de una manera semejante a la nuestra; $y$, a su vez, incentivar el empleo del conocimiento extranjero.

231. FLETCHER, George P. Comparative law as a subversive discipline. En:The American Journal of Comparative Law, vol. XLVI, núm. 4, 1998, p. 683 y ss. 
siento últimamente al oír hablar o leer sobre comparación jurídica, concierne al futuro del método. La tendencia en los estudios comparados es la atención excesiva que le dispensan sus seguidores a la justificación del método empleado, aspecto que denotaría su debilidad. No quiero que tal afirmación de a entender que una ciencia (cualquiera que esta sea) no debe prestar atención a los debates metodológicos, muy por el contrario creo que es algo favorable, salvo cuando todo el interés se centra (o al menos buena parte) en tal materia.

Si, en cambio, la atención del comparatista se centra únicamente en tal materia, creo que esta manera de proceder podría llevarnos a debatir sobre el estado de salud de dicha metodología. Asimismo, esto explicaría con facilidad porque existen quienes sostienen que no resulta útil el análisis de lo que sucede fuera de nuestras fronteras (situación que se percibe en los salones de ciertas firmas legales, en las aulas universitarias o en los corredores judiciales). En efecto, si los académicos continuamos alejando el discurso sobre la comparación jurídica de quienes, al final del día, son nuestros consumidores, entonces se seguirán suscitando dudas acerca de las propias virtudes (y el compromiso) de los comparatistas para difundir un método cuya utilidad debiera encontrarse fuera de cualquier cuestionamiento ${ }^{232}$.

El debate metodológico que se ha elevado en materia de comparación recuerda en algunos pasajes aquellas discusiones del siglo XIX y parte del siglo XX en que los juristas (alemanes e italianos) se trabaron para dilucidar "I $a$ " teoría del negocio jurídico o alcanzar "la" definición de derecho subjetivo (aspectos cuya utilidad para el campo practico también es indudable), pero que, curiosamente, un sector de quienes asumen estudios de derecho comparado critican enérgicamente. La crítica en cuestión se centrará en la poca utilidad del debate sobre tópicos de ese tipo, lo cual no podemos compartir pero no es lo que deseamos resaltar. Como respuesta cabría anotar algunas de las ideas expuestas por los postmodernos: la verdad no existe, por lo que la calificación de inútil se efectúa en atención a una percepción de la superioridad de nuestro marco de referencia sobre el ajeno, cuando estos resultan en realidad -tal como se ha visto-inconmensurables. Sin embargo, y siguiendo esta misma lógica, la percepción que tienen los operadores jurídicos (estudiantes, legisladores, jueces, etc.) acerca de los debates metodológicos a los que se abocan un amplio sector de los comparatistas se asemeja a la posición de estos últimos acerca de las denominadas discusiones dogmáticas.

Sin perjuicio de lo anterior, estoy convencido de la utilidad de tales debates si es que no se pierde de vista el aspecto práctico que toda metodología, en general, y que toda aproximación al Derecho, en particular, debe considerar y cumplir. Ignorar esta realidad incuestionable no hará más que alejar el conocimiento teórico de quienes están llamados a respetar las normas, lo cual ocasionará las dificultades en la difusión del método, pérdida de una guía fundamental no sólo en la creación normativa si o en cuanto a la difusión que podría alcanzarse del método comparado.

Por su parte, y para concluir, una posición que contradiga de modo extremo el debate teórico o metodológico incurrirá precisamente en un error semejante en sus alcances, pero de signo contrario al aquí denunciado. En efecto, como todo campo de estudio, la comparación merece y necesita focalizar su atención en perspectivas y/o en nociones nuevas o reformular las antiguas, pero no se debe olvidar el elemento de carácter práctico que requiere cumplir, así como también la claridad en la trasmisión de mensajes. El poder de la doctrina, como enseña un ilustre autor, se centra en su propia capacidad para lograr persuadir

232. Una interesante exposición sobre la importancia y utilidad de la comparación jurídica se encuentra en la obra de GUTTERIDGE, Harold Cooke. Comparative law: An introduction to the comparative method of legal study and research, Cambridge University press, Londres, 1947, pp. 23-40. 
al auditorio ${ }^{233}$. De no cumplirse con los requerimientos aludidos se dejará a los operadores sin un apoyo importante para su labor.

El rol que desempeñará la comparación jurídica en los próximos años dependerá casi de modo exclusivo de las decisiones que se efectúen ahora. La consolidación del método debe darse en el corto plazo, so riesgo que por la pérdida de hablantes devenga en el fracaso o decaimiento del propio método. Para ello, solo se requerirá tomar en consideración los consejos que se acaban de sugerir, mejorando así la calidad del discurso y su accesibilidad. Superado este gran problema, la comparación jurídica se consolidará gracias a su propia solidez interna y por la validez de los enfoques que ésta propone.

233. SACCO, Rodolfo. Legal Formants: A Dynamic Approach to Comparative Law (Installment II), cit., p. 349. Este extremo del papel de la doctrina también ha sido subrayado en nuestro medio por LEÓN, Leysser L., La reforma del Código Civil vista en serio. En: Dike: Portal de Información y Opinión Legal de la Pontificia Universidad Católica del Perú, el texto íntegro del trabajo citado puede ser descargado en http://www.pucp.edu.pe/dike/doctrina/civ art62.PDF, p. 3 (de la versión pdf). 